\title{
Further Analysis of Clockwise Loops and Anticlockwise Loops Observed in a Stock-Recruitment Relationship
}

\author{
Kei Tanaka1, Naoki Suzuki², Kazumi Sakuramoto ${ }^{2 *}$ \\ ${ }^{1}$ Development of Agriculture, Forestry and Fisheries, Department Fishery Division, Shimonoseki City Center of Farming \\ Fisheries, Shimonoseki, Japan \\ ${ }^{2}$ Development of Ocean Science and Technology, Tokyo University of Marine Science and Technology, Tokyo, Japan \\ Email: *sakurak@kaiyodai.ac.jp
}

How to cite this paper: Tanaka, K., Suzuki, N. and Sakuramoto, K. (2021) Further Analysis of Clockwise Loops and Anticlockwise Loops Observed in a StockRecruitment Relationship. Open Access Library Journal, 8: e7164.

https://doi.org/10.4236/oalib.1107164

Received: January 20, 2021

Accepted: March 13, 2021

Published: March 16, 2021

Copyright $\odot 2021$ by author(s) and Open Access Library Inc.

This work is licensed under the Creative Commons Attribution International License (CC BY 4.0).

http://creativecommons.org/licenses/by/4.0/ (c) (i) Open Access

\begin{abstract}
Loop-shaped trajectories are commonly observed in the stock-recruitment relationship (SRR). A mechanism that explains why the loops emerge in SRR has been proposed, and the aim of this study was to validate this mechanism using 62 stocks that live in the waters around Japan, the Northwest Atlantic Fisheries Organization area, and elsewhere. We discuss the relationship between the age at maturity and the slope of the regression line adapted for the SRR data. Further, we discuss whether or not the age at maturity determines whether clockwise or anticlockwise loops are dominant. The results were as follows: 1) The slopes of the regression line adapted for the SRR had positive values when the age at maturity was low. As the age at maturity increased, the slopes decreased to zero and then became negative values. As the age at maturity increased even further, the slopes again changed from negative values to zero and then from zero to positive values. 2) Clockwise loops were dominant when the age at maturity was low, and anticlockwise loops were dominant when the age at maturity was high. As the age at maturity increased even more, clockwise loops again became dominant. These findings coincide well with the results presented by Tanaka et al. In the past, a density-dependent effect has been considered to be the main factor driving the fluctuations, but the present results indicated that a different mechanism may control the SRR and the fluctuations in the population.
\end{abstract}

\section{Subject Areas}

Marine Biology 


\section{Keywords}

Stock Recruitment Relationship, Clockwise Loop, Anticlockwise Loop, Age at Maturity, SRR, NAFO, Japanese Stocks

\section{Introduction}

One of the most important tasks in fisheries resource management is to elucidate the mechanism of fluctuation in fish populations. This mechanism is usually referred to as the stock-recruitment relationship (SRR). Without exception, scientists in the field have found that a density-dependent effect is an important factor in controlling population fluctuations [1] [2]. Typical, traditional SRR models include the well-known Ricker [3] and Beverton and Holt [4] models, which are based on an SRR that involves a density-dependent mechanism. Recently, however, a meta-analysis of the SRR found that the density-dependent effect was not an important factor, and that environmental factors were much more important in driving population fluctuations. For instance, Myers et al. [5] noted the following: "Estimates of spawner abundance and number of surviving progeny for 128 fish stocks indicated only 3 stocks with significant depensation. Estimates of the statistical power of the tests strengthen the conclusion that depensatory dynamics are not apparent for fish populations at the levels studied." In addition, Szuwalski et al. [6] noted: "However, we show recruitment and spawning biomass are not positively related over the observed range of stock sizes for $61 \%$ of 224 stocks in the RAM Legacy Stock Assessment Database. Furthermore, $85 \%$ of stocks for which spawning biomass may not drive recruitment dynamics over the observed ranges exhibit shifts in average recruitment, which is often used in proxies for target biomasses. Our results suggest that the environment more strongly influences recruitment than spawning biomass over the observed stock sizes for many stocks." The results of these studies indicate that the traditional understanding of the SRR is questionable because only a small amount of actual data supports the basis of the traditional SRR models.

Recently, Sakuramoto proposed a new explanation of the mechanism underlying the SRR [7]-[12], and, in a simulation study, showed the mechanisms that explained the clockwise and anticlockwise loops that emerge in the SRR. That is, when recruitment, $\mathrm{R}$, fluctuates cyclically in response to environmental factors, and the spawning stock biomass (SSB) also fluctuates cyclically with a time lag (mainly determined by age at maturity), the SRR shows a clockwise loop or an anticlockwise loop for each period of environmental change. The former loops appear when the age at maturity is less than half of the environmental cycle, and the latter loops appear when the age at maturity is more than half of the environmental cycle.

Sakuramoto [11] also discussed the slope of the regression line for the plot of $\ln (\mathrm{R})$ against $\ln (\mathrm{SSB})$. When the age at maturity is low enough relative to the length of the cycle of environmental fluctuations, the slope of the regression line 
is high and close to unity. However, the higher the age at maturity becomes, the more the slope of the regression line decreases. When the age at maturity becomes greater than approximately half the length of the cycle of environmental fluctuations, the slope decreases to almost zero. As a result, the relationship between R and SSB is masked and cannot be detected. Furthermore, when the age at maturity increases and close to half the length of the cycle of environmental fluctuations, the slope of the regression line becomes negative, and when the age at maturity continues to increase beyond half the length of the cycle, the slope of the regression line becomes positive again.

Sakuramoto [11] analyzed the Pacific stock of Japanese sardines and Pacific bluefin tuna and showed that, for the former, the slope of the regression line was close to unity, and three clockwise loops appeared. In contrast, for the latter stock, the slope of the regression line had no significant slope and showed anticlockwise loops. Sakuramoto concluded that the mechanism mentioned above could explain why no relationship between R and SSB was detected for Pacific bluefin tuna.

The aim of this study was to elucidate whether or not the concept mentioned above is valid using 62 stocks. That is, we examine: 1) whether or not the slope of the regression line adapted for SRR changes depending on the age at maturity; and 2) whether or not the direction of the loops, i.e., clockwise or anticlockwise, changes depending on the age at maturity.

\section{Materials and Methods}

\subsection{Data}

The data for the stocks located around Japan used in this study were provided by the Fisheries Agency and Fisheries Research Agency Japan [13]. Hereafter we refer to these 29 stocks as the "Japanese stocks." The data for the stocks located around the NAFO area and others were provided by Ransom Myers's stock recruitment database [14]. Hereafter we refer to these 33 stocks as "Myers's stocks."

\subsection{Rule for Judging the Clockwise or Anticlockwise Direction of Loops in SRR}

According to Tanaka et al. [15], we first plot $\ln \left(R_{t+m}\right)$ against $\ln \left(S S B_{t}\right)$, where $t$ and $m$ denote the year and age at maturity, respectively. We then judge whether or not the line from $\left(S S B_{t}, R_{t+m}\right)$ to $\left(S S B_{t+1}, R_{t+m+1}\right)$ is part of a clockwise loop or an anticlockwise loop. The rule that determines the direction of the loops as either clockwise or anticlockwise is as follows [15]. The direction of the line from year $t$ to year $t+1$ is judged based on the direction of the line from year $t+1$ to year $t+2$ (Figure 1). When the direction of the line from year $t+1$ to year $t+2$ is " $\mathrm{A}$ " as shown in Figure 1, the line from year $t$ to year $t+1$ is judged to be part of a clockwise loop. When the direction of the line from year $t+1$ to year $t+2$ is "B," the line from year $t$ to year $t+1$ is judged to be part of an anticlockwise loop (we refer to this as "Rule 1"). After all of the directions of the lines from 
year $t$ to year $t+1$ were determined, we modified the direction determined by "Rule 2" as shown in Figure 1. That is, when three successive lines were judged to run in the clockwise, anticlockwise, and clockwise directions, respectively, we replaced the middle anticlockwise direction with the clockwise direction and determined the directions of the three successive lines to be clockwise, clockwise, and clockwise, respectively, because the direction of the loop does not seem to change year by year. Similarly, when the series of directions was anticlockwise, clockwise, and anticlockwise, the middle clockwise direction was replaced with the anticlockwise direction, and we determined the directions of the loop to be anticlockwise, anticlockwise, and anticlockwise, respectively. We also calculated the slope of the regression line for the plot of $\ln \left(R_{t+m}\right)$ against $\ln \left(S S B_{t}\right)$.

Rule 1
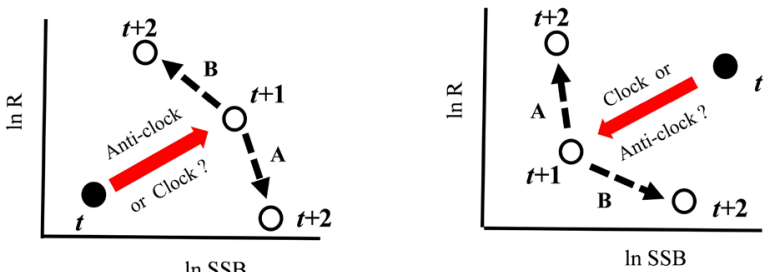

$\ln \mathrm{SSB}$

$\ln \mathrm{SSB}$

Rule 2


Figure 1. Rule used to judge the direction of the line from $t$ to $t+1$. When the direction of the line from $t+1$ to $t+2$ is $\mathrm{A}$, the line from $t$ to $t+1$ is judged to be part of a clockwise loop. When the direction of the line from $t+1$ to $t+2$ is $\mathrm{B}$, the line from $t$ to $t+1$ is judged to be part of an anticlockwise loop.

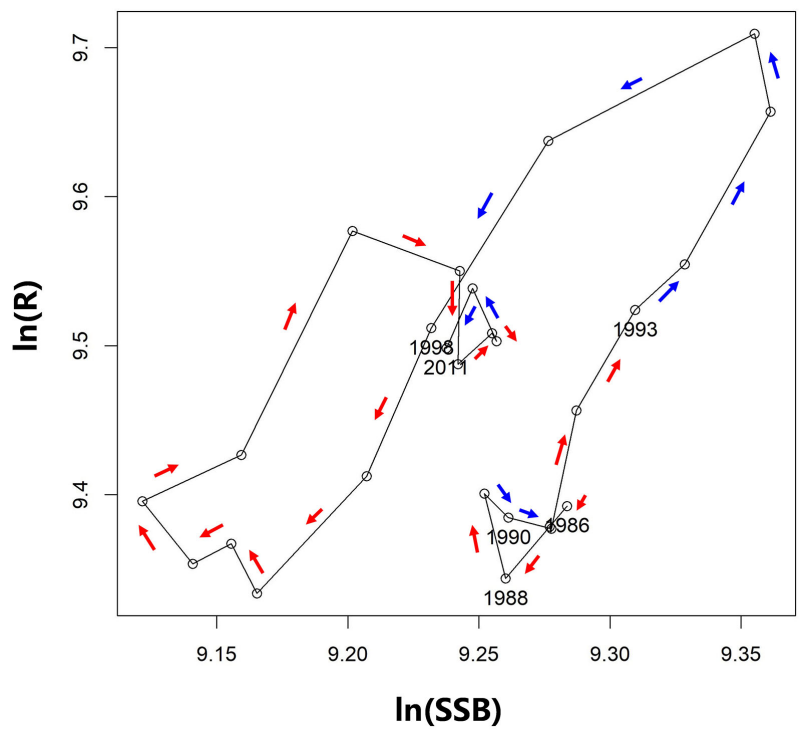

Figure 2. Clockwise or anticlockwise loops appeared in the SRR of the Western Japan Sea and East China Sea stock of red sea bream (stock number 22). 


\section{Calculation of Mean Age at Maturity}

As we said before, the ratio of the age at maturity to the cycle of environmental fluctuations determines the behavior of the SRR. In this study, we used three estimates of the age at maturity. The first was the age at $100 \%$ maturity, the second was the simple means age at maturity as calculated by Equation (1), and the third was the weighted mean of the age at maturity as calculated by Equation (2). Generally, the lag in the pattern between recruitment and SSB greatly depends on the mean age at maturity. The mean age at maturity should be calculated using the number of fish categorized by age. However, the number of fish was only available for the Japanese stock, shown as stock numbers 1 to 29 in Table 1 . Therefore, the weighted mean age at maturity was calculated only for the Japanese stock. For the Myers's stock, the weighted mean age at maturity was not used. The simple mean age at maturity $\left(a_{m}(\right.$ simple mean $\left.)\right)$ was calculated as follows:

$$
a_{m}(\text { simple mean })=a_{m}+\left(a_{\max }-a_{m}\right) / 2
$$

Here, $a_{m}$ and $a_{\max }$ are the minimum age at which $100 \%$ of fish are matured and the longevity of the fish, respectively. The weighted mean age at maturity $\left(a_{m}(\right.$ weighted mean $\left.)\right)$ was calculated as follows:

$$
a_{m}(\text { weighted mean })=a_{m}+\frac{\sum_{a_{k}=a_{m}}^{a_{\max }} a_{k} \cdot N_{a_{k}}}{\sum_{a_{k}=a_{m}}^{a_{\max }} N_{a_{k}}}
$$

Here, $a_{k}$ and $N_{a_{k}}$ denote the age at maturity and the number of fish at age $a_{k}$, respectively.

We then developed figures showing the relationship between the slope of the regression line and each of the three types of age at maturity for each stock, respectively.

Table 1. Stocks used in the analysis. Stock 1 to 29 are referred to as "Japanese stocks" "Ratio" denotes the value calculated by $n_{1} /\left(n_{1}+n_{2}\right)$. Here, $n_{1}$ and $n_{2}$ represent the numbers of lines that exhibit clockwise and anticlockwise loops, respectively. When the ratio is greater than or equal to 0.55 , the stock is colored orange, and when the ratio is less than or equal to 0.35 , the stock is co-

\begin{tabular}{|c|c|c|c|c|c|c|c|c|c|c|c|c|c|c|}
\hline \multirow{2}{*}{$\begin{array}{c}\text { Stock } \\
\text { No. }\end{array}$} & \multirow{2}{*}{ Species } & \multirow{2}{*}{ Stock } & $\begin{array}{l}\text { Mature } \\
\text { age }\end{array}$ & $\begin{array}{l}\text { life } \\
\text { span }\end{array}$ & $\begin{array}{c}\text { Simple } \\
\text { mean }\end{array}$ & Weighted & \multirow{2}{*}{ b } & \multicolumn{2}{|c|}{ 95\% confidence limit } & \multirow{2}{*}{ p-value } & Clock-wise & \multicolumn{2}{|r|}{$\begin{array}{c}\text { Unti- } \\
\text { clock-wise }\end{array}$} & \multirow{2}{*}{$\begin{array}{l}\text { Ratio } \\
\mathrm{n}_{1} /\left(\mathrm{n}_{1}\right. \\
\left.+\mathrm{n}_{2}\right)\end{array}$} \\
\hline & & & $100 \%$ & & & mean & & Lower & Upper & & $n_{1}$ & & $n_{2}$ & \\
\hline 1 & Squid & Winter & 0.58 & 1 & 0.79 & 0.58 & 1.13 & 0.843 & 1.421 & $4.29\left(10^{-9}\right)$ & 27 & $>$ & 6 & 0.82 \\
\hline 2 & Squid & autumn & 1 & 1 & 1 & 1 & 1.04 & 0.788 & 1.286 & $1.33\left(10^{-9}\right)$ & 33 & $>$ & 0 & 1.00 \\
\hline 3 & Round herring & $\begin{array}{c}\text { the Tsushima } \\
\text { Warm }\end{array}$ & 1 & 3 & 2 & 1.15 & 0.48 & 0.173 & 3.326 & $3.04\left(10^{-3}\right)$ & 17 & $<$ & 19 & 0.47 \\
\hline 4 & $\begin{array}{l}\text { Japanese } \\
\text { anchovy }\end{array}$ & the Pacific stock & 1 & 4 & 2.5 & 1.11 & 0.52 & 0.383 & 0.649 & $4.01\left(10^{-9}\right)$ & 34 & $>$ & 0 & 1.00 \\
\hline 5 & $\begin{array}{l}\text { Japanese } \\
\text { anchovy }\end{array}$ & $\begin{array}{c}\text { the Tsushima } \\
\text { Warm }\end{array}$ & 1 & 2 & 1.5 & 1.05 & 0.53 & 0.309 & 0.742 & $2.13\left(10^{-5}\right)$ & 30 & $>$ & 5 & 0.86 \\
\hline
\end{tabular}
lored blue. 


\section{Continued}

\begin{tabular}{|c|c|c|c|c|c|c|c|c|c|c|c|c|c|c|}
\hline 6 & $\begin{array}{l}\text { Japanese } \\
\text { Spanish } \\
\text { mackerel }\end{array}$ & Seto Inland & 1.5 & 7 & 4.25 & 1.67 & 1.13 & 0.89 & 1.373 & $9.67\left(10^{-10}\right)$ & 10 & $<$ & 15 & 0.40 \\
\hline 7 & Flounder & $\begin{array}{l}\text { Western Japan sea } \\
\text { and the East China }\end{array}$ & 3 & 12 & 7.5 & 3.74 & -1.14 & -2.292 & 0.018 & $5.33\left(10^{-2}\right)$ & 16 & $>$ & 9 & 0.64 \\
\hline 8 & $\begin{array}{l}\text { Japanese } \\
\text { sardine }\end{array}$ & the Pacific stock & 2 & 7 & 4.5 & 2.76 & 0.77 & 0.603 & 0.943 & $5.37\left(10^{-11}\right)$ & 23 & $>$ & 14 & 0.62 \\
\hline 9 & $\begin{array}{l}\text { Japanese } \\
\text { sardine }\end{array}$ & $\begin{array}{l}\text { the Tsushima } \\
\text { Warm }\end{array}$ & 2 & 7 & 4.5 & 2.68 & 0.91 & 0.812 & 1.013 & $2.20\left(10^{-16}\right)$ & 26 & $=$ & 26 & 0.50 \\
\hline 10 & $\begin{array}{c}\text { Blue } \\
\text { mackerel }\end{array}$ & the Pacific stock & 2 & 6 & 4 & 2.37 & 0.24 & -0.099 & 0.581 & $1.55\left(10^{-1}\right)$ & 7 & $<$ & 11 & 0.39 \\
\hline 11 & $\begin{array}{c}\text { Japanese horse } \\
\text { mackerel }\end{array}$ & the Pacific stock & 2 & 5 & 3.5 & 2.18 & 0.67 & 0.2 & 1.138 & $6.24\left(10^{-3}\right)$ & 17 & $>$ & 13 & 0.57 \\
\hline 12 & $\begin{array}{c}\text { Japanese horse } \\
\text { mackerel }\end{array}$ & $\begin{array}{c}\text { the Tsushima } \\
\text { Warm }\end{array}$ & 2 & 5 & 3.5 & 2.23 & 0.85 & 0.386 & 1.303 & $6.23\left(10^{-4}\right)$ & 25 & $>$ & 14 & 0.64 \\
\hline 13 & $\begin{array}{l}\text { Yellowback } \\
\text { seabream }\end{array}$ & the Japan Sea and & 2 & 8 & 5 & 2.46 & 0.56 & 0.236 & 0.875 & $1.27\left(10^{-3}\right)$ & 20 & $>$ & 12 & 0.63 \\
\hline 14 & Pacific saury & Nothern Pacific & 1 & 2 & 1.5 & 1.5 & 0.7 & -0.365 & 1.774 & $1.67\left(10^{-1}\right)$ & 5 & $>$ & 4 & 0.56 \\
\hline 15 & Blue mackerel & the East China & 3 & 6 & 4.5 & 3 & 0.4 & -0.172 & 0.97 & $1.60\left(10^{-1}\right)$ & 14 & $>$ & 6 & 0.70 \\
\hline 16 & Alaska pollock & Northern Japan & 3 & 10 & 6.5 & 4.29 & 1.28 & 0.882 & 1.683 & $3.62\left(10^{-7}\right)$ & 19 & $>$ & 11 & 0.63 \\
\hline 17 & Chub mackerel & 1 the Pacific stock & 3 & 7.5 & 5.25 & 3.44 & 0.67 & 0.2 & 1.138 & $6.24\left(10^{-3}\right)$ & 24 & $>$ & 19 & 0.56 \\
\hline 18 & Chub mackerel & 1 the East China & 3 & 6 & 4.5 & 3 & 0.35 & 0.108 & 0.585 & $5.52\left(10^{-3}\right)$ & 37 & $>$ & 2 & 0.95 \\
\hline 19 & $\begin{array}{l}\text { Roundnose } \\
\text { flounder }\end{array}$ & Japan sea stock & 3 & 7 & 5 & 3.4 & 0.52 & -0.825 & 1.865 & $4.26\left(10^{-1}\right)$ & 8 & $<$ & 10 & 0.44 \\
\hline 20 & $\begin{array}{l}\text { Pointhead } \\
\text { flounder }\end{array}$ & Japan sea stock & 3 & 7 & 5 & 3.36 & 0.29 & -0.485 & 1.064 & $4.36\left(10^{-1}\right)$ & 3 & $<$ & 12 & 0.20 \\
\hline 21 & $\begin{array}{l}\text { Japanese } \\
\text { amberjack }\end{array}$ & & 3 & 7 & 5 & 3 & 0.79 & 0.279 & 1.3 & $4.58\left(10^{-3}\right)$ & 12 & $>$ & 6 & 0.67 \\
\hline 22 & Red sea bream & Western Japan sea & 3.5 & 20 & 11.75 & 4.22 & 0.98 & 0.413 & 1.545 & $1.55\left(10^{-3}\right)$ & 16 & $>$ & 9 & 0.64 \\
\hline 23 & Red sea bream & $\begin{array}{l}\text { Eastern Seto } \\
\text { Inland }\end{array}$ & 3.5 & 17.5 & 10.5 & 3.75 & 0.35 & 0.234 & 0.475 & $9.39\left(10^{-7}\right)$ & 14 & $<$ & 21 & 0.40 \\
\hline 24 & Red sea bream & $\begin{array}{c}\text { Central } \\
\text { and western }\end{array}$ & 4 & 17.5 & 10.75 & 4.91 & -0.12 & -0.605 & 0.368 & $6.24\left(10^{-1}\right)$ & 23 & $>$ & 12 & 0.66 \\
\hline 25 & Bastard halibut & Seto Inland & 4 & 15 & 9.5 & 4.45 & -0.41 & -2.23 & 1.413 & $6.41\left(10^{-1}\right)$ & 11 & $>$ & 6 & 0.65 \\
\hline 26 & $\begin{array}{l}\text { Japanese } \\
\text { pufferfish }\end{array}$ & Ise and Mikawa & 3 & 10 & 6.5 & 3 & -0.92 & -1.567 & -0.267 & $8.31\left(10^{-3}\right)$ & 3 & $<$ & 16 & 0.16 \\
\hline 27 & Sandfish & Western Japan sea & 2 & 5 & 3.5 & 2.36 & 0.72 & 0.096 & 1.344 & $3.03\left(10^{-2}\right)$ & 3 & $<$ & 4 & 0.43 \\
\hline 28 & $\begin{array}{l}\text { Alaska } \\
\text { pollock }\end{array}$ & the Pacific stock & 6 & 10 & 8 & 6.5 & -0.37 & -1.135 & 0.397 & $3.33\left(10^{-1}\right)$ & 6 & $<$ & 25 & 0.19 \\
\hline 29 & Snow crab & Northern Pacific & 6 & 10 & 8 & & 0.41 & -0.372 & 1.2 & $2.78\left(10^{-1}\right)$ & 4 & $<$ & 11 & 0.27 \\
\hline 30 & Cod & NAFO5Z & 2 & 25 & 13.5 & & 0.32 & -0.131 & 0.763 & $1.59\left(10^{-1}\right)$ & 24 & $>$ & 9 & 0.73 \\
\hline 31 & Haddock & NAFO5Z & 2 & 20 & 11 & & 1.02 & 0.652 & 1.395 & $6.60\left(10^{-7}\right)$ & 19 & $<$ & 48 & 0.28 \\
\hline 32 & Silver hake & NAFO5Ze & 2 & 12 & 7 & & 0.86 & 0.638 & 1.09 & $8.14\left(10^{-9}\right)$ & 12 & $<$ & 21 & 0.36 \\
\hline 33 & Red hake & NAFOG & 2 & 12 & 7 & & 0.34 & -0.196 & 0.868 & $1.92\left(10^{-1}\right)$ & 7 & $>$ & 5 & 0.58 \\
\hline
\end{tabular}


Continued

\begin{tabular}{|c|c|c|c|c|c|c|c|c|c|c|c|c|c|}
\hline 34 & Red hake & NAFOS & 2 & 12 & 7 & -0.27 & -2.502 & 1.961 & $7.98\left(10^{-1}\right)$ & 7 & $=$ & 7 & 0.50 \\
\hline 35 & $\begin{array}{l}\text { Yellowtail } \\
\text { flounder- } \\
\text { NAFO5Z }\end{array}$ & NAFO6Z & 2 & 12 & 7 & 0.47 & 0.055 & 0.89 & $2.83\left(10^{-2}\right)$ & 3 & $<$ & 19 & 0.14 \\
\hline 36 & Cod & NAFO5Y & 3 & 12 & 7.5 & 0.37 & -0.209 & 0.95 & $2.02\left(10^{-1}\right)$ & 15 & $<$ & 18 & 0.45 \\
\hline 37 & Silver hake & NAFO4VWX & 3 & 25 & 14 & 0.37 & -0.783 & 1.518 & $4.97\left(10^{-1}\right)$ & 6 & $=$ & 6 & 0.50 \\
\hline 38 & $\begin{array}{l}\text { Pollock or } \\
\text { saithe }\end{array}$ & NAFO4VWX5 & 3 & 25 & 14 & 0.73 & -2.001 & 3.454 & $5.56\left(10^{-1}\right)$ & 4 & $<$ & 5 & 0.44 \\
\hline 39 & Mackerel & NAFO2to6 & 3 & 17 & 10 & 0.94 & 0.347 & 1.524 & $2.75\left(10^{-3}\right)$ & 16 & $<$ & 19 & 0.46 \\
\hline 40 & Herring & NAFO4-5 & 4 & 25 & 14.5 & 0.15 & -0.114 & 0.411 & $2.51\left(10^{-1}\right)$ & 12 & $>$ & 9 & 0.57 \\
\hline 41 & Herring & $\begin{array}{c}\text { NAFO4T } \\
\text { (Fall spawners) }\end{array}$ & 4 & 25 & 14.5 & -0.07 & -0.468 & 0.32 & $6.70\left(10^{-1}\right)$ & 0 & $<$ & 8 & 0.00 \\
\hline 42 & Herring & NAFO4WX & 4 & 25 & 14.5 & 0.11 & -1.021 & 1.24 & $8.31\left(10^{-1}\right)$ & 2 & $<$ & 8 & 0.20 \\
\hline 43 & Cod & NAFO4X & 4 & 25 & 14.5 & -0.16 & -0.733 & 0.404 & $5.63\left(10^{-1}\right)$ & 32 & $>$ & 12 & 0.73 \\
\hline 44 & Haddock & NAFO4X & 4 & 20 & 12 & 0.05 & -0.817 & 0.925 & $8.99\left(10^{-1}\right)$ & 8 & $<$ & 15 & 0.35 \\
\hline 45 & White hake & NAFO4T & 4 & 23 & 13.5 & -0.66 & -1.203 & -0.114 & $2.18\left(10^{-2}\right)$ & 9 & $>$ & 4 & 0.69 \\
\hline 46 & $\begin{array}{c}\text { American } \\
\text { plaice- } \\
\text { NAFO3LNO }\end{array}$ & NAFO4LNO & 4 & 30 & 17 & 0.26 & 0.08 & 0.443 & $7.48\left(10^{-3}\right)$ & 3 & $<$ & 15 & 0.17 \\
\hline 47 & $\begin{array}{l}\text { American } \\
\text { plaice- } \\
\text { NAFO5YZ }\end{array}$ & NAFO6YZ & 4 & 30 & 17 & -0.3 & -0.676 & 0.077 & $1.05\left(10^{-1}\right)$ & 10 & $>$ & 0 & 1.00 \\
\hline 48 & Herring & $\begin{array}{c}\text { NAFO4R } \\
\text { (Fall spawners) }\end{array}$ & 5 & 25 & 15 & -1.28 & -2.41 & -0.143 & $3.07\left(10^{-2}\right)$ & 4 & $<$ & 8 & 0.33 \\
\hline 49 & Herring & $\begin{array}{c}\text { NAFO4R } \\
\text { (Spring spawners) }\end{array}$ & 5 & 25 & 15 & -0.77 & -1.969 & 0.426 & $1.84\left(10^{-1}\right)$ & 5 & $<$ & 7 & 0.42 \\
\hline 50 & Cod & NAFO3M & 5 & 25 & 15 & -0.04 & -1.963 & 1.877 & $9.60\left(10^{-1}\right)$ & 5 & $>$ & 4 & 0.56 \\
\hline 51 & Haddock & NAFO4TVW & 5 & 20 & 12.5 & 0.54 & 0.281 & 0.789 & $1.35\left(10^{-4}\right)$ & 16 & $<$ & 21 & 0.43 \\
\hline 52 & Cod & NAFO3NO & 6 & 25 & 15.5 & 0.64 & 0.031 & 1.251 & $4.02\left(10^{-2}\right)$ & 24 & $>$ & 6 & 0.80 \\
\hline 53 & Cod & NAFO3Ps & 6 & 25 & 15.5 & 0.35 & -0.031 & 0.738 & $7.02\left(10^{-2}\right)$ & 14 & $<$ & 16 & 0.47 \\
\hline 54 & Cod & NAFO4VsW & 6 & 25 & 15.5 & -0.06 & -0.513 & 0.399 & $7.99\left(10^{-1}\right)$ & 14 & $<$ & 16 & 0.47 \\
\hline 55 & $\begin{array}{c}\text { Yellowtail } \\
\text { flounder- } \\
\text { NAFO3LNO }\end{array}$ & NAFO4LNO & 6 & 12 & 9 & 0.27 & -0.7 & 1.236 & $5.60\left(10^{-1}\right)$ & 3 & $<$ & 11 & 0.21 \\
\hline 56 & Cod & NAFO2J3KL & 7 & 25 & 16 & 0.66 & 0.275 & 1.045 & $1.59\left(10^{-3}\right)$ & 21 & $>$ & 6 & 0.78 \\
\hline 57 & Cod & NAFO3Pn4RS & 7 & 25 & 16 & 0.6 & -0.278 & 1.484 & $1.65\left(10^{-1}\right)$ & 2 & $<$ & 18 & 0.10 \\
\hline 58 & Cod & NAFO4TVn & 7 & 25 & 16 & 0.01 & -0.32 & 0.345 & $9.38\left(10^{-1}\right)$ & 15 & $<$ & 25 & 0.38 \\
\hline 59 & Herring & North Sea & 3 & 25 & 14 & 0.47 & 0.311 & 0.636 & $7.397\left(10^{-7}\right)$ & 19 & $<$ & 21 & 0.48 \\
\hline 60 & $\begin{array}{l}\text { Atlantic } \\
\text { Menhaden }\end{array}$ & U.S. Atlantic & 2.5 & 12 & 7.25 & 0.12 & -0.061 & 0.305 & $1.86\left(10^{-1}\right)$ & 24 & $>$ & 15 & 0.62 \\
\hline 61 & $\begin{array}{l}\text { Pollock or } \\
\text { Sithe }\end{array}$ & Iceland & 5 & 25 & 15 & -0.46 & -0.995 & 0.078 & $9.13\left(10^{-2}\right)$ & 19 & $>$ & 12 & 0.61 \\
\hline 62 & $\begin{array}{l}\text { Pollock or } \\
\text { Sithe }\end{array}$ & Faroe & 5 & 25 & 15 & -0.19 & -1.177 & 0.79 & $6.90\left(10^{-1}\right)$ & 16 & $>$ & 15 & 0.52 \\
\hline
\end{tabular}




\section{Results}

\section{Clockwise or Anticlockwise Loops in SRR}

Figure 2 shows the SRR of the Western Japan Sea and East China Sea stock of red sea bream (stock number 22) as an example. All of the SRR figures are shown in Appendix. In the case of the Western Japan Sea and East China Sea stock of red sea bream, both clockwise loops and anti-clockwise loops were recognized; however, in this case, the clockwise loops were dominant. The results are summarized in Table 1. Table 1 shows the name of the species, the name of the stock, the age at $100 \%$ maturity, the life span (i.e., the maximum age), the simple mean age at maturity, the weighted mean age at maturity, the slope of the regression line, the $95 \%$ confidence limit of the slope, the p-values of the slope, the number of lines that showed a clockwise loop direction $\left(n_{1}\right)$, the number of lines showing an anticlockwise loop direction $\left(n_{2}\right)$, and the ratio calculated by $n_{1} /\left(n_{1}+n_{2}\right)$. In Table 1 , the orange shows the stock for which the ratio was greater than or equal to 0.55 , and the blue shows the stock for which the ratio was less than or equal to 0.35 .

The age at $100 \%$ maturity of the snow crab in the Northern Pacific (stock number 29) is not known. However, these crabs molt more than 10 times before they mature. We assume that 10 cycles of molting would require more than 5 years. Therefore, we assume that the age at $100 \%$ maturity of this stock is 5 years old. The life spans for stocks 30 - 62 are not known.

Figure 3 shows the relationship between the slope of the regression line and the age at $100 \%$ maturity for the Japanese stock. The numerical values attached to the circles indicate the stock number. The red circles in Figure 3 indicate the stocks for which the ratio $n_{1} /\left(n_{1}+n_{2}\right)$ is greater than or equal to 0.55 . That is, clockwise loops are dominant. The blue circles indicate the stocks for which the ratio $n_{1} /\left(n_{1}+n_{2}\right)$ is less than or equal to 0.35 . That is, anticlockwise loops are dominant.

When the age at maturity is low, the slopes of the regression line are around positive unity. The slopes decrease linearly until negative unity as the age at maturity increases. When the age at maturity is low, red circles are dominant; that is, clockwise loops are dominant. However, when the age at maturity increases to around 4-year-old, blue circles appear; that is, anticlockwise loops are dominant.

Figure 4 shows the relationship between the slope of the regression line and the simple mean age at maturity for Japanese stock. The red and blue circles indicate the same stocks as described above. When the age at maturity is low, the slopes of the regression lines are around positive unity. The slopes decrease linearly until negative unity as the age at maturity increases. When the age at maturity exceeds around 7 to 8 years old, the slopes of the regression lines again increase from negative unity to positive unity. When the age at maturity is low, red circles are dominant; however, when the age at maturity increases to around 7 to 8 years old, blue circles appear. Then, as the age at maturity further increases, red circles are again dominant. These patterns coincide well with those noted by Sakuramoto [11] [12] [16] and Tanaka et al. [15]. 


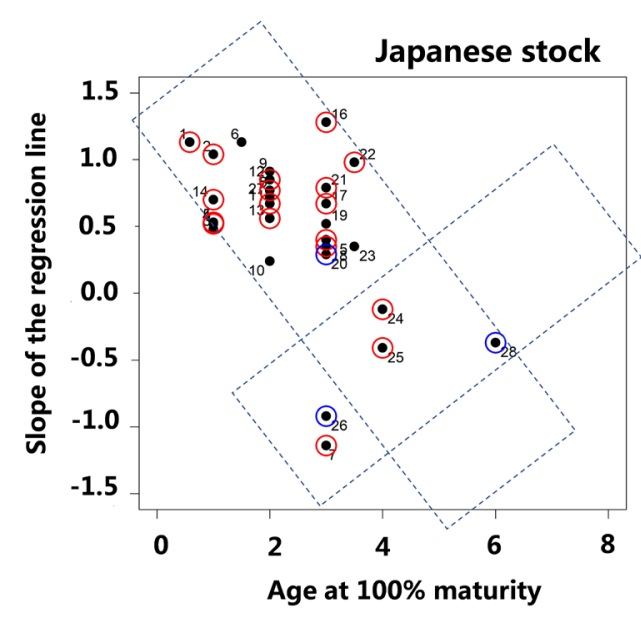

Figure 3. The relationship between the slope of the SRR and the age at $100 \%$ maturity for Japanese stock. The red circles indicate the stocks that satisfy $n_{1} /\left(n_{1}+n_{2}\right) \geq 0.55$. The blue circles indicate the stocks that satisfy $n_{1} /\left(n_{1}+n_{2}\right) \leq 0.35$. Here, $n_{1}$ and $n_{2}$ denote the number of lines that are segments of clockwise and anticlockwise loops, respectively. The numerical values attached to the circles indicate the numbers of stocks.



Figure 4. The relationship between the slope of the SRR and the simple mean age at maturity for Japanese stock.

Figure 5 shows the relationship between the slope of the regression line and the weighted mean age at maturity for Japanese stock. The red and blue circles indicate the same stocks as described above. The pattern is intermediate between those shown in Figure 3 and Figure 4. That is, when the age at maturity is low, the slopes of the regression lines are around positive unity. The slopes decrease linearly until negative unity as the age at maturity increases. However, the age at maturity at which the slope changes from a decreasing trend to an increasing trend is around 4 years old, which is similar to the case shown in Figure 3 but lower than in the case shown in Figure 4.

Figure 6 shows the relationship between the slope of the regression line and the age at $100 \%$ maturity for all stocks investigated in this study. When the age at maturity is low, the slopes of the regression lines are around positive unity. 
The slopes decrease linearly until negative unity as the age at maturity increases. However, when the age at maturity exceeds around 5 years old, the slopes again increase from negative unity to zero and from zero to positive unity.

Figure 7 shows the relationship between the slope of the regression line and the simple mean age at maturity for all stocks. The red and blue circles indicate the same stocks as described above. When the age at maturity is low, the slope of the regression line is around positive unity. The slope decreases linearly until negative unity as the age at maturity increases. When the age at maturity exceeds around 10 years old, the slope of the regression line again increases from negative unity to positive unity. When the age at maturity is low, red circles are dominant; however, when the age at maturity increases to around 10 years old, the blue circles appear. Then, as the age at maturity further increases, the red circles again become dominant. These patterns coincided well with those noted by Sakuramoto [11] [12] [16] and Tanaka et al. [15].

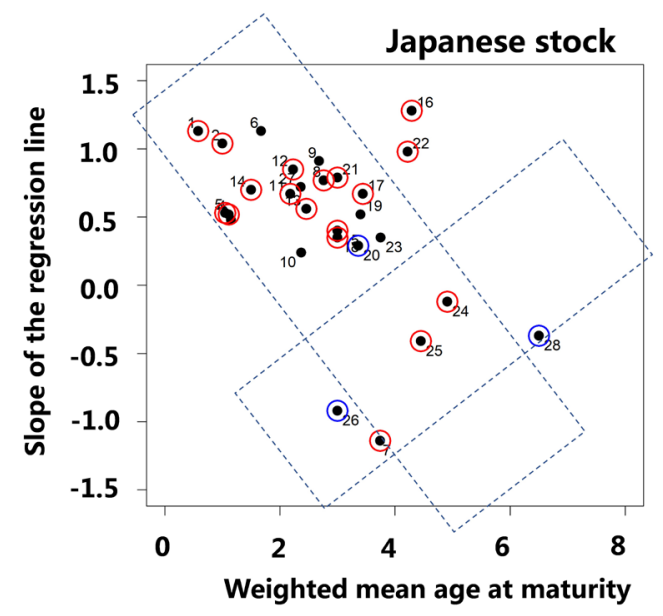

Figure 5. The relationship between the slope of the SRR and the weighted mean age at maturity for Japanese stock.



Figure 6. The relationship between the slope of the SRR and the age at $100 \%$ maturity for all stocks. 


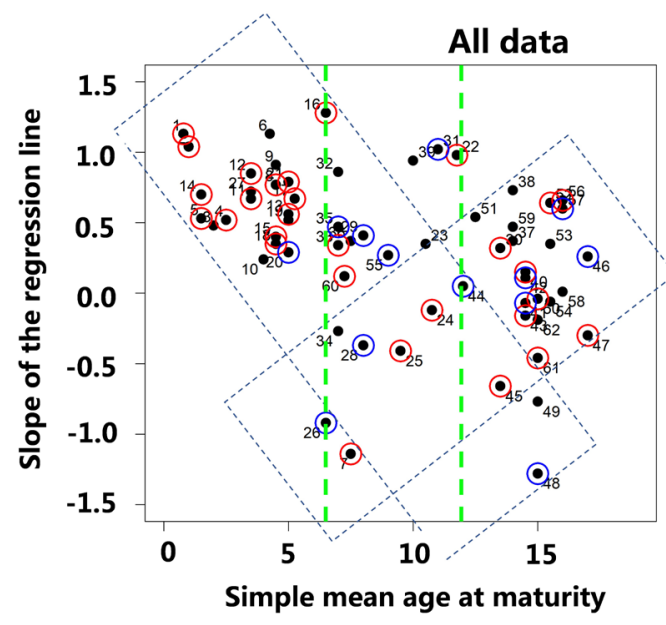

Figure 7. The relationship between the slope of the SRR and the simple mean age at maturity for all stocks.

\section{Discussion}

As Sakuramoto [11] [12] [16] and Tanaka et al. [15] showed, the slope of the regression line for the SRR and the direction of the loop in successive years of the plot for the SRR, i.e., whether a clockwise loop or an anticlockwise loop appears in the SRR, are determined by the ratio of the age at maturity to the length of the cycle of environmental fluctuations. In this study, we only focused on the age at maturity and we did not analyze the environmental conditions because we did not have a sufficient understanding of the environmental factors that drive the fluctuations of the stocks. In addition, we did not have data for the number of fish in the Myers's stock. Therefore, because of the lack of data, the analysis is not able to derive accurate results. However, we believe that we can judge the validity of the theory proposed by Sakuramoto [11] [12] [16] and Tanaka et al. [15].

That is, the relationship between the slope of the regression line and the mean age at maturity is as follows. When the age at maturity is low, the slope of the regression line is around positive unity. The slope decreases linearly until negative unity as the age at maturity increases. When the age at maturity exceeds half the length of the cycle of environmental fluctuation, the slope of the regression line again increases from negative unity to positive unity. When the age at maturity is low, clockwise loops are dominant, and as the age at maturity increases, anticlockwise loops are dominant. As the age at maturity increases even further, clockwise loops are again dominant.

The cycle of environmental fluctuations varies by location, and even within the same location, the cycle of environmental fluctuations varies over time. Further, the average age of maturity also varies because the age composition of the stock changes depending on the stock abundance. When the stock becomes depleted, younger fish are dominant, and when the stock is abundant, older fish are also abundant. This indicates that the ratio of the average age at maturity to 
the length of the cycle of environmental fluctuations tends to change over time even within the same stock. This must be why the clockwise loops and anticlockwise loops in the SRR were not clearly distinguished for each stock, although the loops were clearly distinguished in the simulations. However, the results in this study show essentially the same features as the results of the simulations described by Sakuramoto [12] [13] and the results reported by Tanaka et al. [15].

\section{Conclusions}

The results elucidated in this paper can be summarized as follows:

1) When the age at maturity is low, the slope of the regression line is around positive unity. The slope decreases linearly to negative unity as the age at maturity increases. When the age at maturity exceeds half the length of the cycle of environmental fluctuation, the slope of the regression line again increases from negative unity to positive unity.

2) When the age at maturity is low, clockwise loops are dominant; however, as the age at maturity increases, anti-clockwise loops become dominant. As the age at maturity increases further, clockwise loops again become dominant.

\section{Conflicts of Interest}

The authors declare no conflicts of interest regarding the publication of this paper.

\section{References}

[1] Sundby, S. (2000) Recruitment of Atlantic Cod Stocks in Relation to Temperature and Advection of Copepod Populations. Sarsia, 85, 277-298. https://doi.org/10.1080/00364827.2000.10414580

[2] Chen, D.G. and Irvine, J.R. (2001) A Semiparametric Model to Examine Stock-Recruitment Relationships Incorporating Environmental Data. Canadian Journal of Fisheries and Aquaculture Sciences, 58, 1178-1186. https://doi.org/10.1139/f01-037

[3] Ricker, W.E. (1954) Stock and Recruitment. Journal of the Fisheries Board of Canada, 11, 559-623. https://doi.org/10.1139/f54-039

[4] Beverton, R.J.H. and Holt, S.J. (1957) Fishery Investigations. Series 2, Her Majesty's Stationery Office, London, 19.

[5] Myers, R.A., Barrowman, N.J., Hutchings, J.A. and Rosenberg, A.A. (1995) Population Dynamics of Exploited Fish Stocks at Low Population Levels. Science, 269, 1106-1108. https://doi.org/10.1126/science.269.5227.1106

[6] Szuwalski, C.S., Vert-Pre, K.A., Punt, A.E., Branch, T.A. and Hilborn, R. (2015) Examining Common Assumptions about Recruitment: A Meta-Analysis of Recruitment Dynamics for Worldwide Marine Fisheries. Fish and Fisheries, 16, 633-640. https://doi.org/10.1111/faf.12083

[7] Sakuramoto, K. (2005) Does the Ricker or Beverton and Holt Type of Stock-Recruitment Relationship Truly Exist? Fisheries Science, 71, 577-592. https://doi.org/10.1111/j.1444-2906.2005.01002.x 
[8] Sakuramoto, K. (2013) A Recruitment Forecasting Model for the Pacific Stock of the Japanese Sardine (Sardinops melanostictus) That Does Not Assume Density-Dependent Effects. Agricultural Sciences, 4, 1-8. https://doi.org/10.4236/as.2013.46A001

[9] Sakuramoto, K. (2013) A Common Concept of Population Dynamics Applicable to both Thrips imaginis (Thysanoptera) and the Pacific Stock of the Japanese Sardine (Sardinops melanostictus). Fisheries and Aquaculture Journal, 4, 085.

[10] Sakuramoto, K. (2015) Illusion of a Density-Dependent Effect in Biology. Agricultural Sciences, 6, 479-488. http://dx.doi.org/10.4236/as.2015.65047

[11] Sakuramoto, K. (2015) A Stock-Recruitment Relationship Applicable to Pacific Bluefin Tuna and the Pacific Stock of Japanese Sardine. American Journal of Climate Change, 4, 446-460. http://dx.doi.org/10.4236/ajcc.2015.45036

[12] Sakuramoto, K. (2016) Case Study: A Simulation Model of the Spawning Stock Biomass of Pacific Bluefin Tuna and Evaluation of Fisheries Regulations. American Journal of Climate Change, 5, 245-260. http://dx.doi.org/10.4236/ajcc.2016.52021

[13] Fisheries Agency and Fisheries Research and Education Agency of Japan (2019) Marine Fisheries Stock Assessment and Evaluation for Japanese Waters (Fiscal Year 2018/2019). Marine Fisheries Stock Assessment and Evaluation for Japanese Waters, Kanagawa. https://abchan.fra.go.jp/

[14] Ransom Myers (2016) The Ransom Myers's Stock Recruitment Database. https://zenodo.org/record/2542919\#.YDuZFWj7SCp

[15] Tanaka, K., Suzuki, N. and Sakuramoto, K. (2017) Clockwise Loops and Anticlockwise Loops Observed in a Stock-Recruitment Relationship. Open Access Library Journal, 4, e3688. https://doi.org/10.4236/oalib.1103688

[16] Sakuramoto, K. (2016) Density-Dependent Effect Occurs Regardless of Density. Open Access Library Journal, 3, e3112. http://dx.doi.org/10.4236/oalib.1103112 


\section{Appendix}

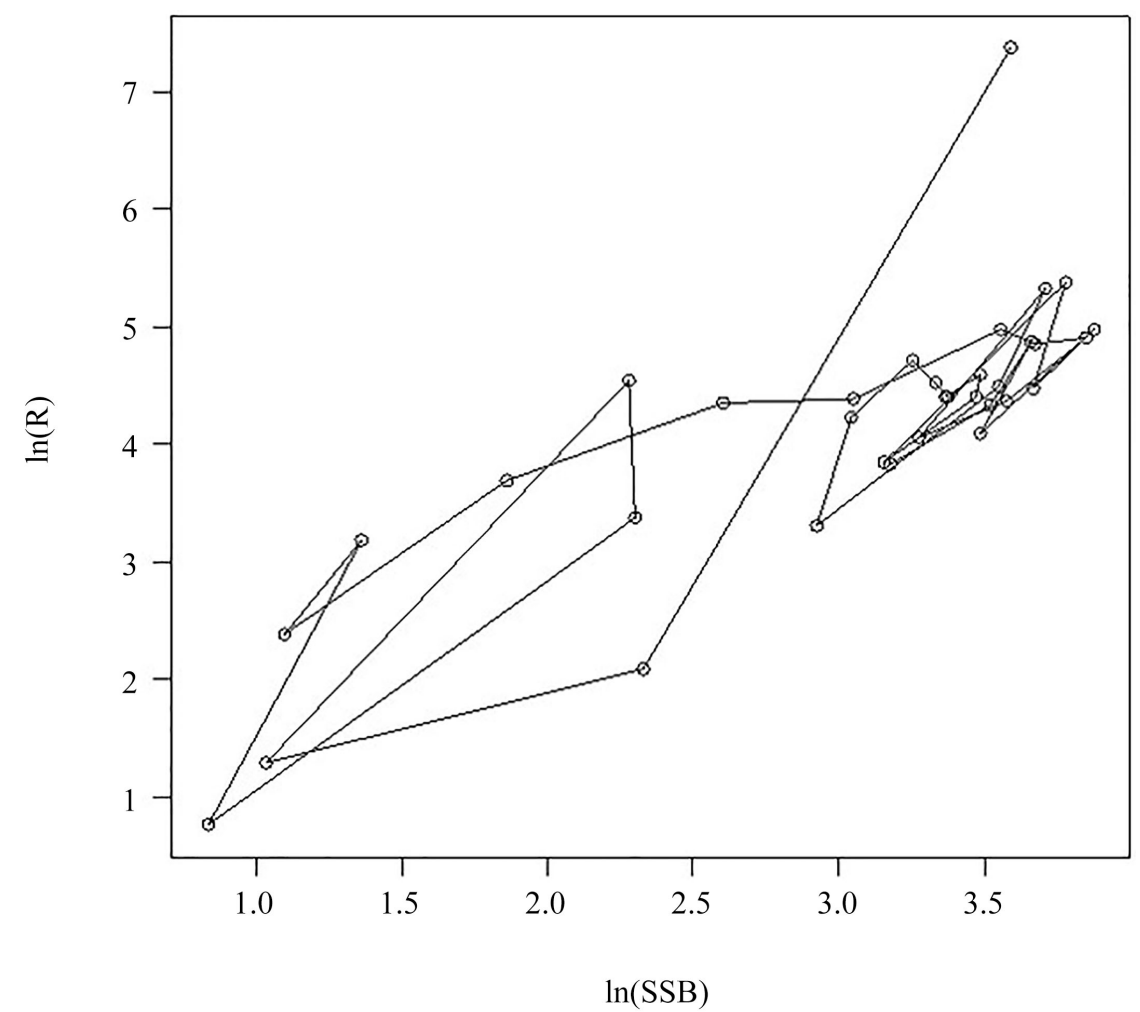

Figure A1. Squid (Winter).

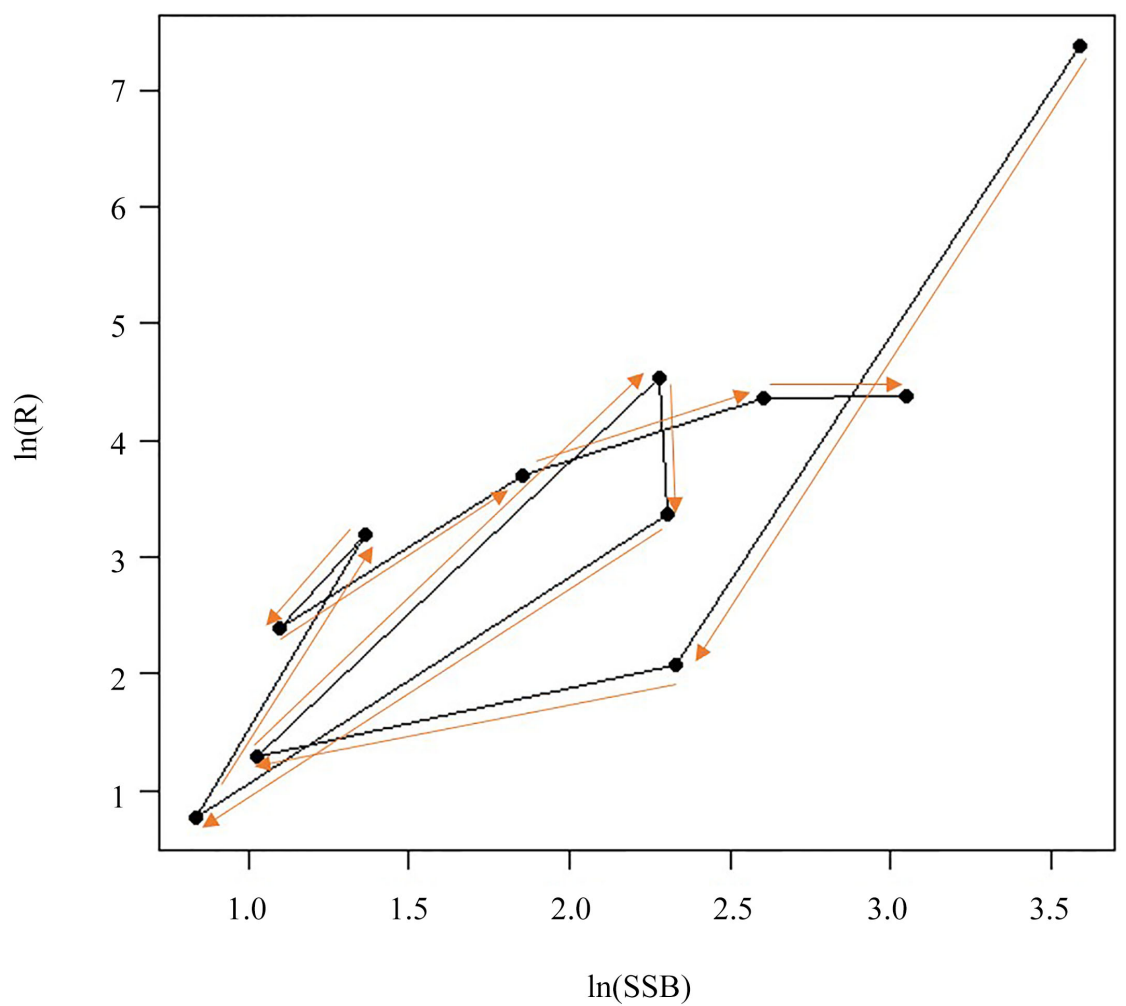

Figure A1(a). Squid (Winter) (Year: 1980-1990). 


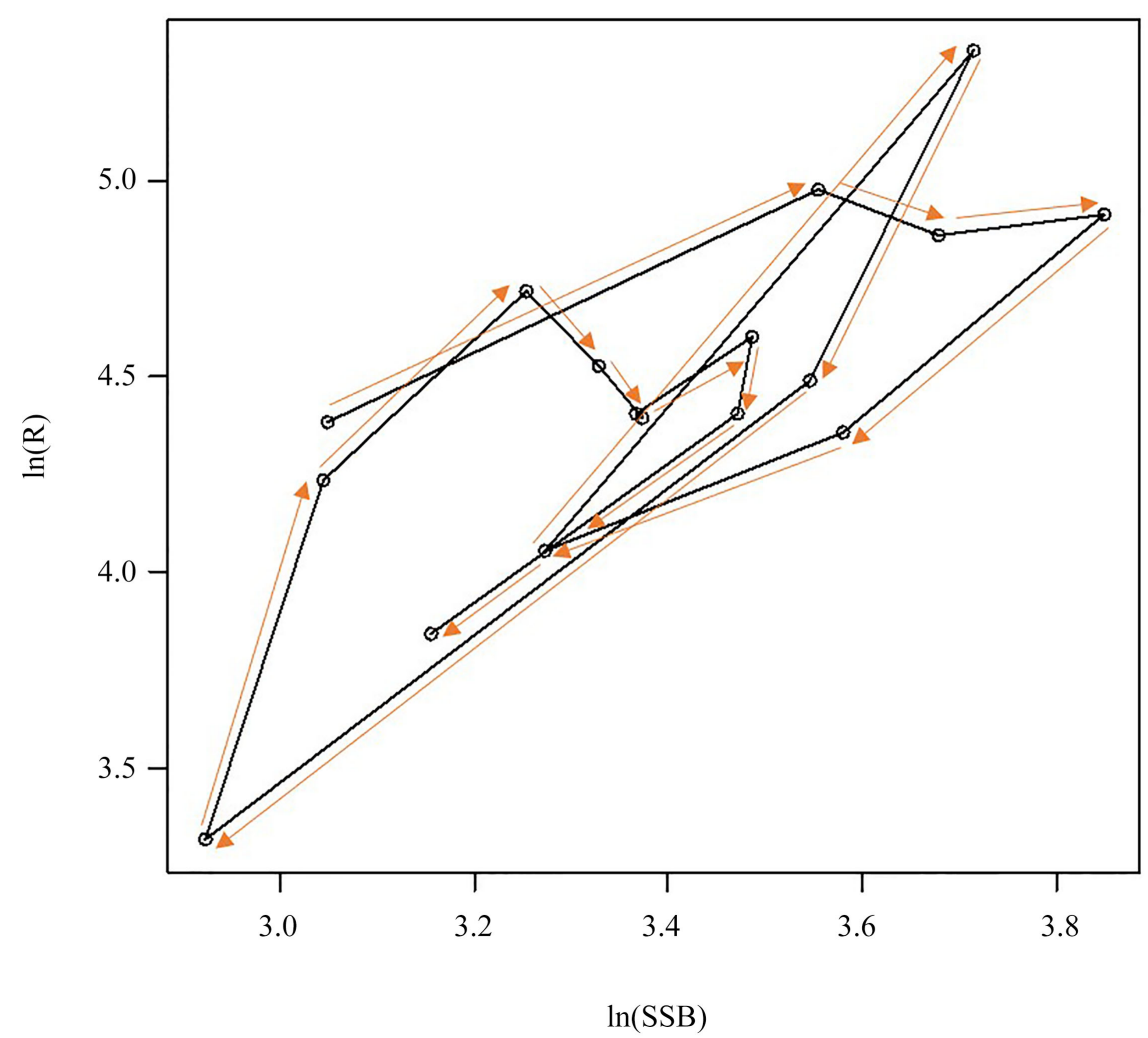

Figure A1(b). Squid (Winter) (Year: 1990-2000).

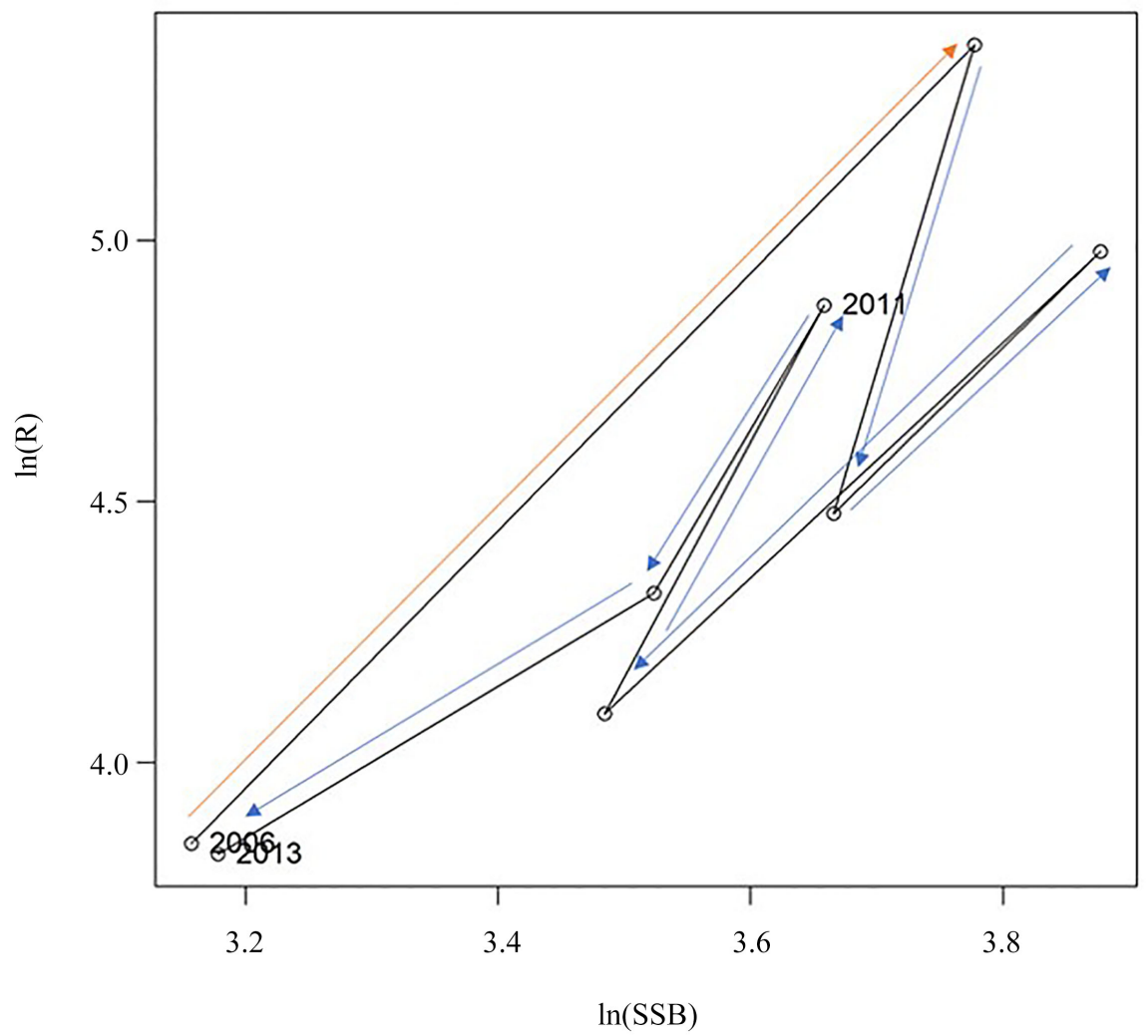

Figure A1(c). Squid (Winter) (Year: 2000-2013). 


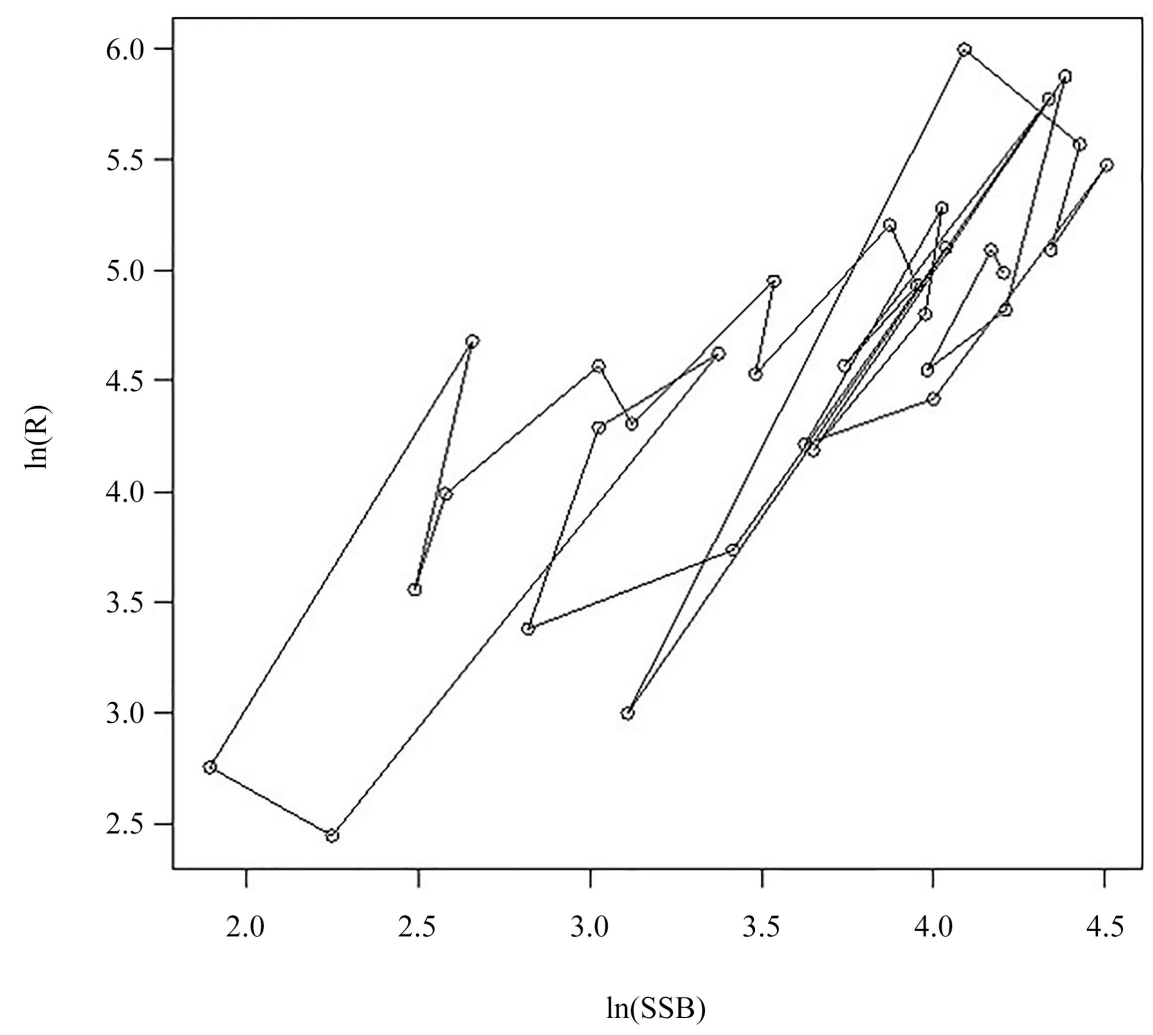

Figure A2. Squid (Autumn).



Figure A2(a). Squid (Autumn) (Year: 1980-1990). 


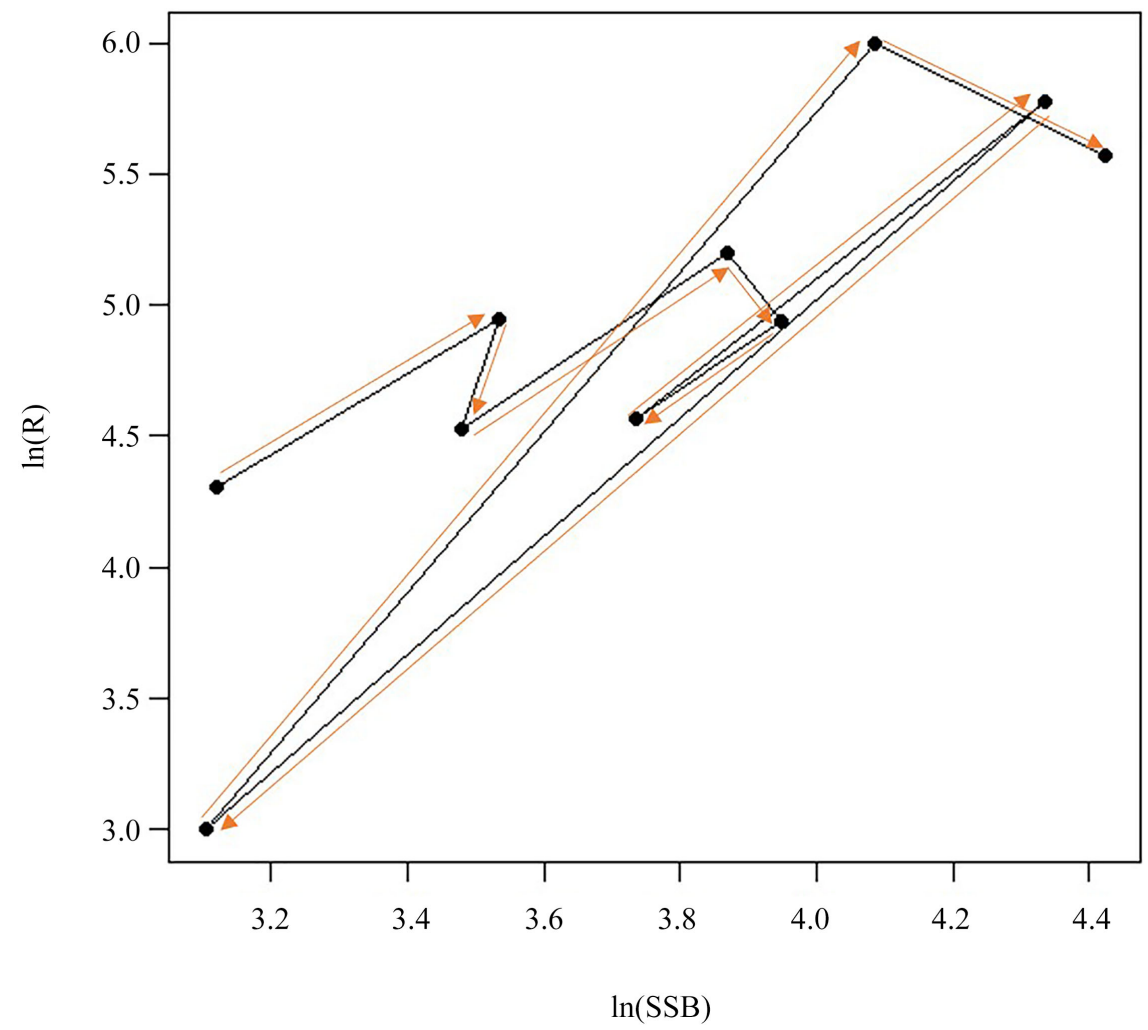

Figure A2(b). Squid (Autumn) (Year: 1991-2000).

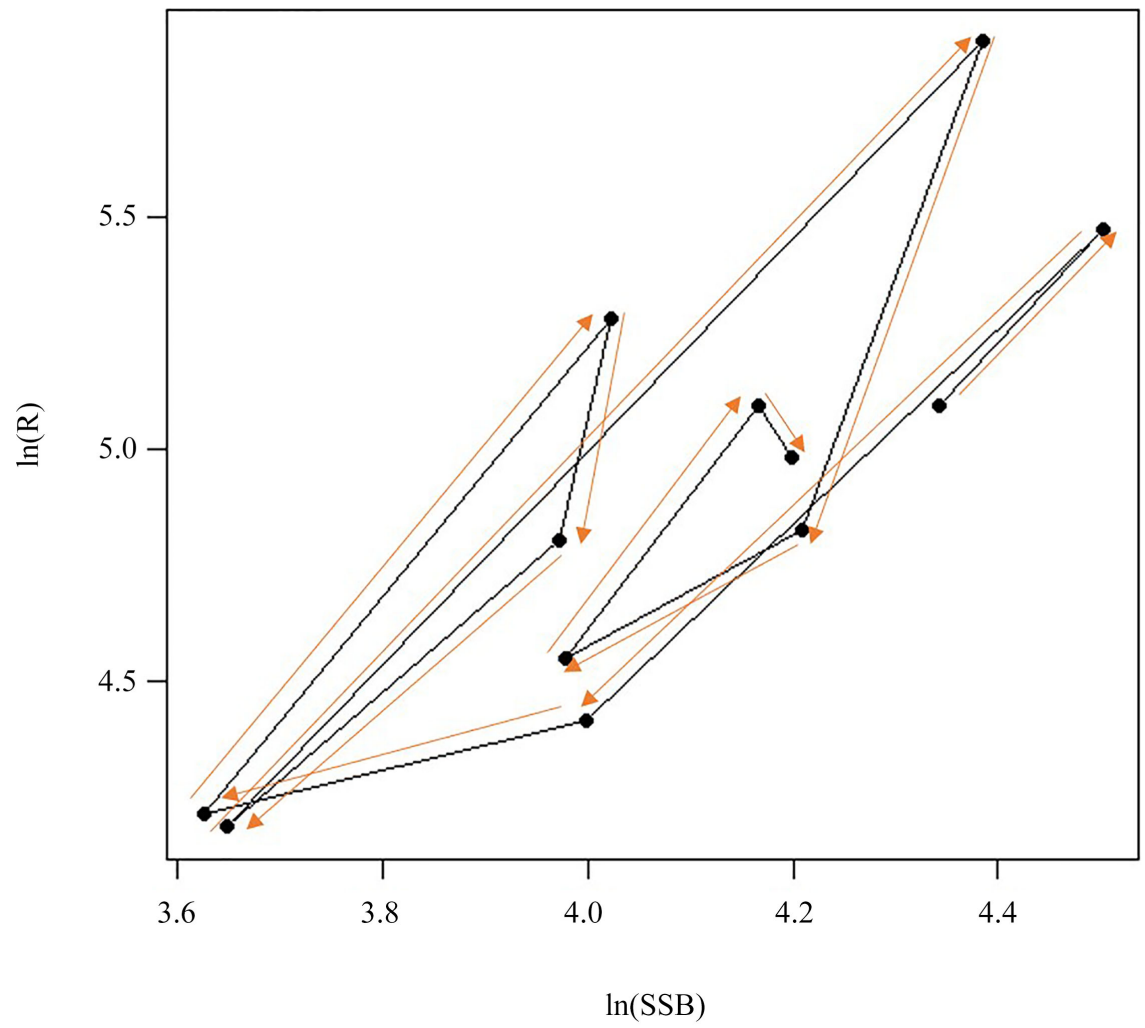

Figure A2(c). Squid (Autumn) (Year: 2001-2013). 




Figure A3. Tshima Warm Current stock of Round herring.

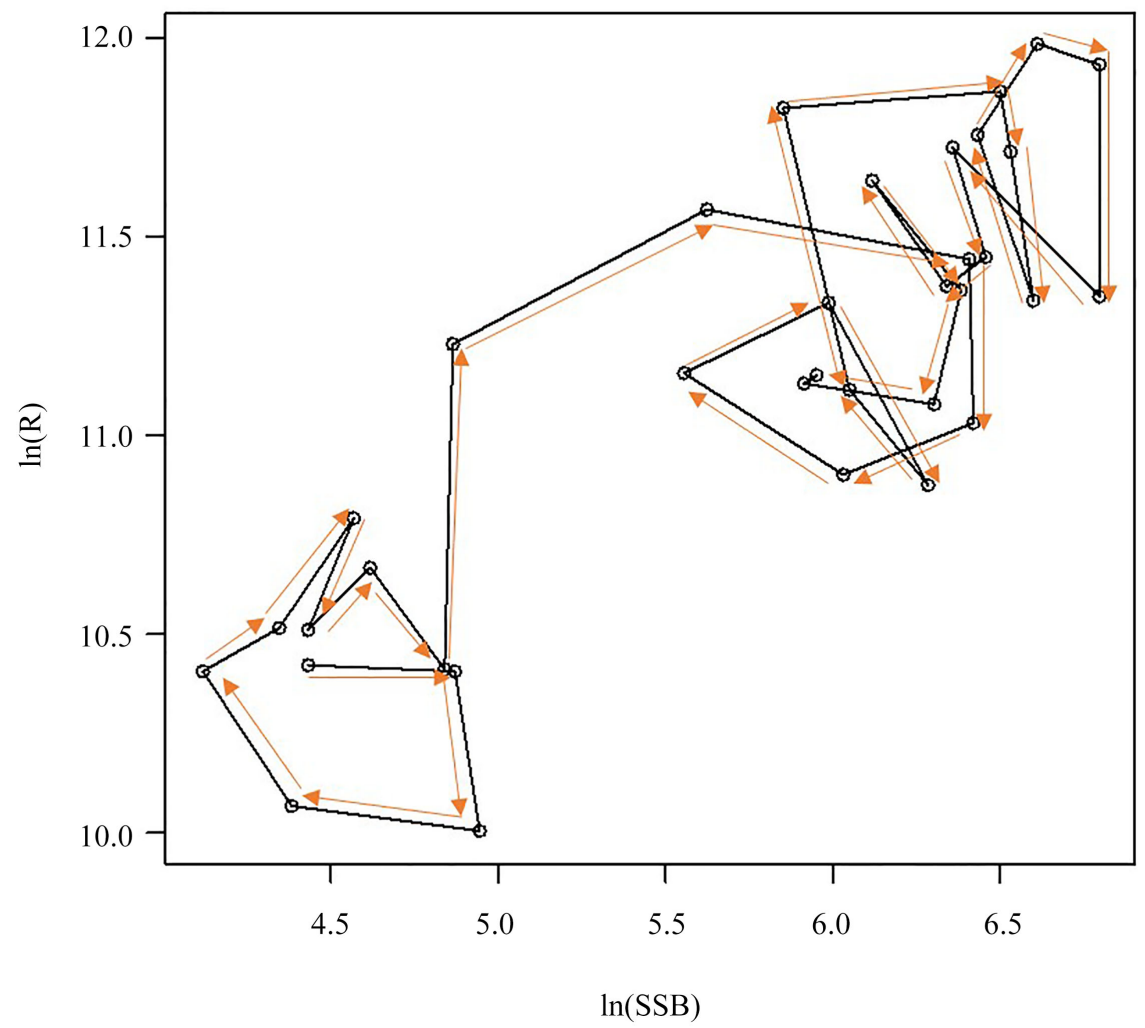

Figure A4. Pacific stock of Japanese Anchovy. 


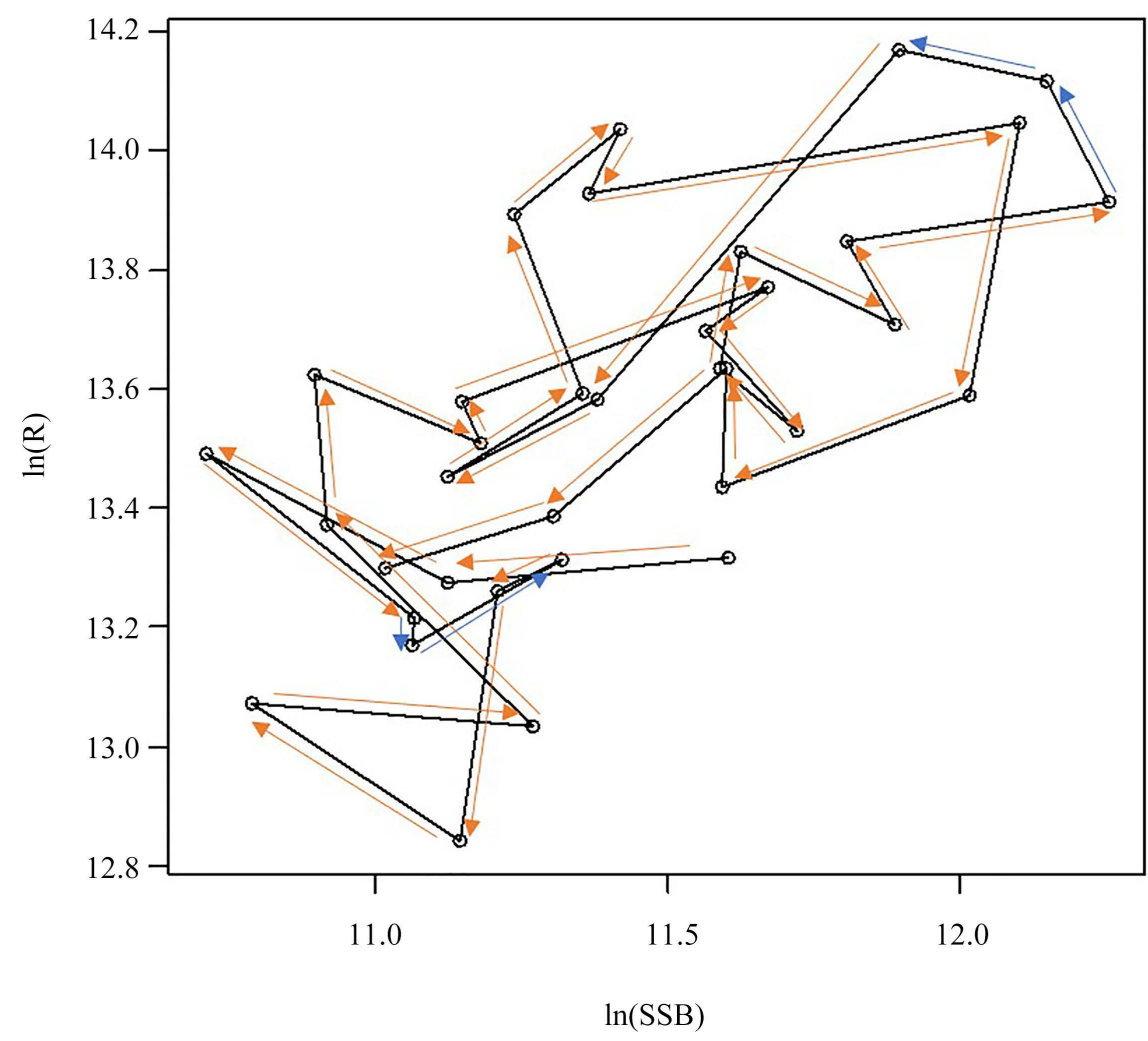

Figure A5. Tsushima warm current stock of Japanese Anchovy.

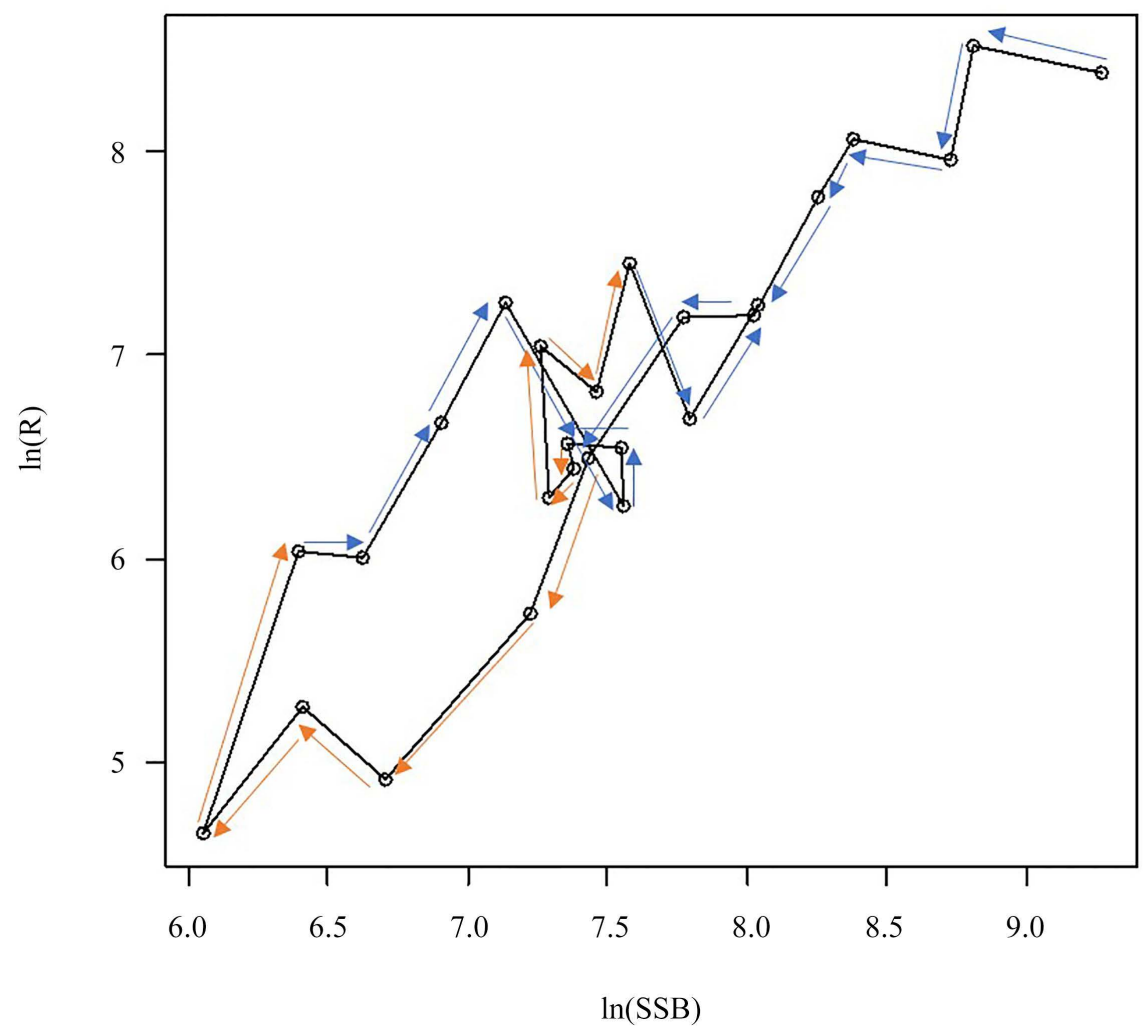

Figure A6. Western Japan sea and the East China of Flounder. 


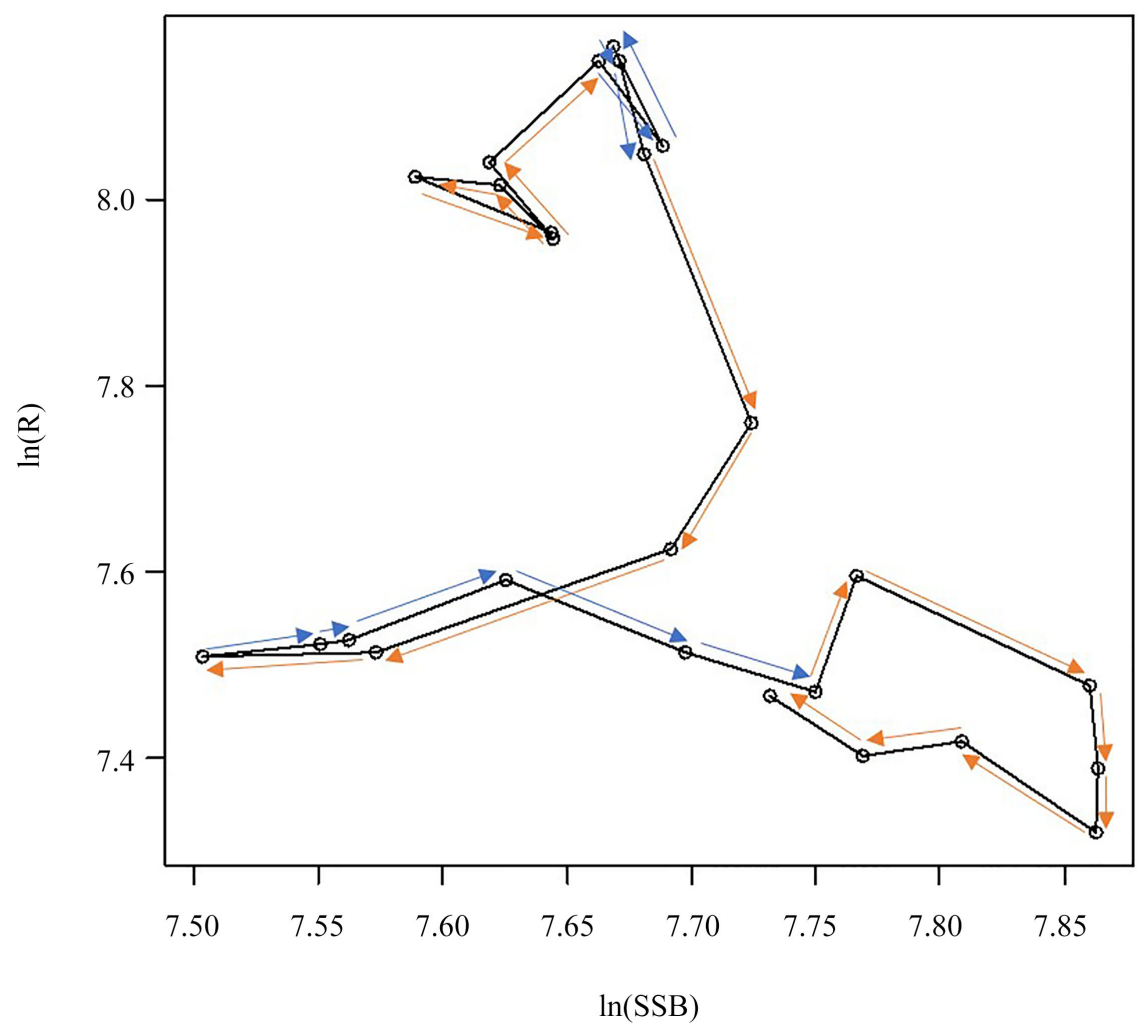

Figure A7. Seto Inland Sea stock of Japanese Spanish mackerel.

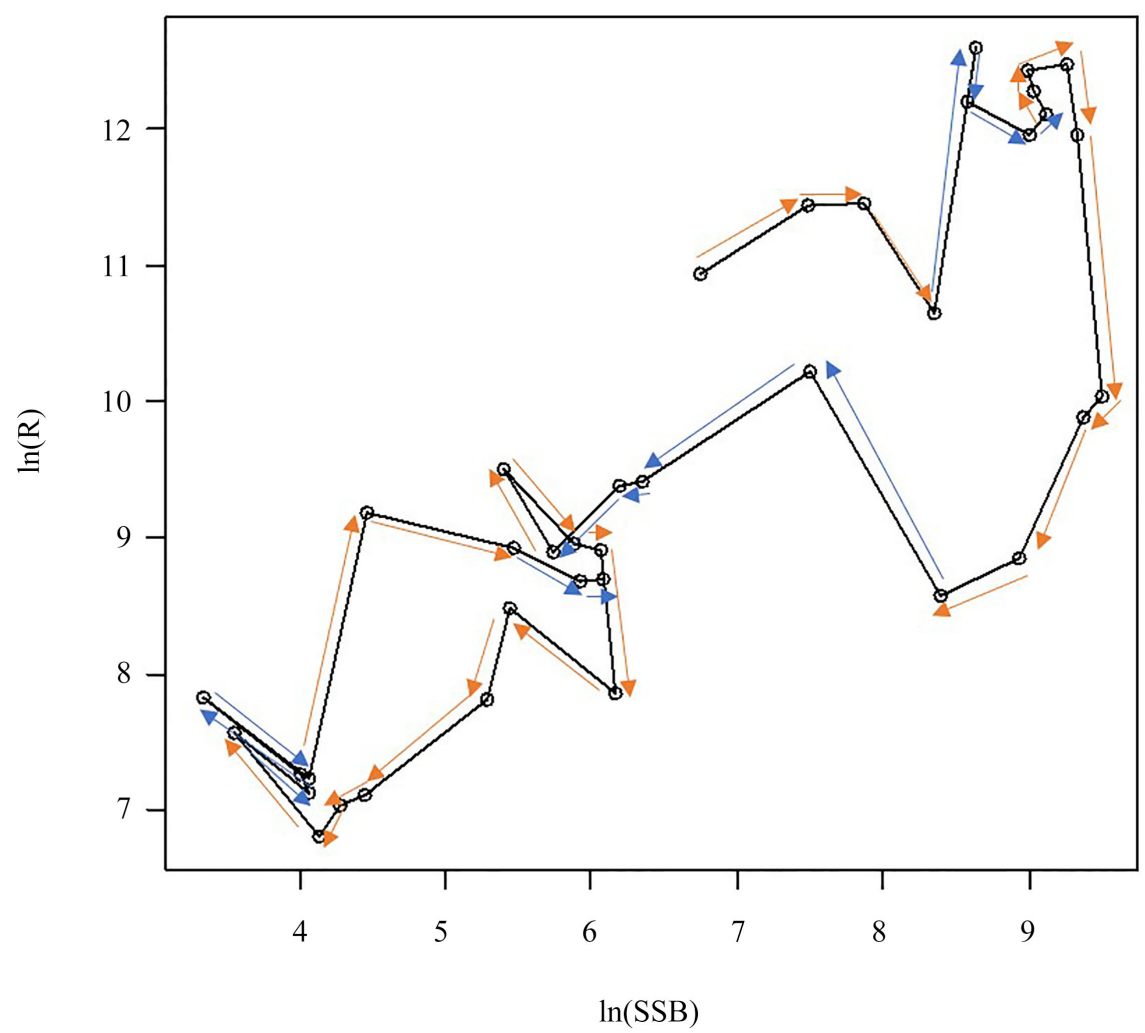

Figure A8. Pacific stock of Japanese sardine. 


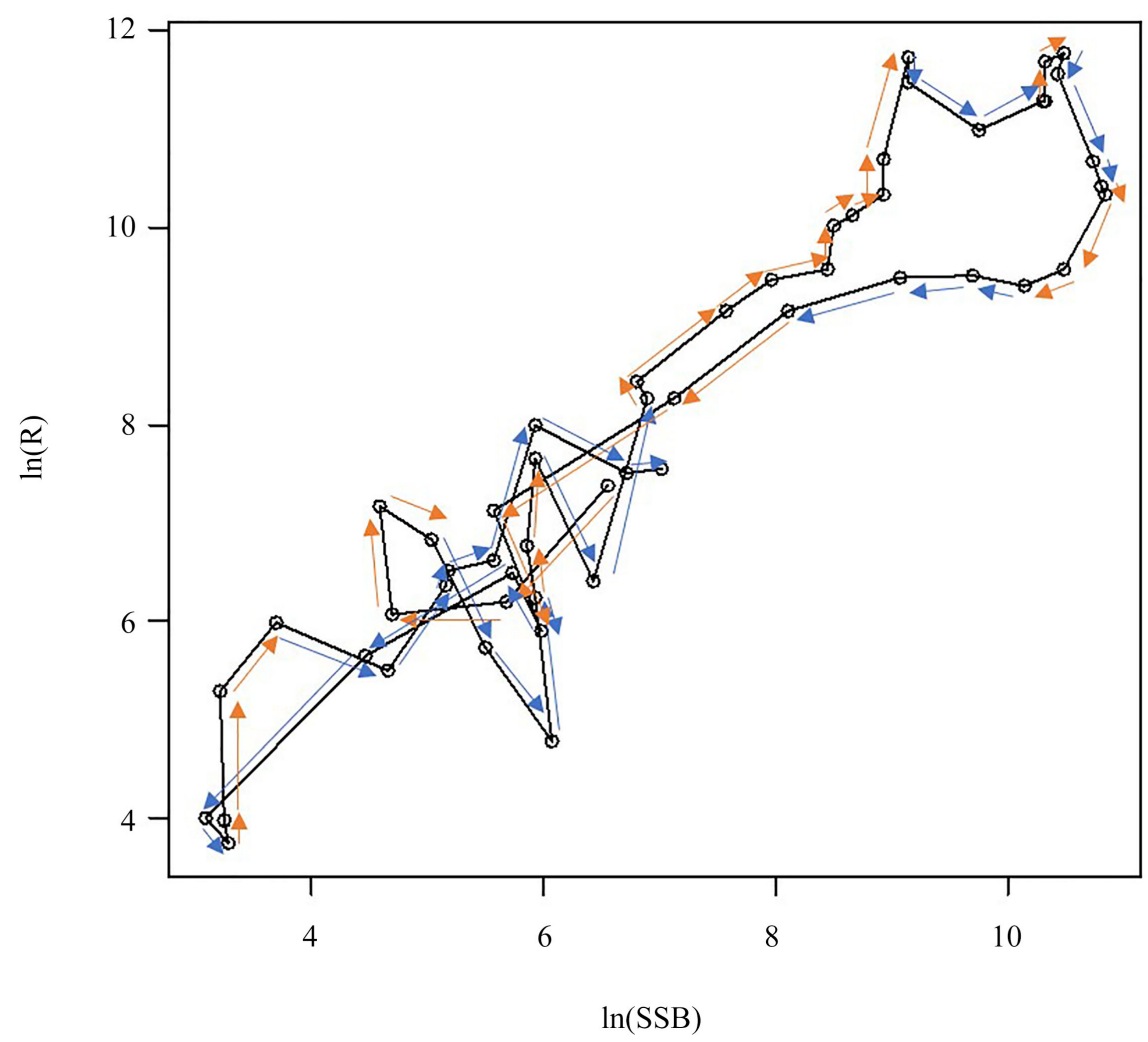

Figure A9. Tsushima warm current stock of Japanese sardine.

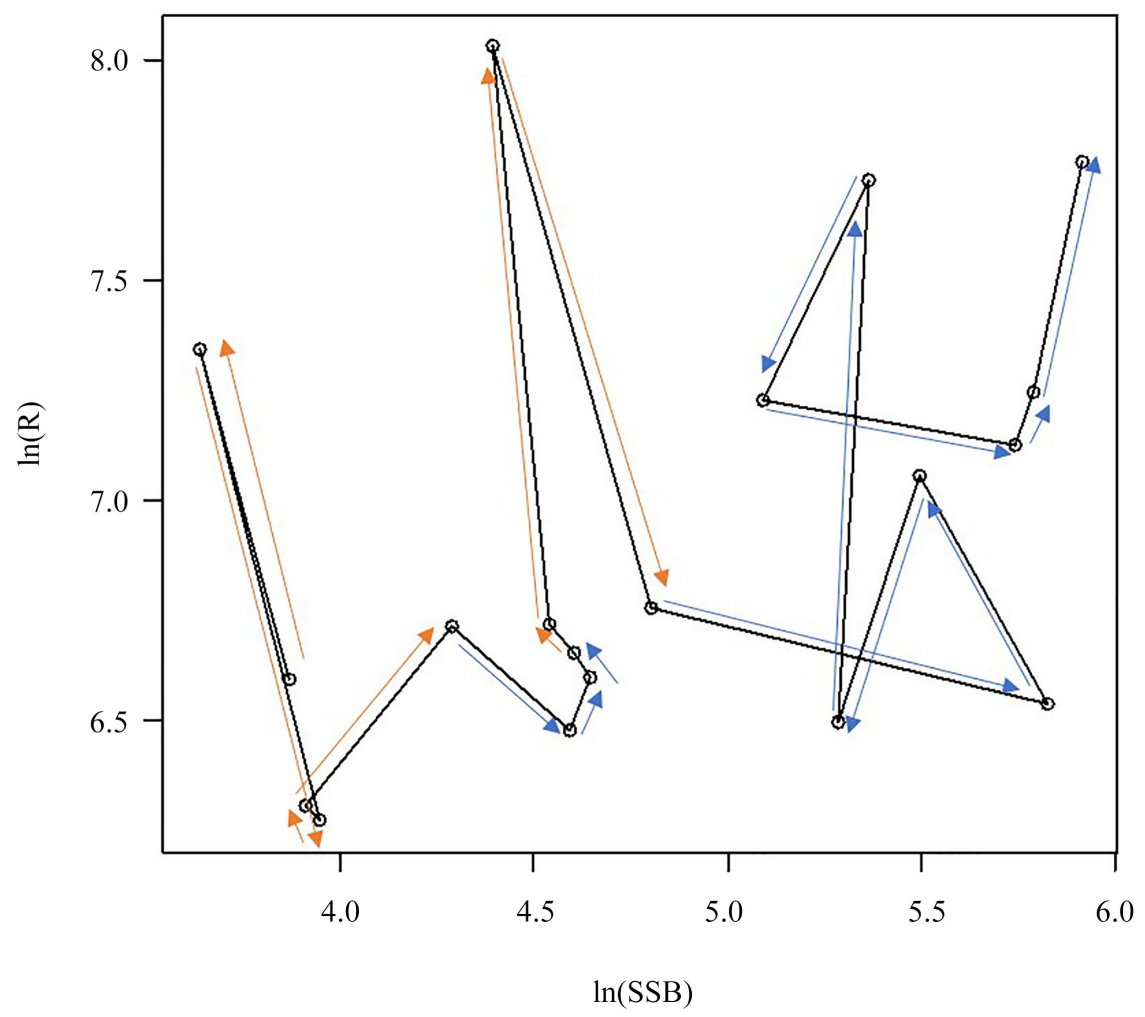

Figure A10. Pacific stock of Blue mackerel. 


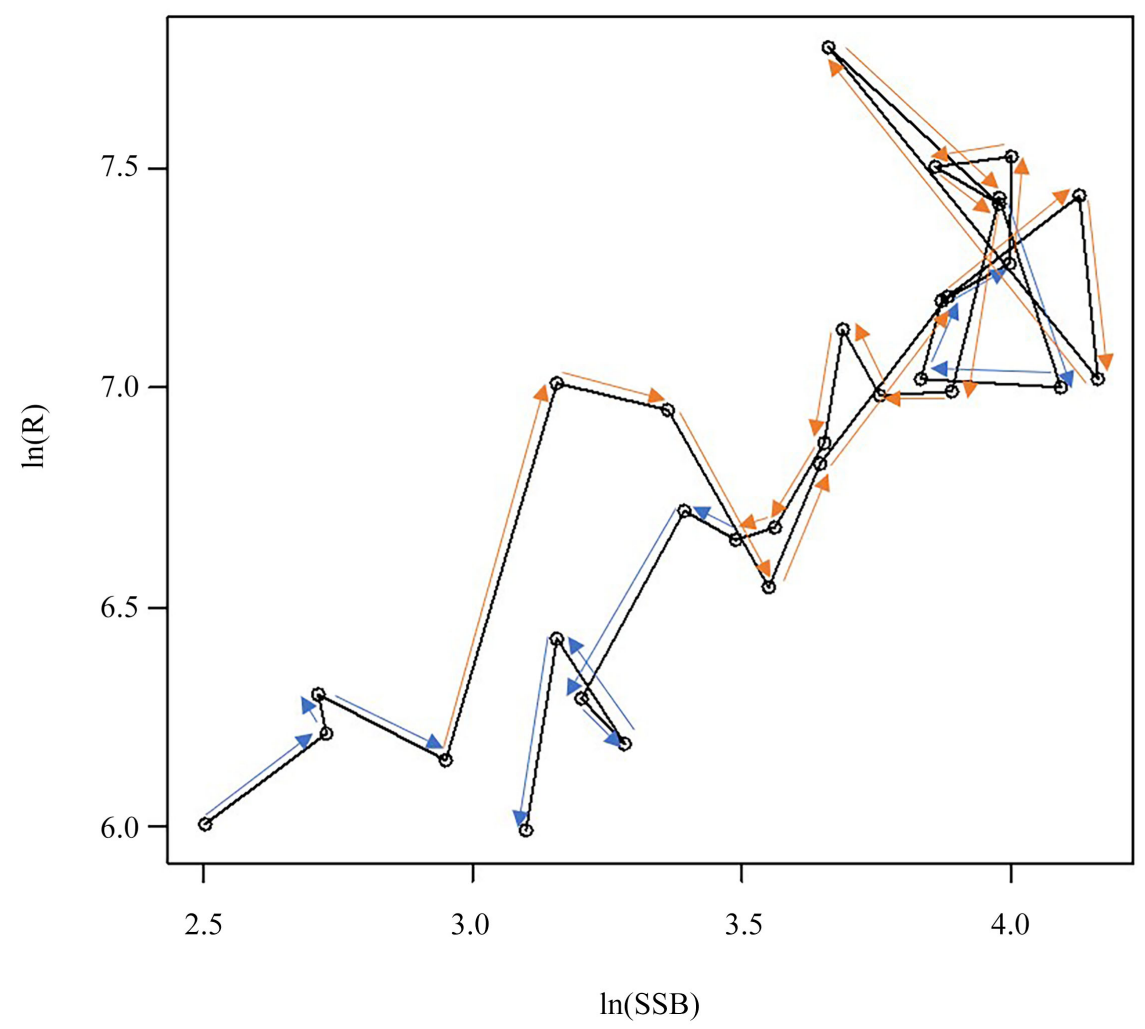

Figure A11. Pacific stock of Japanese horse mackerel.



Figure A12. Tsushima warm current stock of Japanese horse mackerel. 


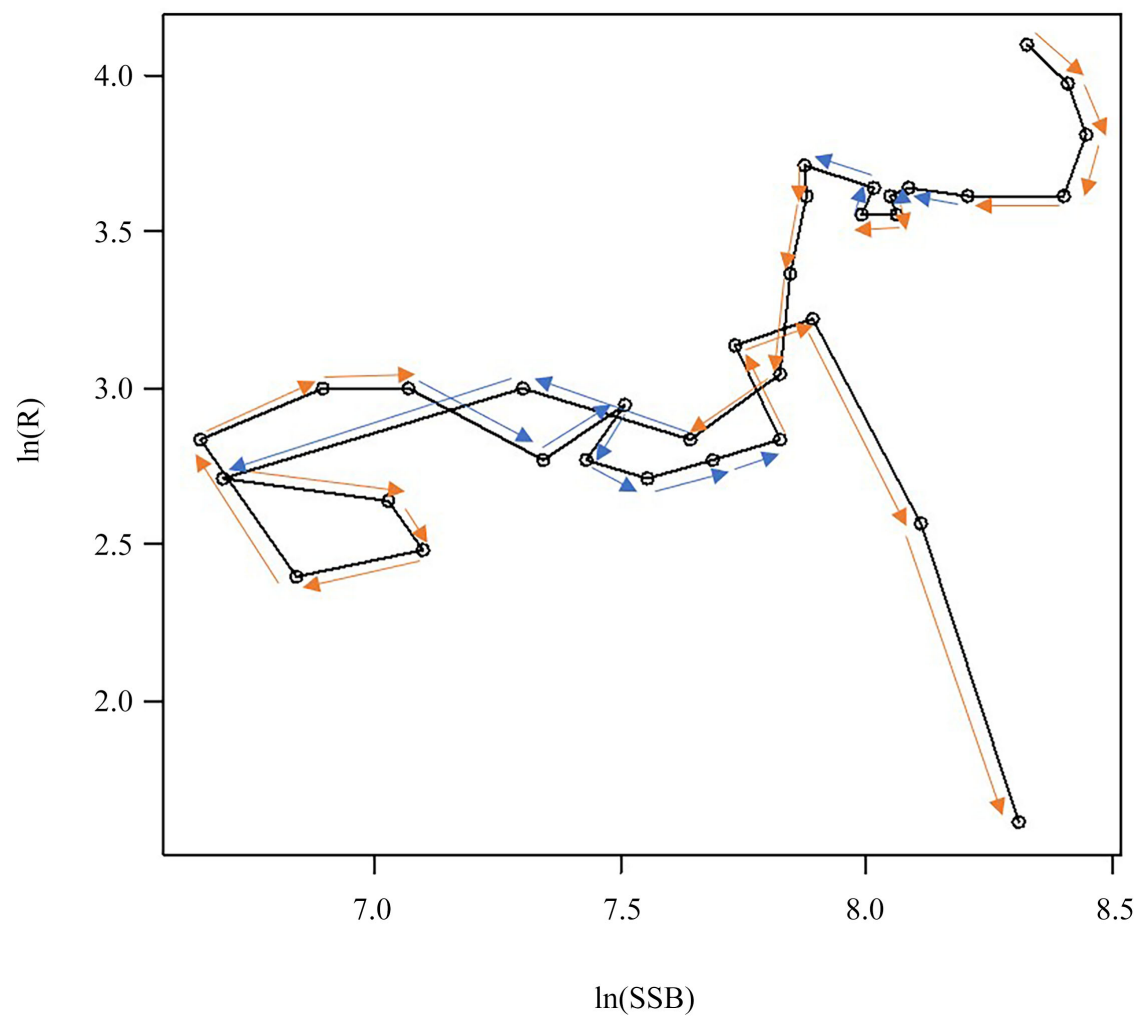

Figure A13. Japan Sea and East China Sea stock of Yellow seabream.



Figure A14. Nothern Pacific of Pacific saury. 


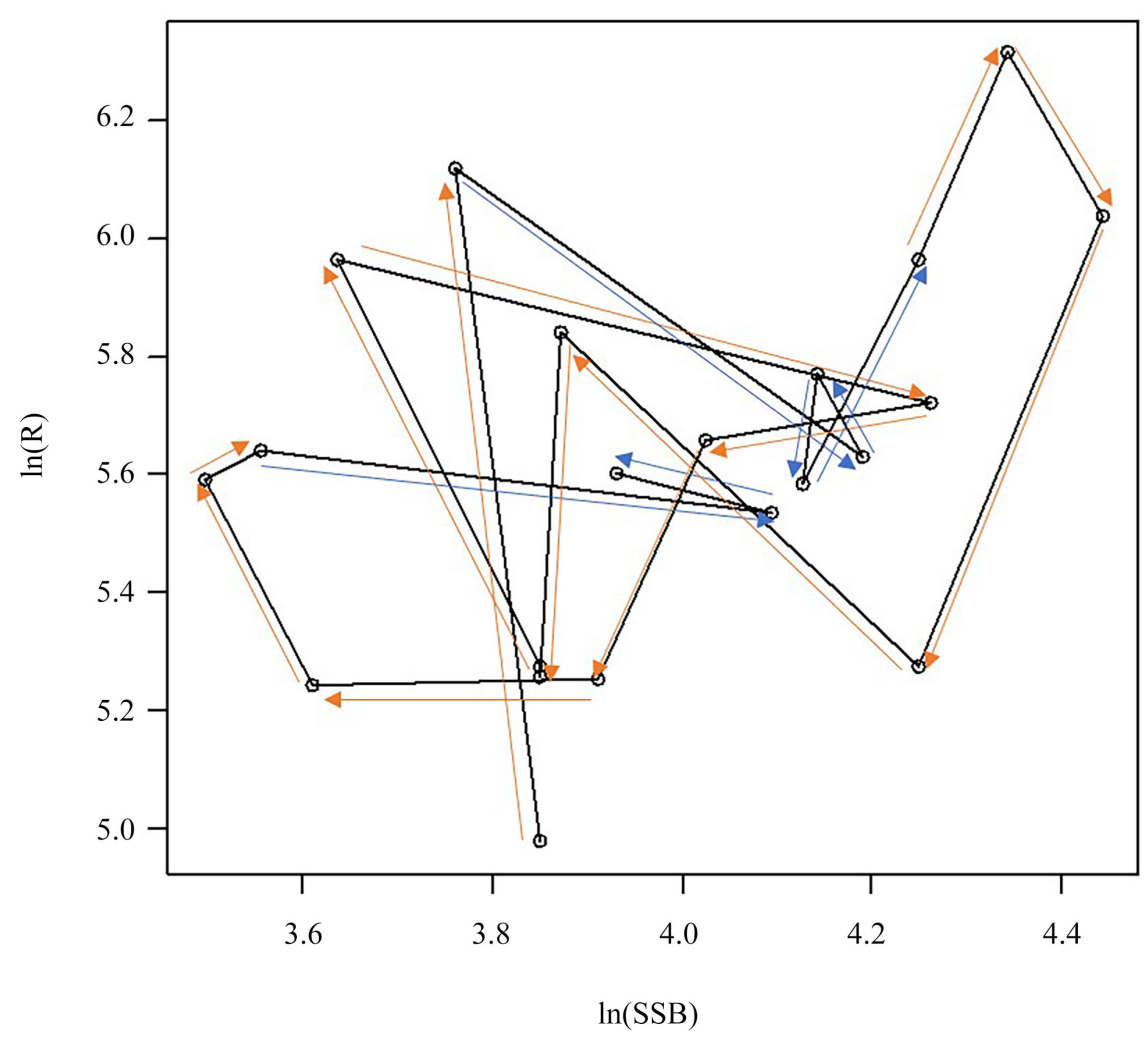

Figure A15. East China Sea stock of Blue mackerel.

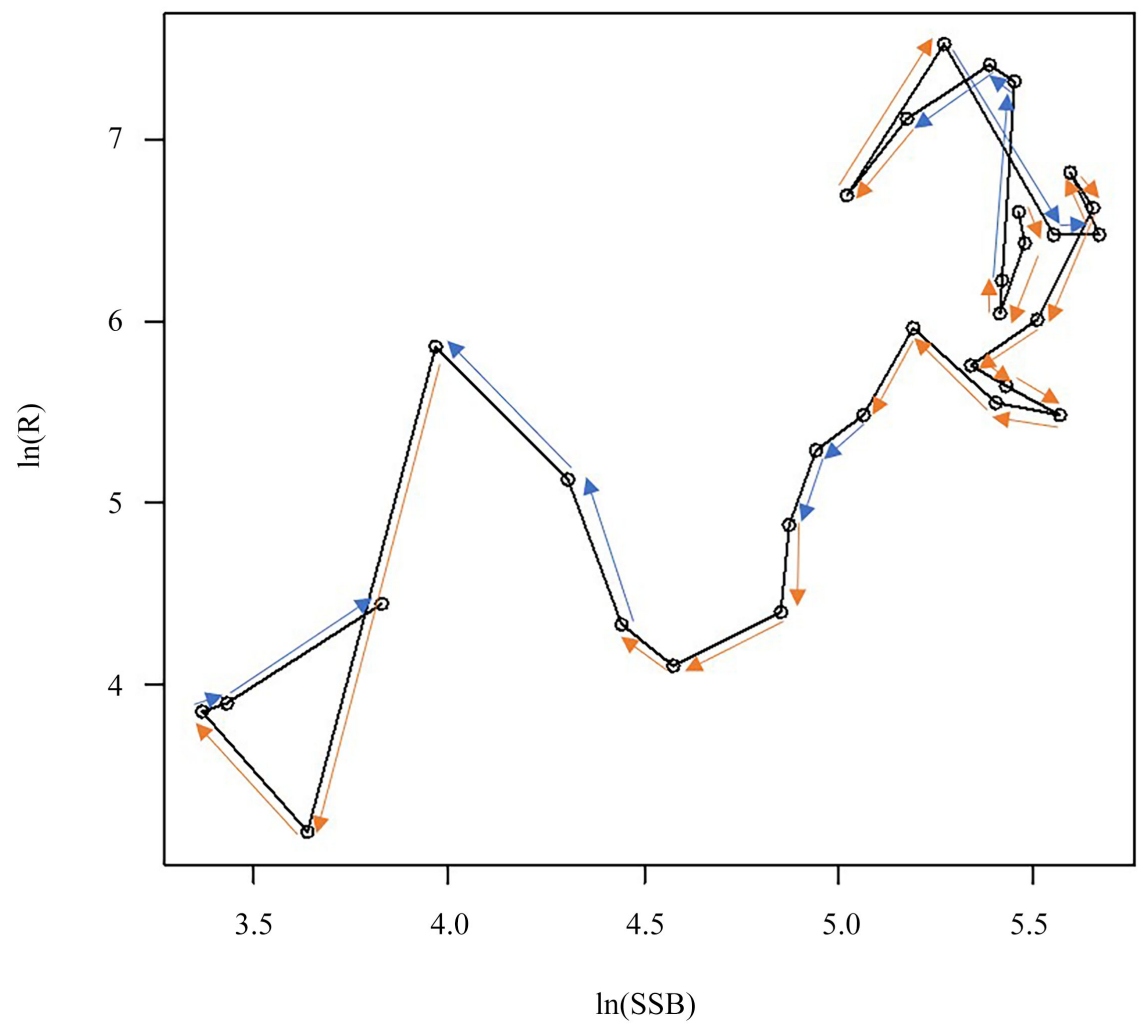

Figure A16. Northern Japan Sea stock of Alaska Pollock. 


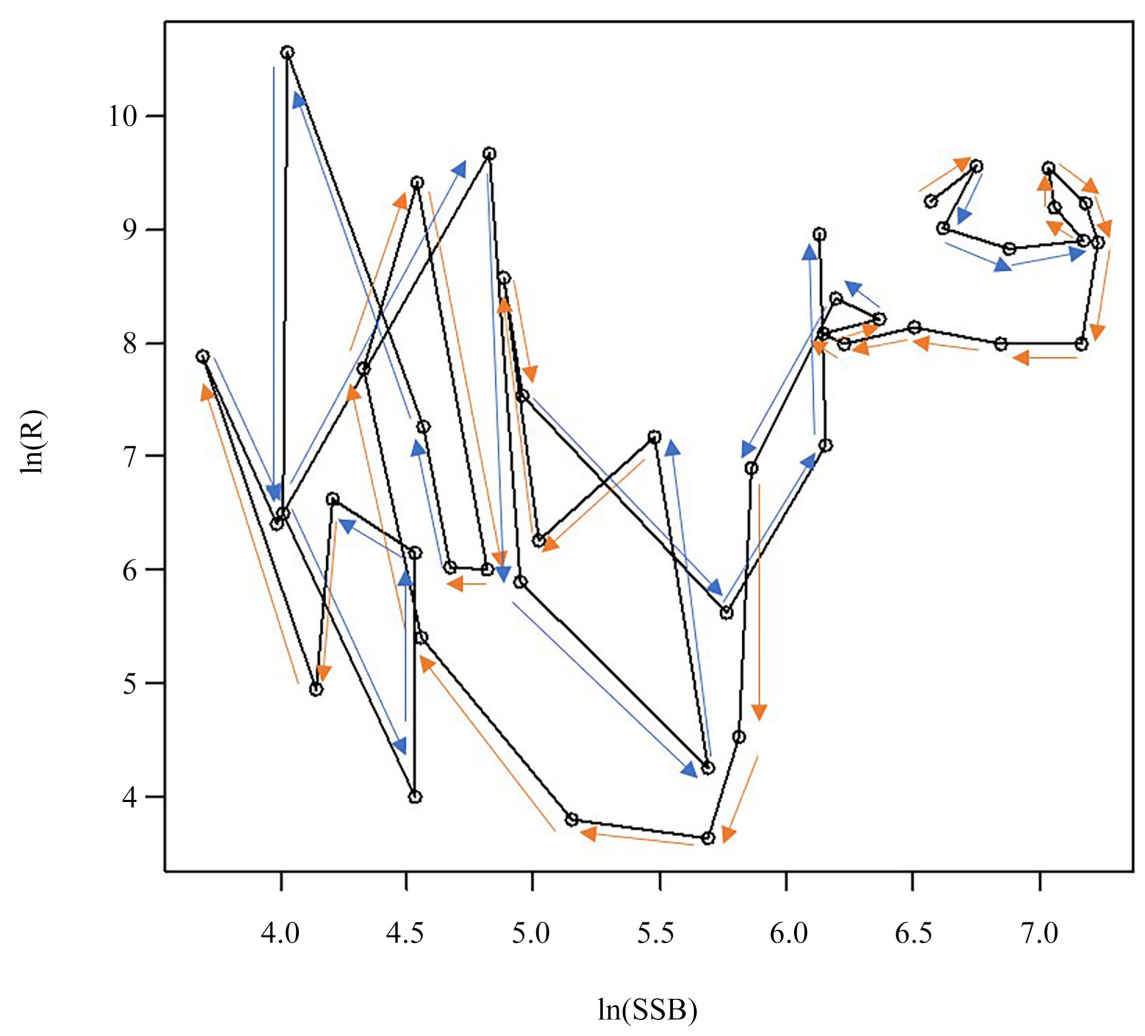

Figure A17. Pacific stock of Chub mackerel.

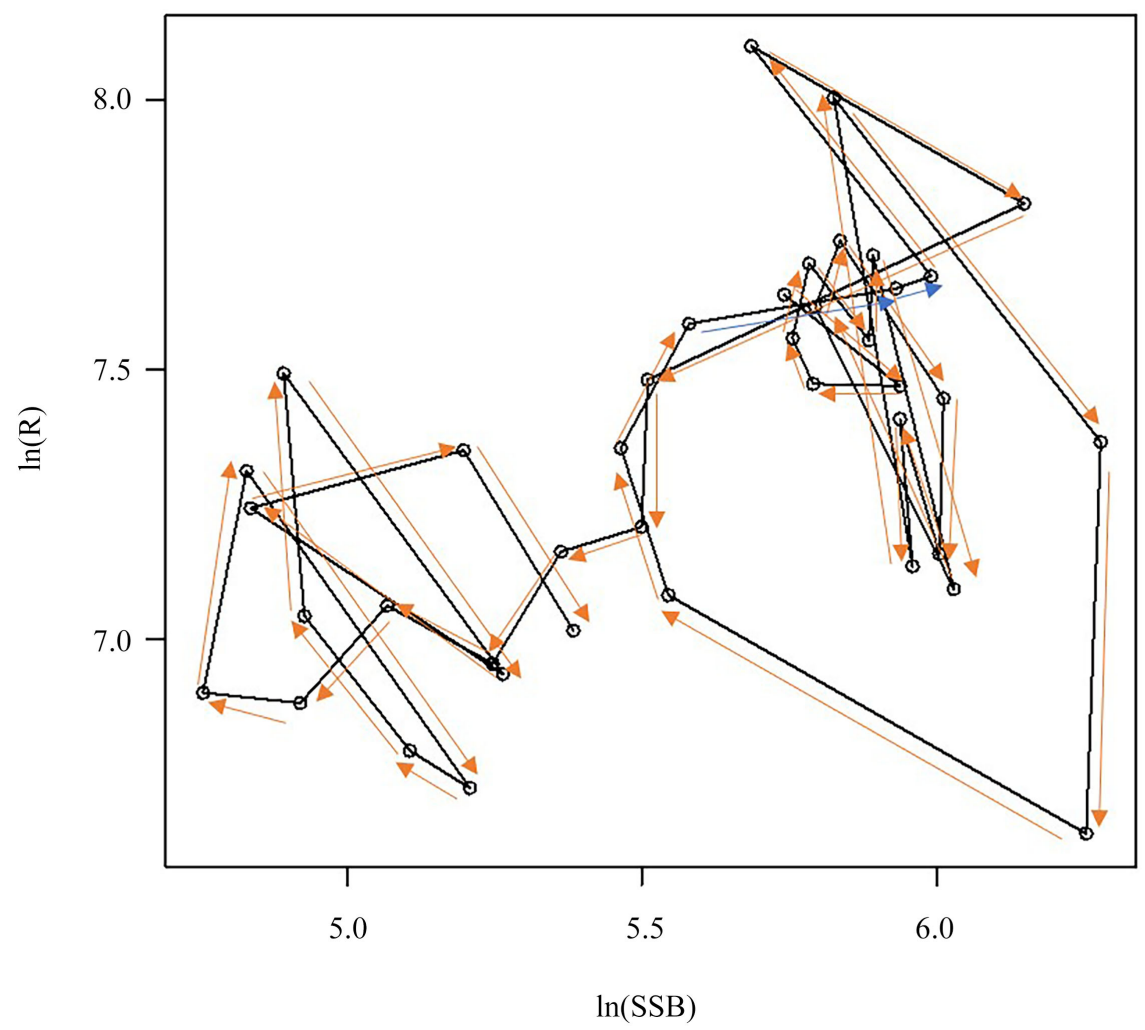

Figure A18. East China Sea stock of Chub mackerel. 


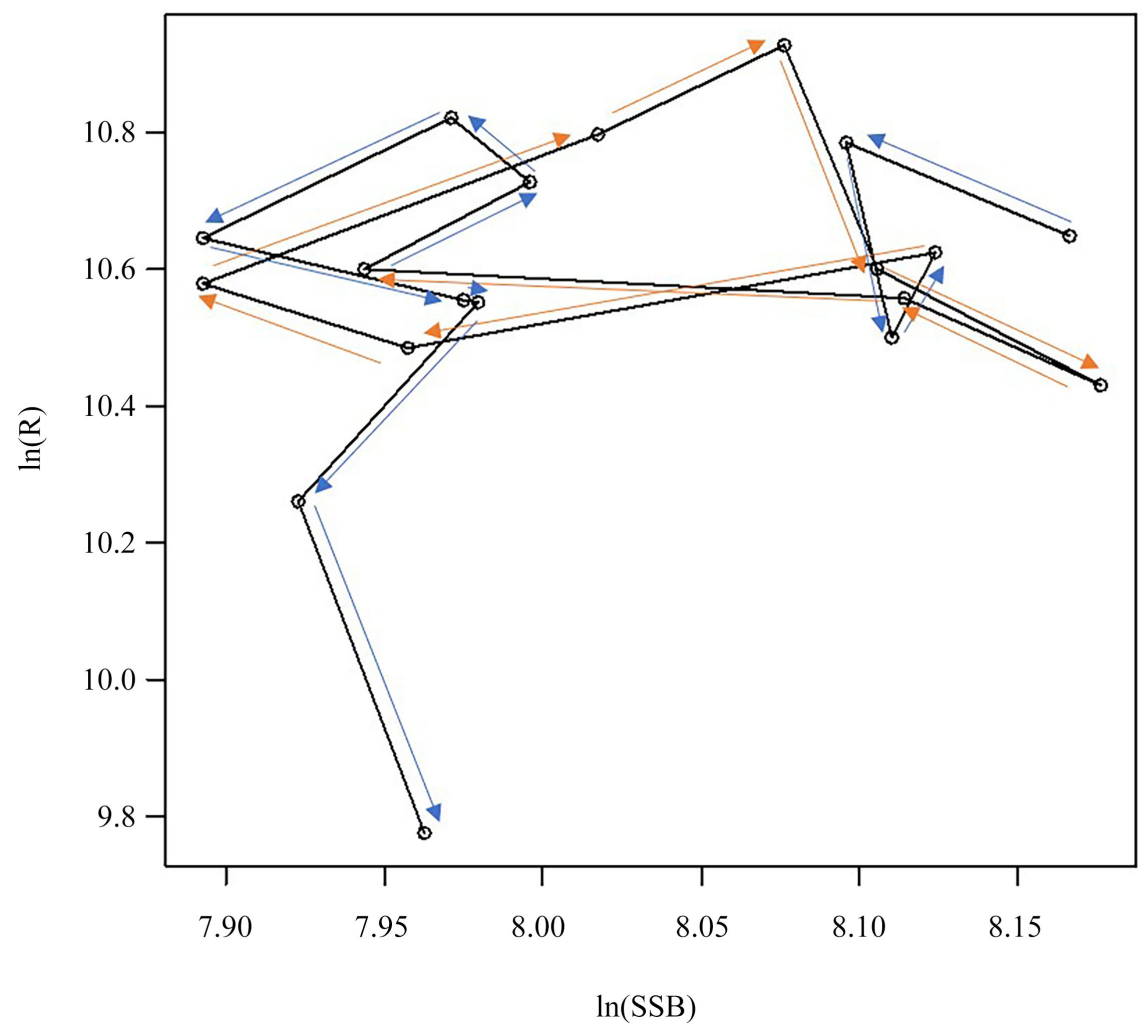

Figure A19. Japan sea stock of Round-nose flounder.

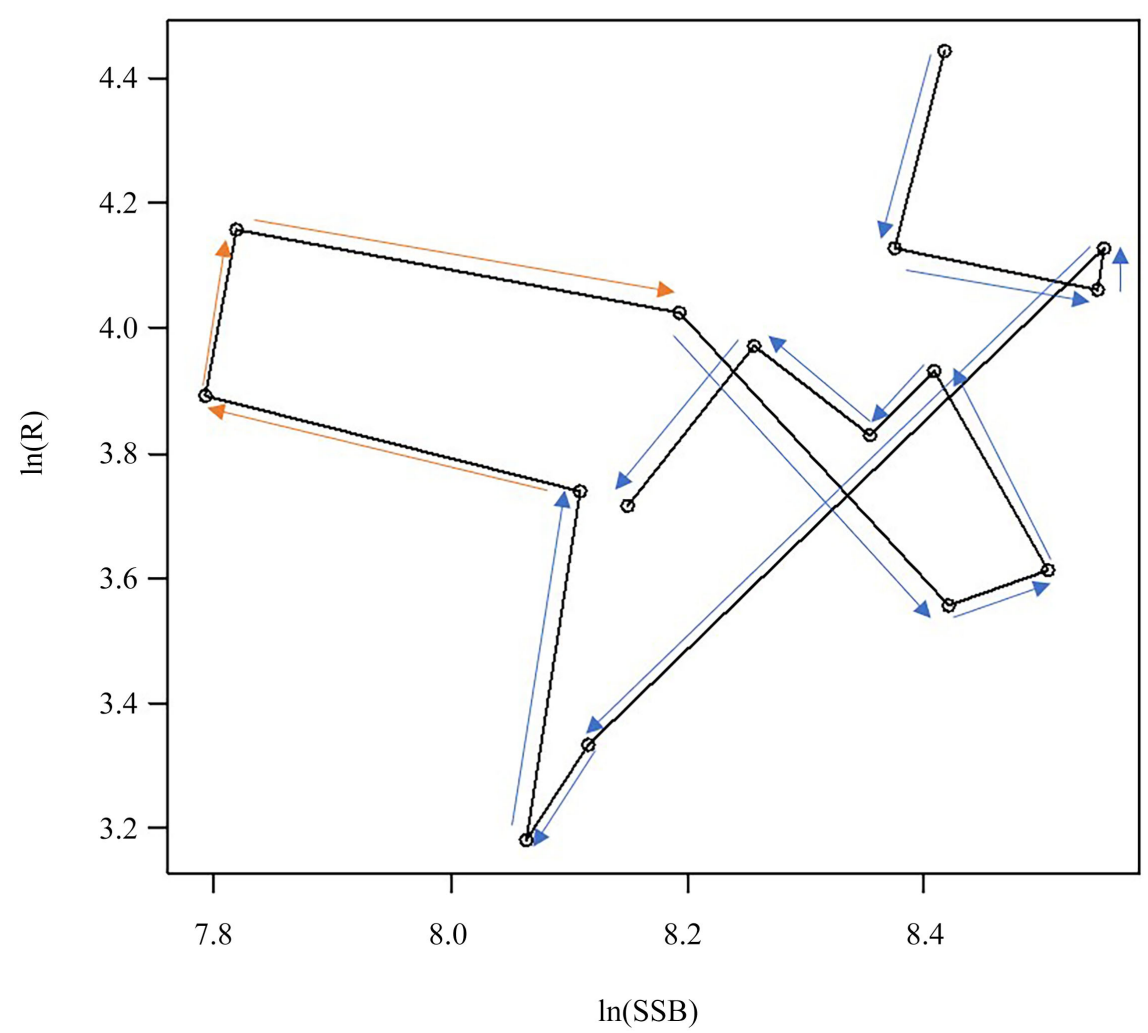

Figure A20. Japan sea stock of Pointhead flounder. 


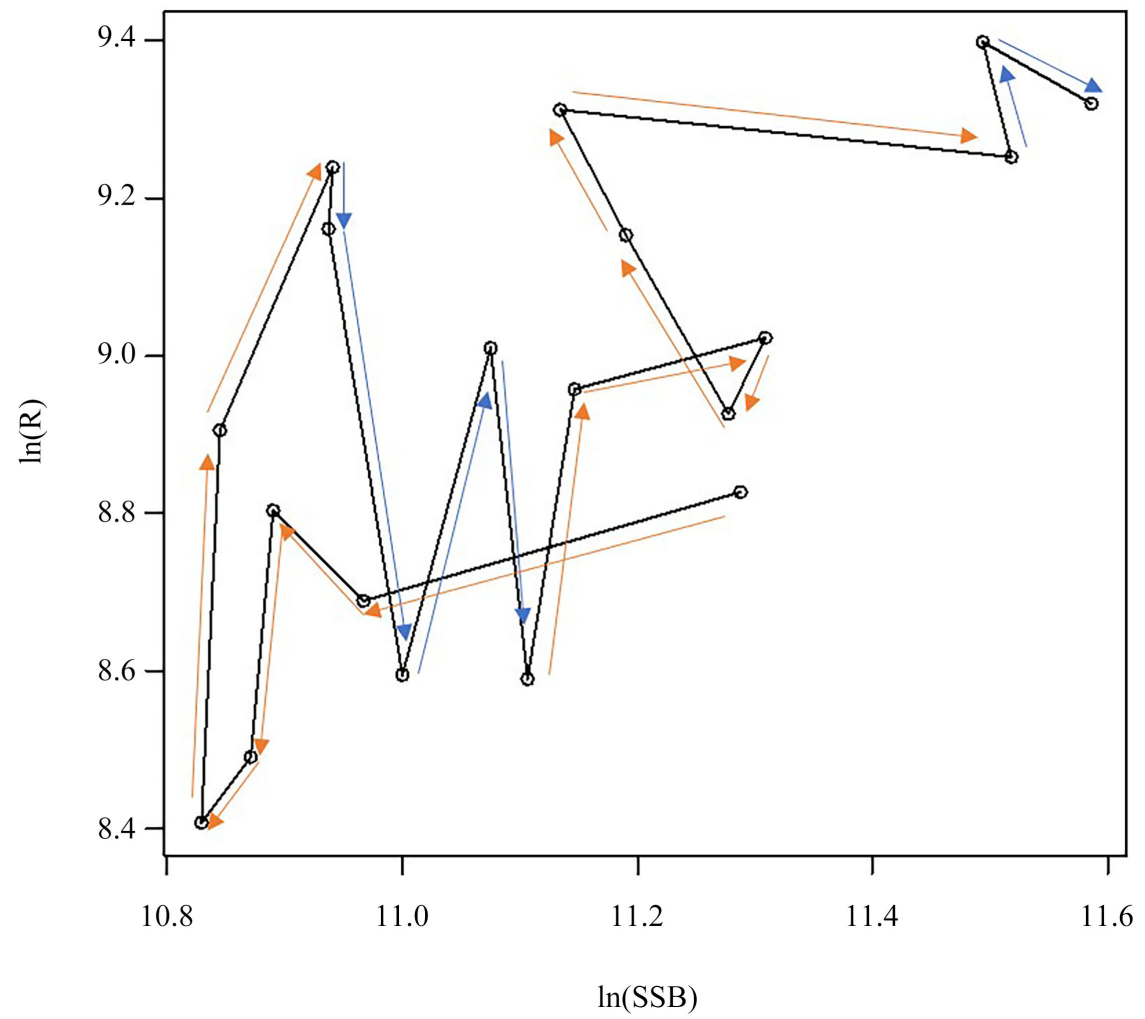

Figure A21. Japanese amberjack.

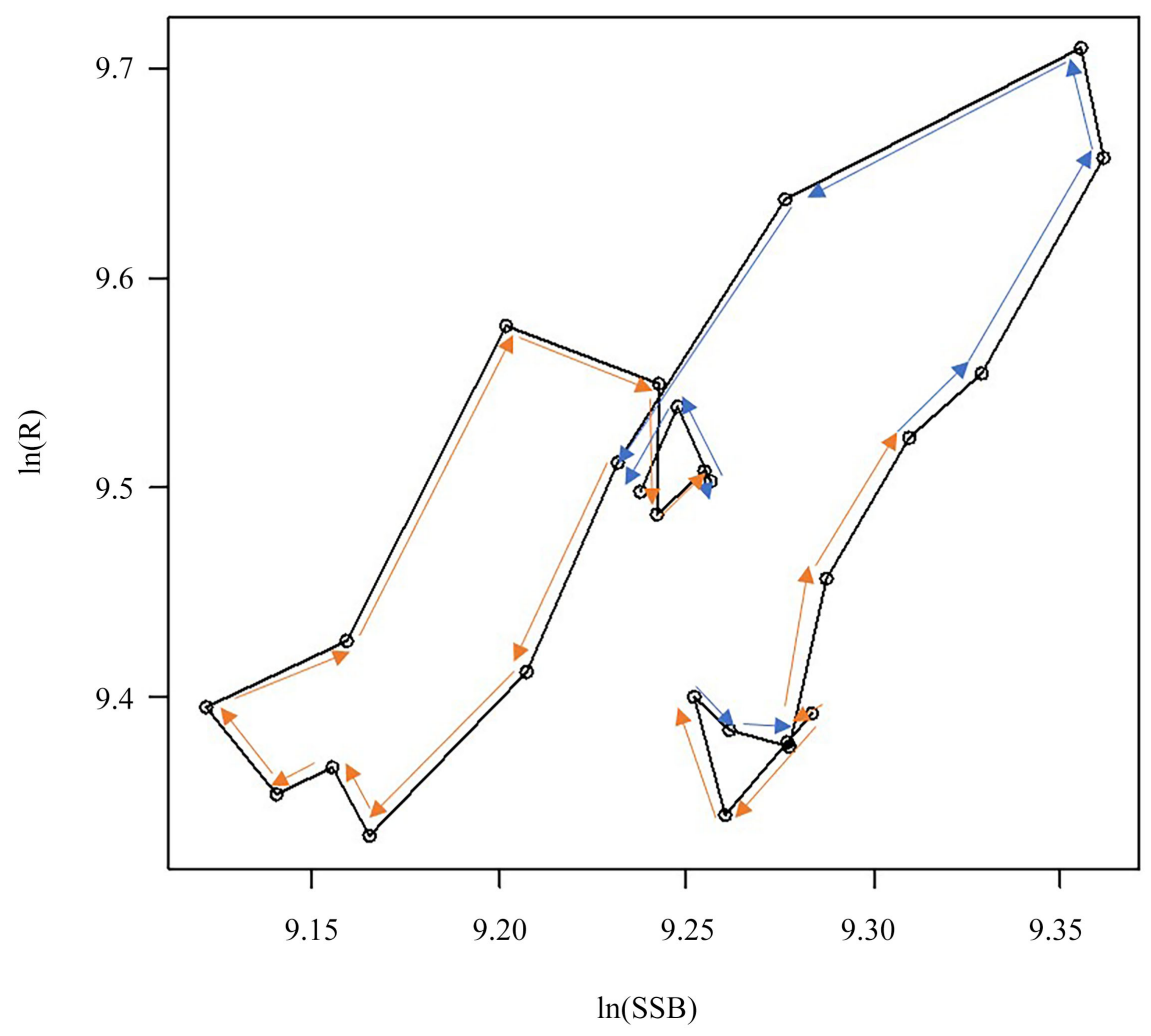

Figure A22. Western Japan Sea and East China Sea stock of Red sea bream. 


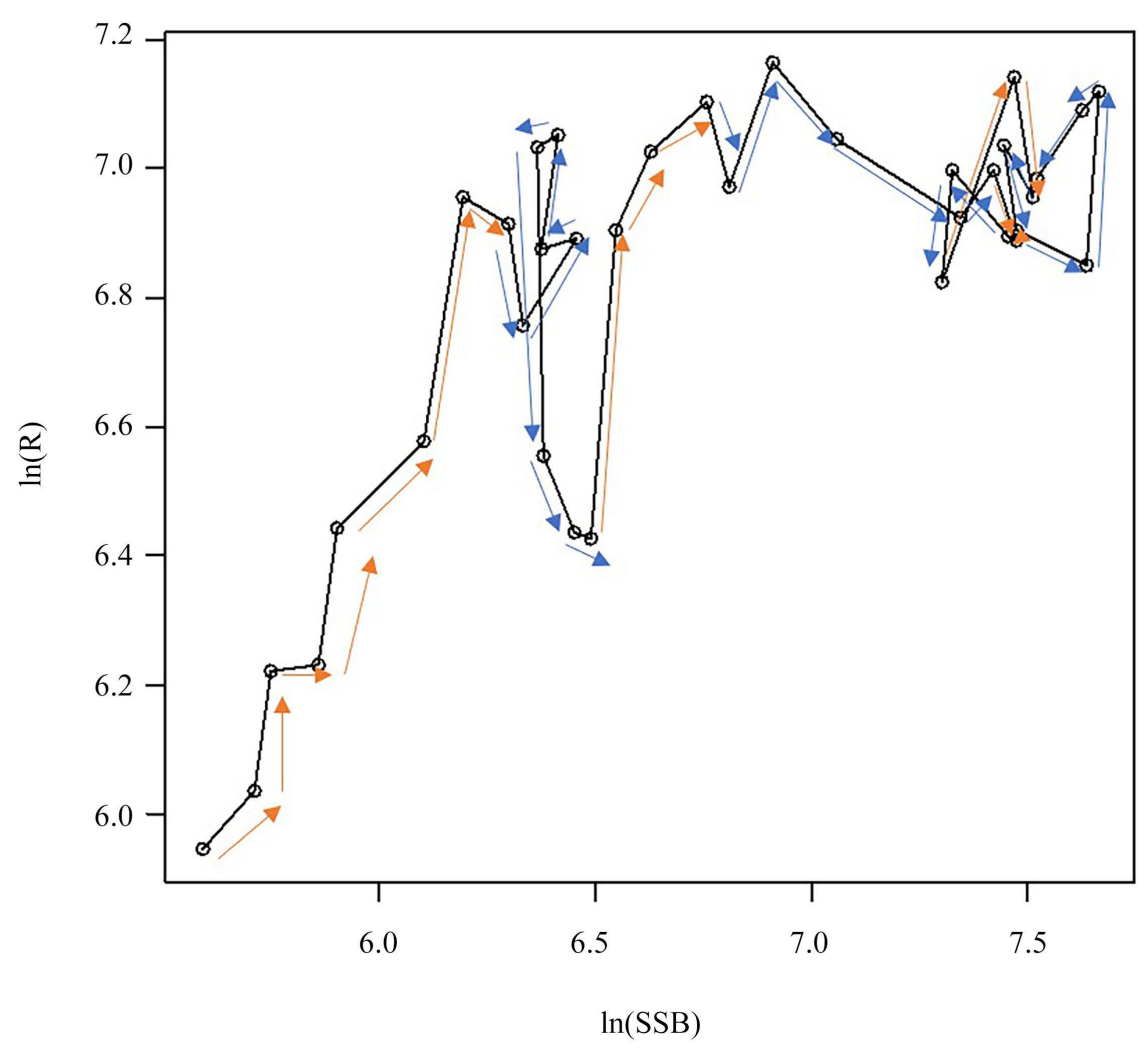

Figure A23. Eastern Seto Inland Sea stock of Red sea bream.

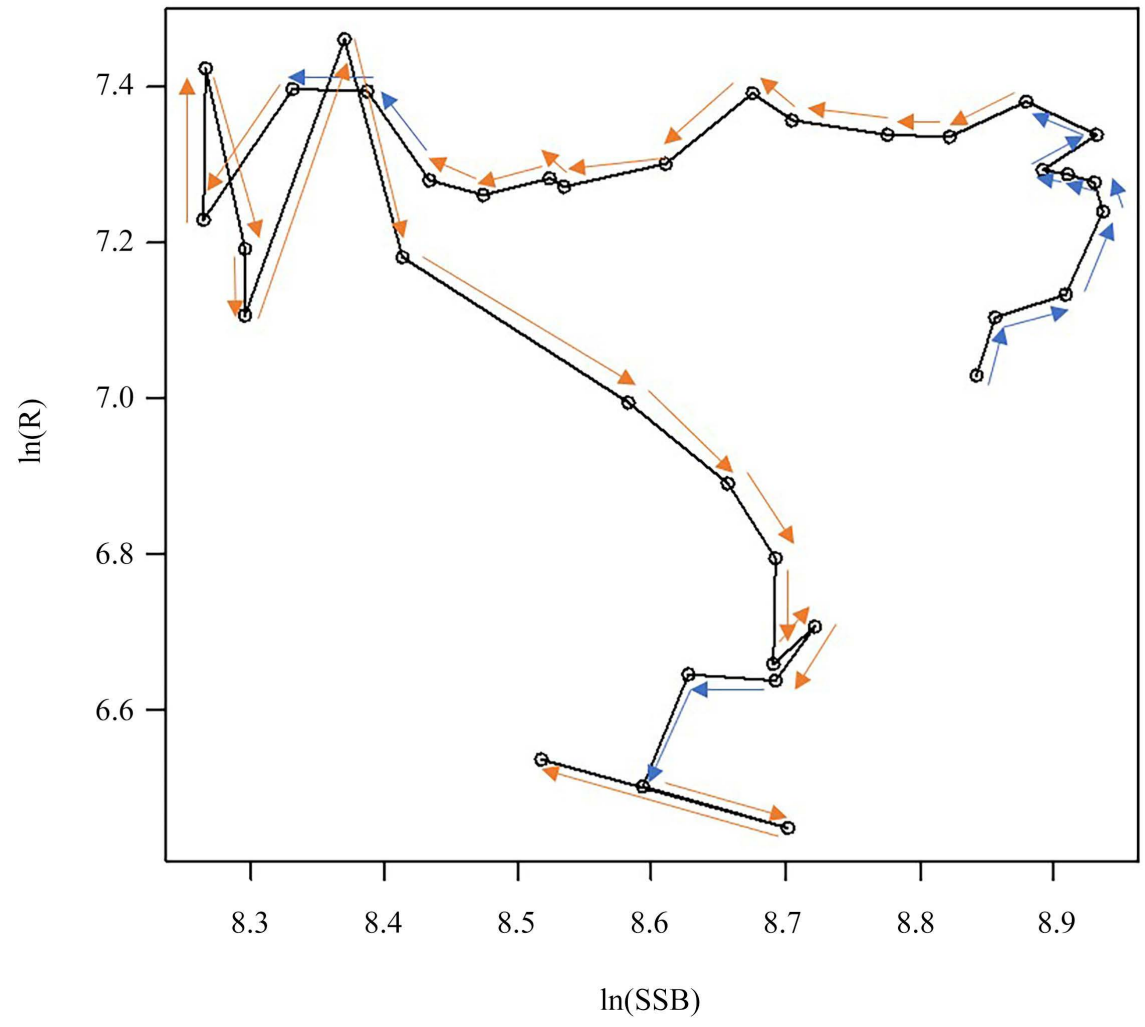

Figure A24. Central and western Seto Inland Sea stock of Red sea bream. 


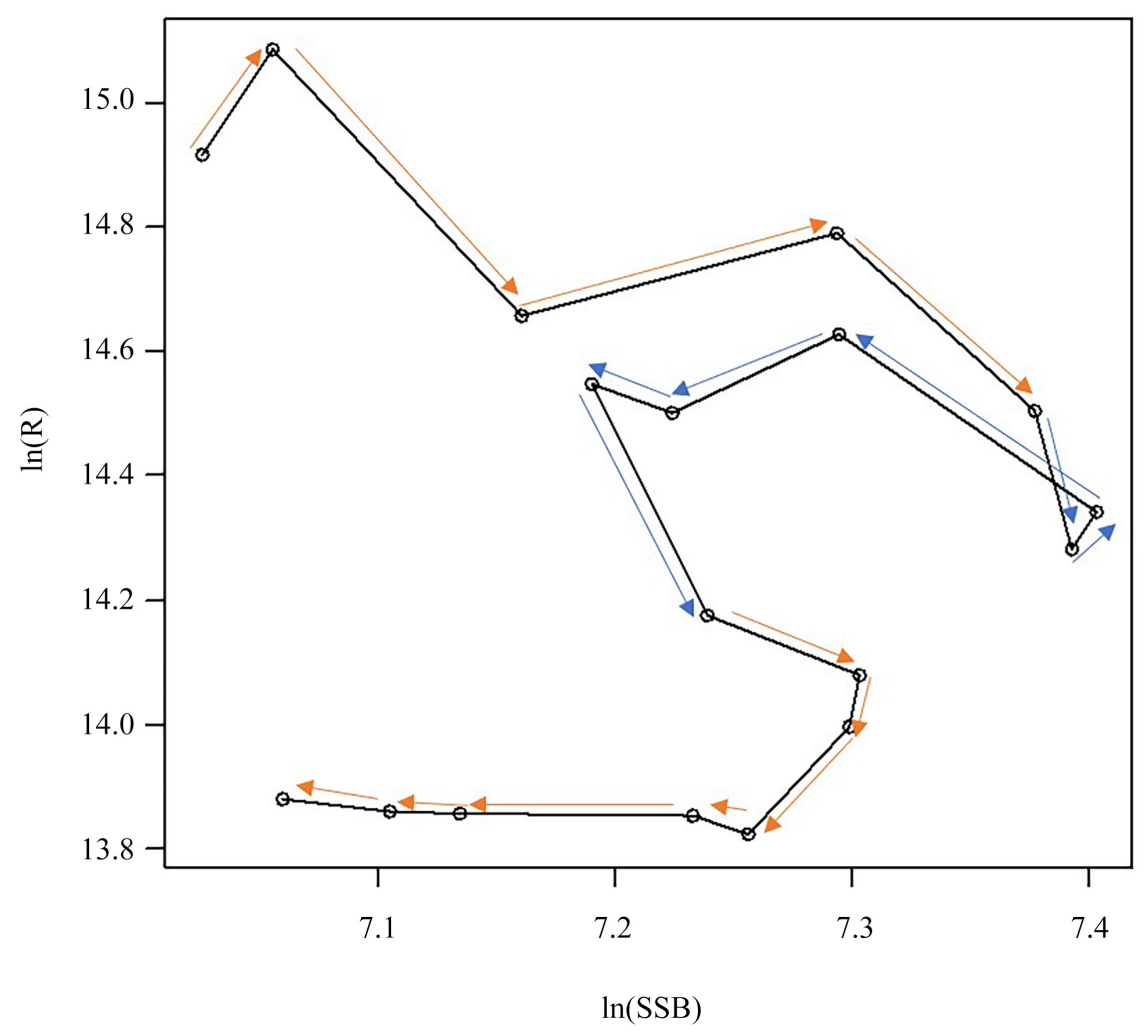

Figure A25. Seto Inland Sea stock of Bastard halibut.

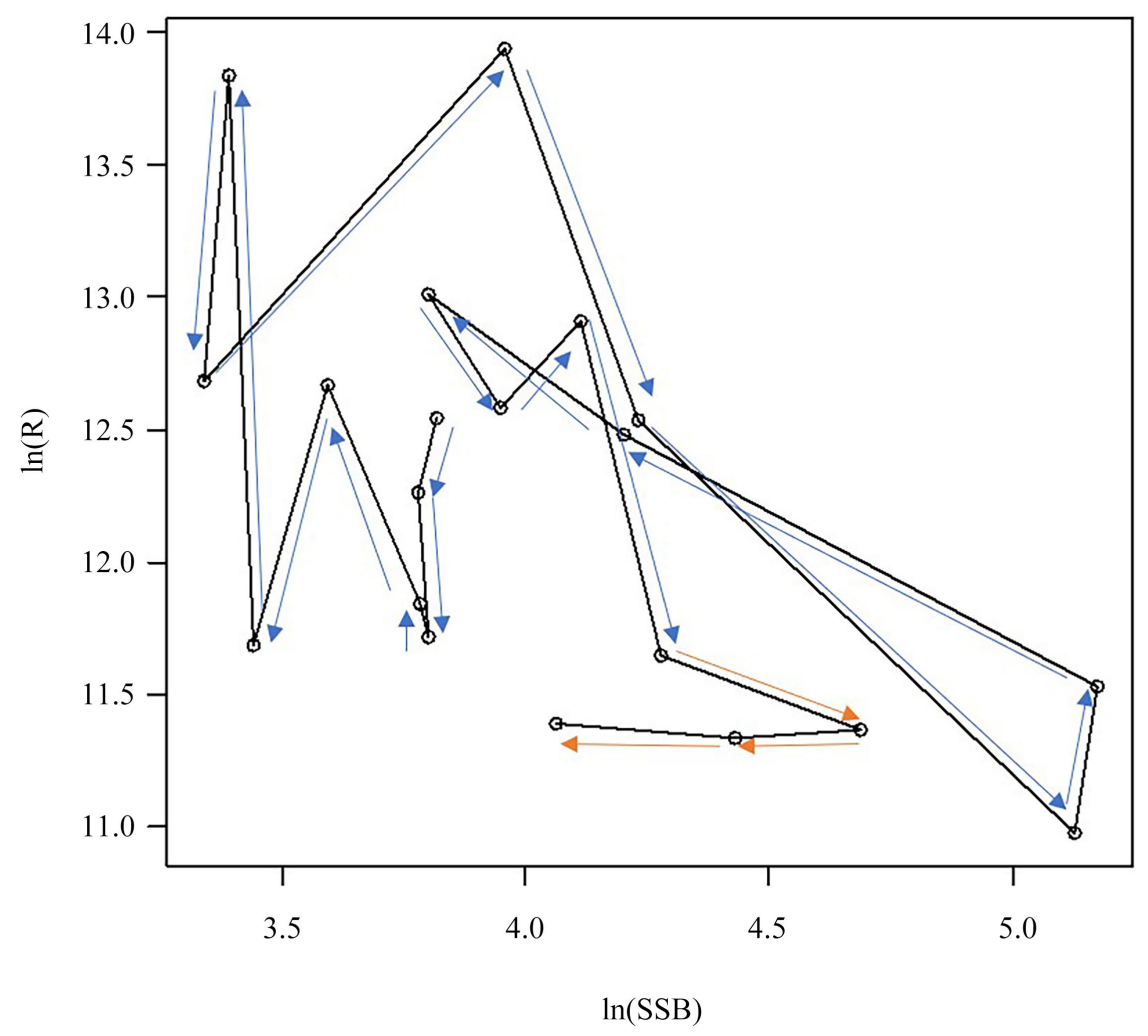

Figure A26. Ise and Mikawa Bays stock of Japanese pufferfish. 


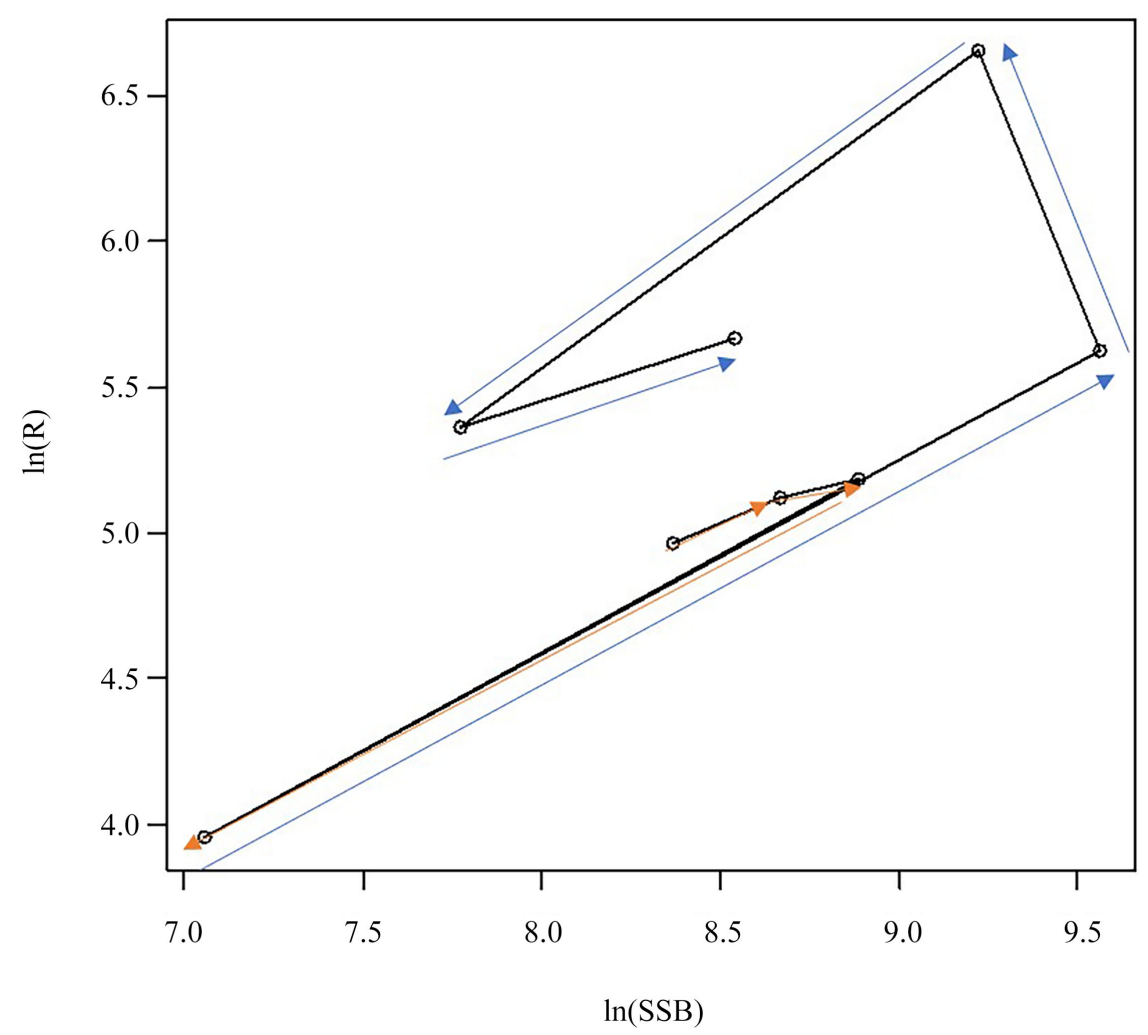

Figure A27. Western Japan sea of Sandfish.

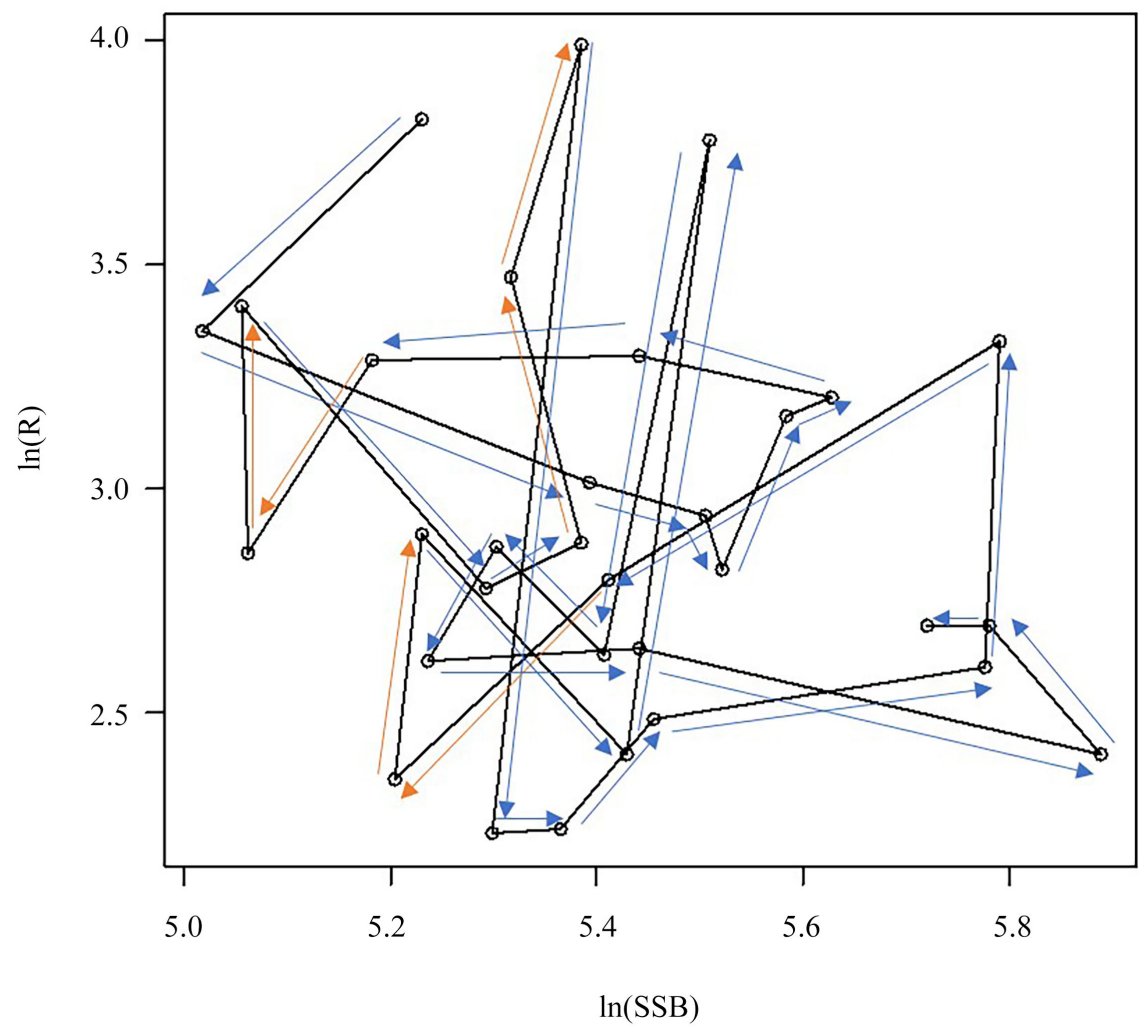

Figure A28. Pacific stock of Alaska Pollock. 


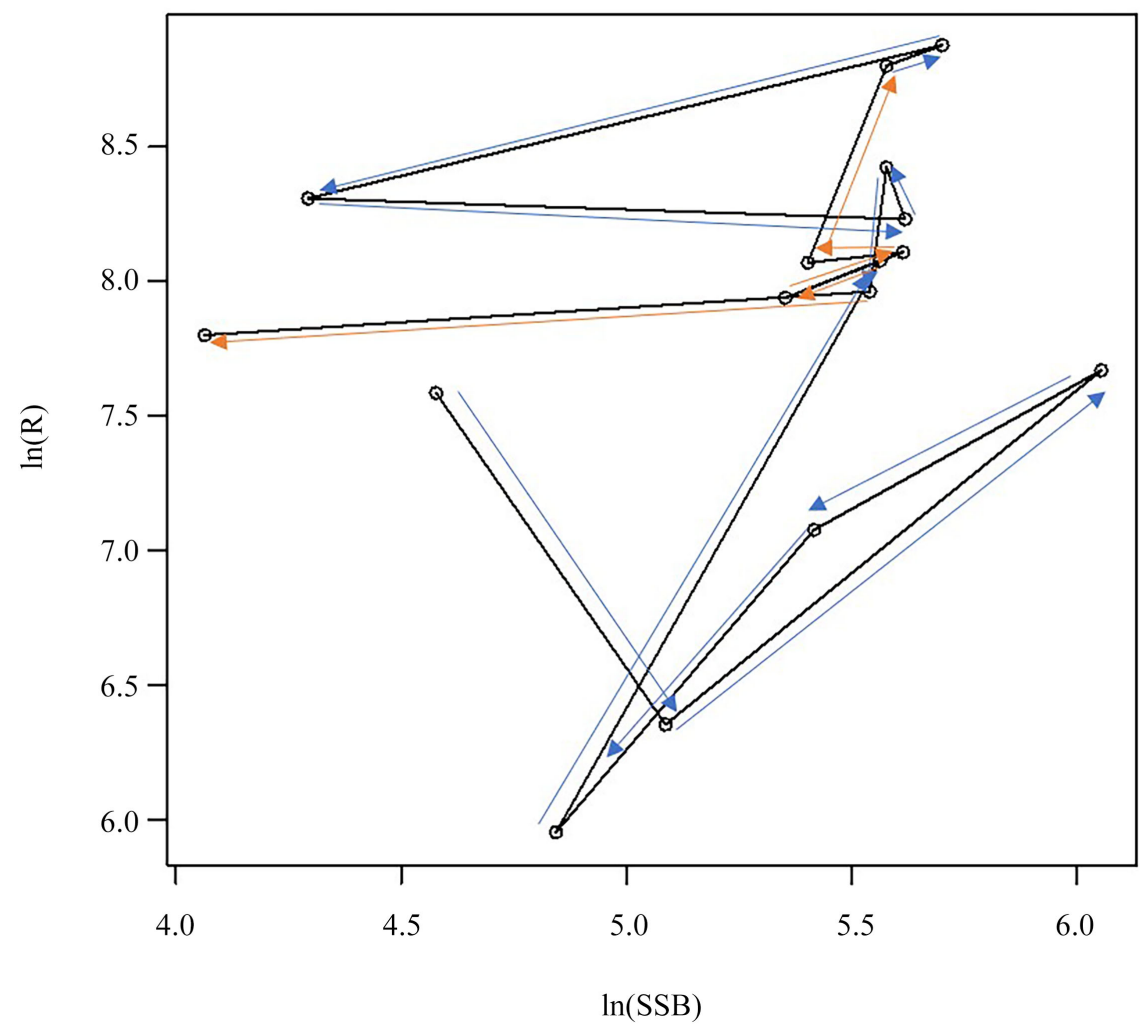

Figure A29. Northern Pacific stock of Snow crab.

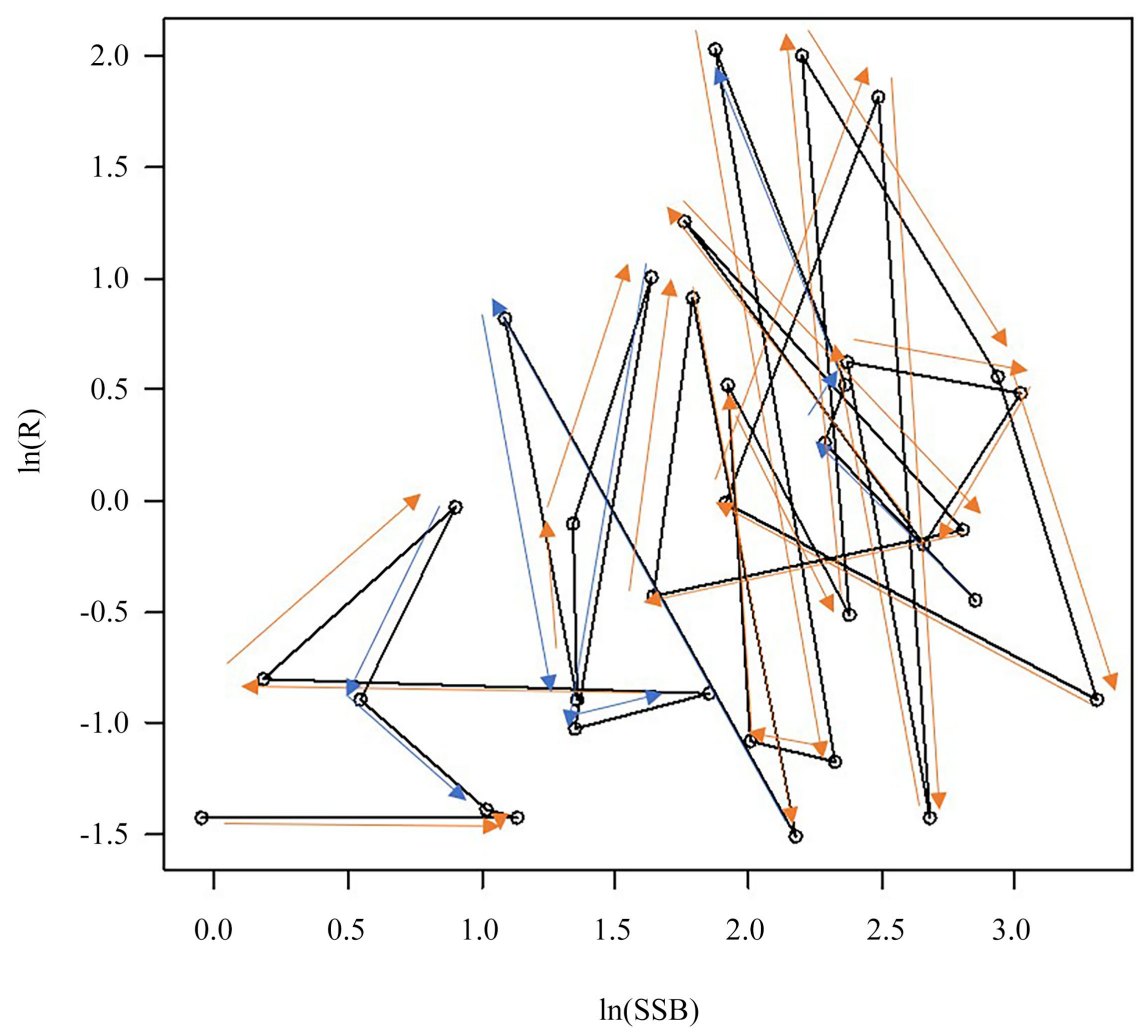

Figure A30. Cod-NAFO5Z. 


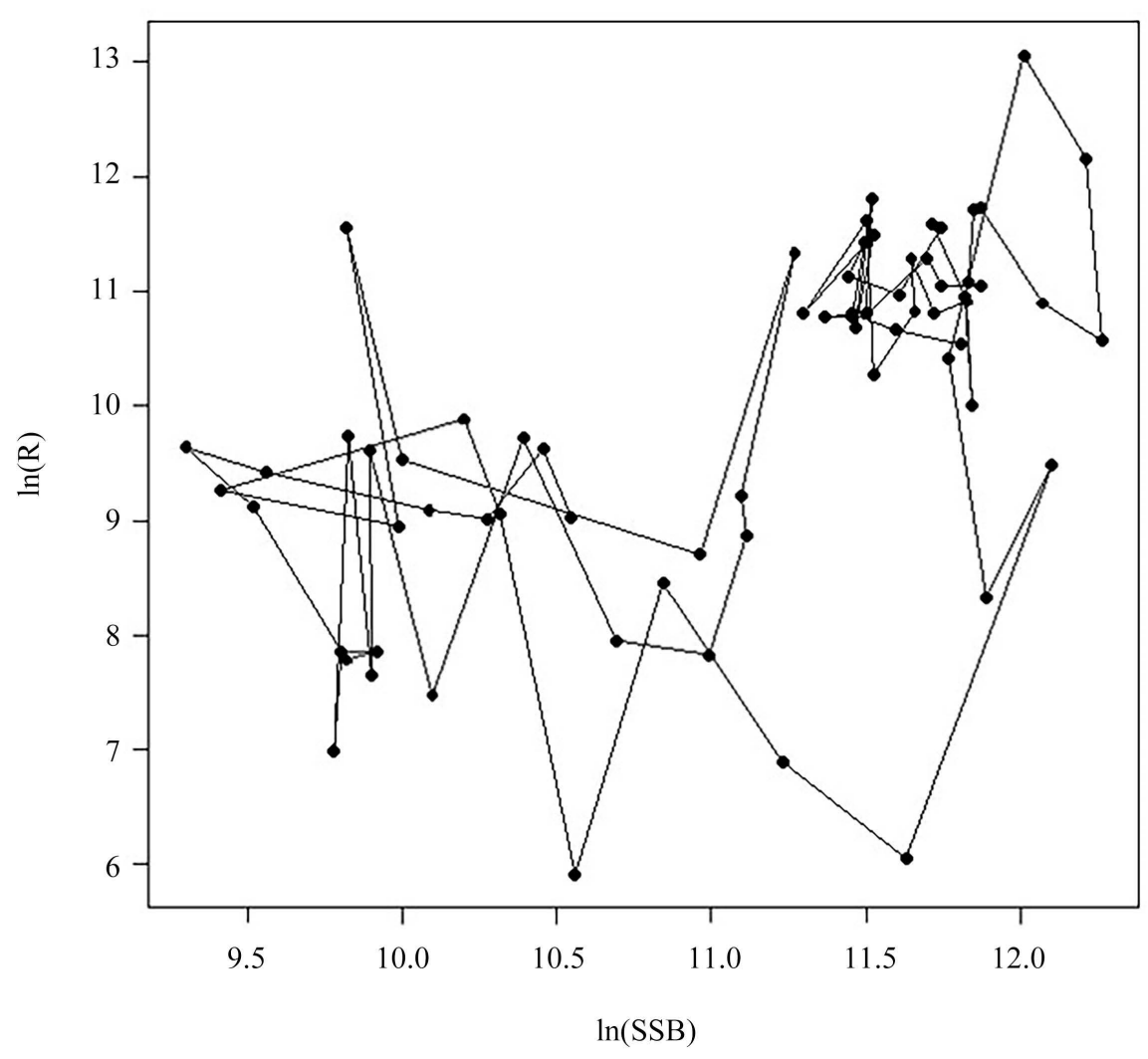

Figure A31. Haddock-NAFO5Z.

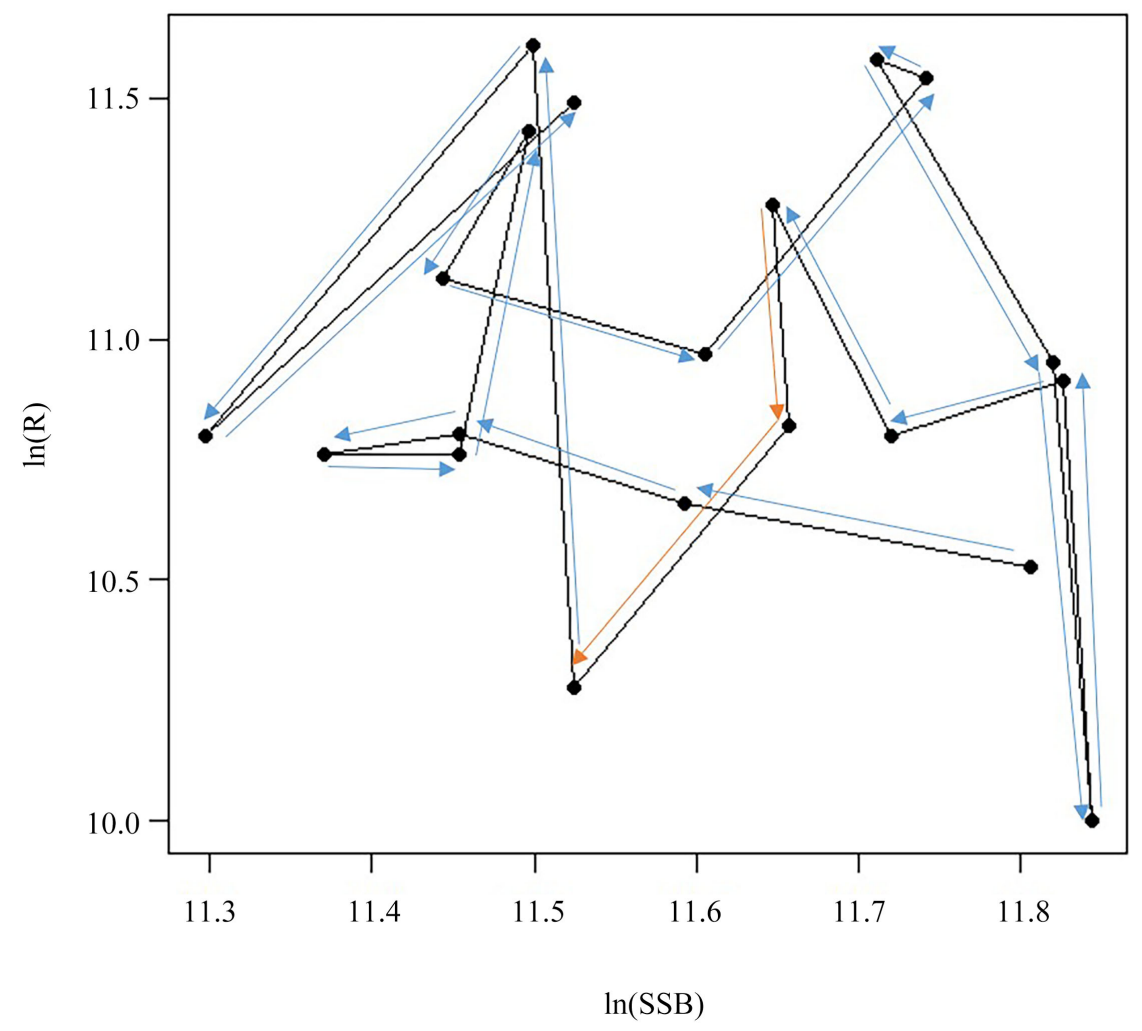

Figure A31(a). Haddock-NAFO5Z(year 1931-1951). 


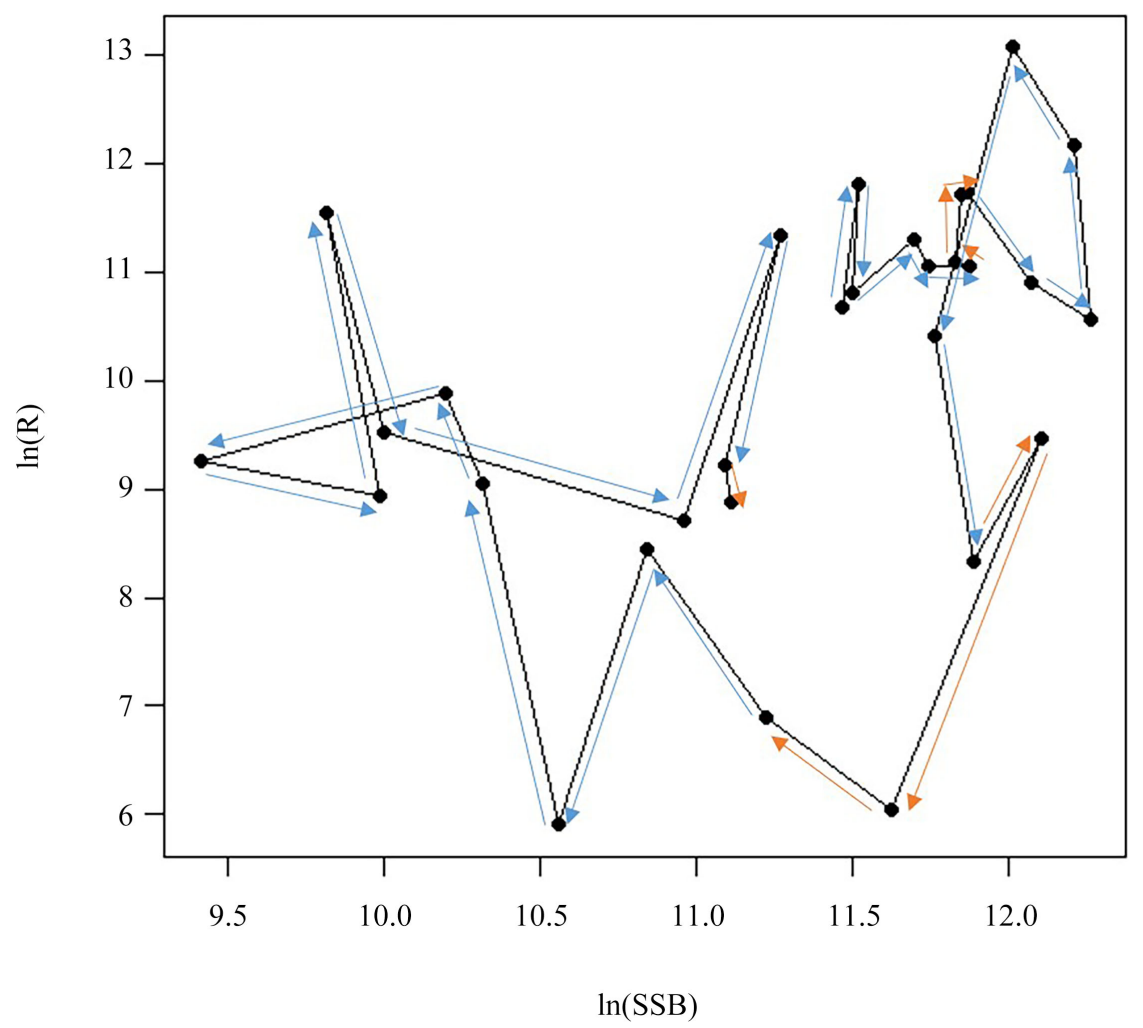

Figure A31(b). Haddock-NAFO5Z(year 1951-1981).

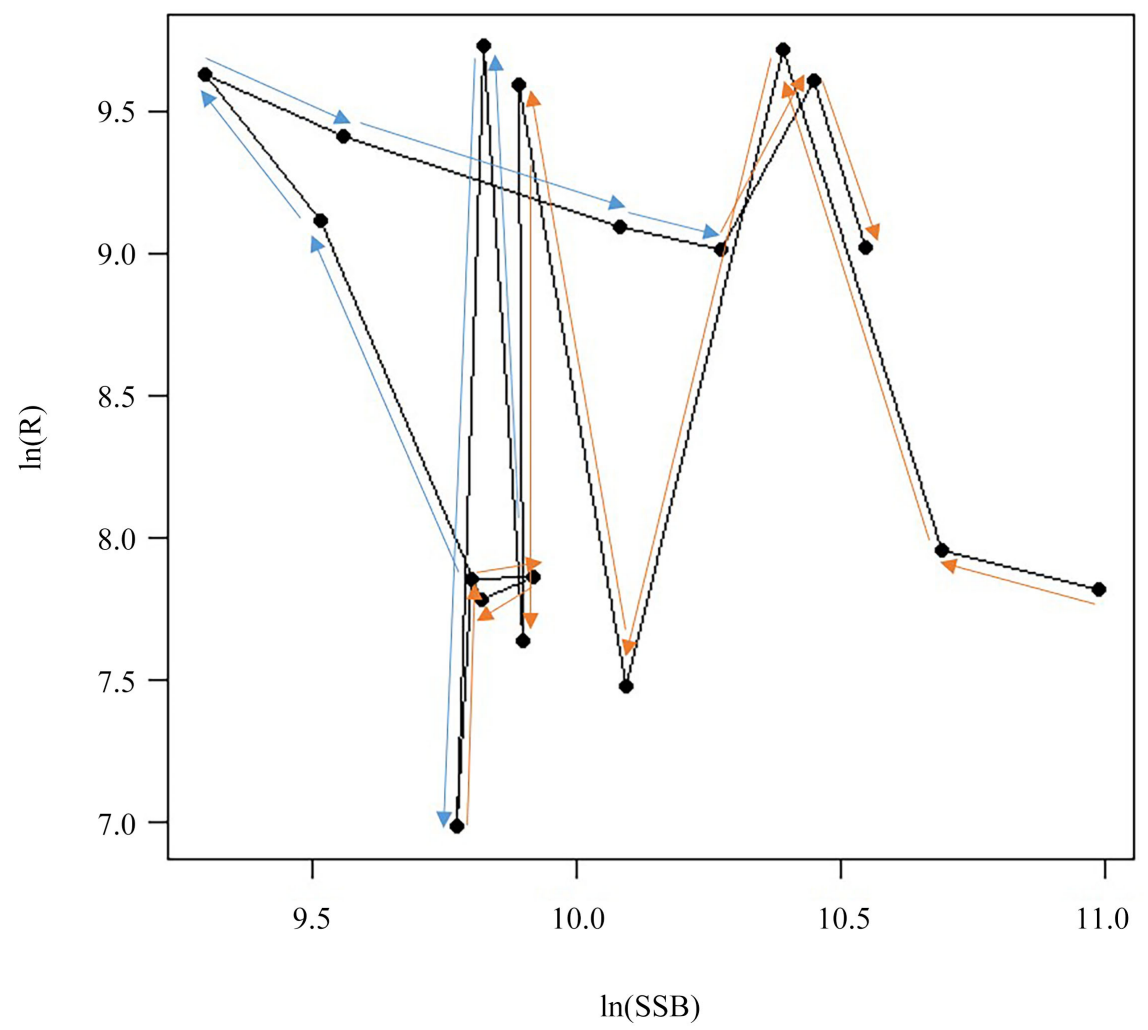

Figure A31(c). Haddock-NAFO5Z(year 1981-1998). 


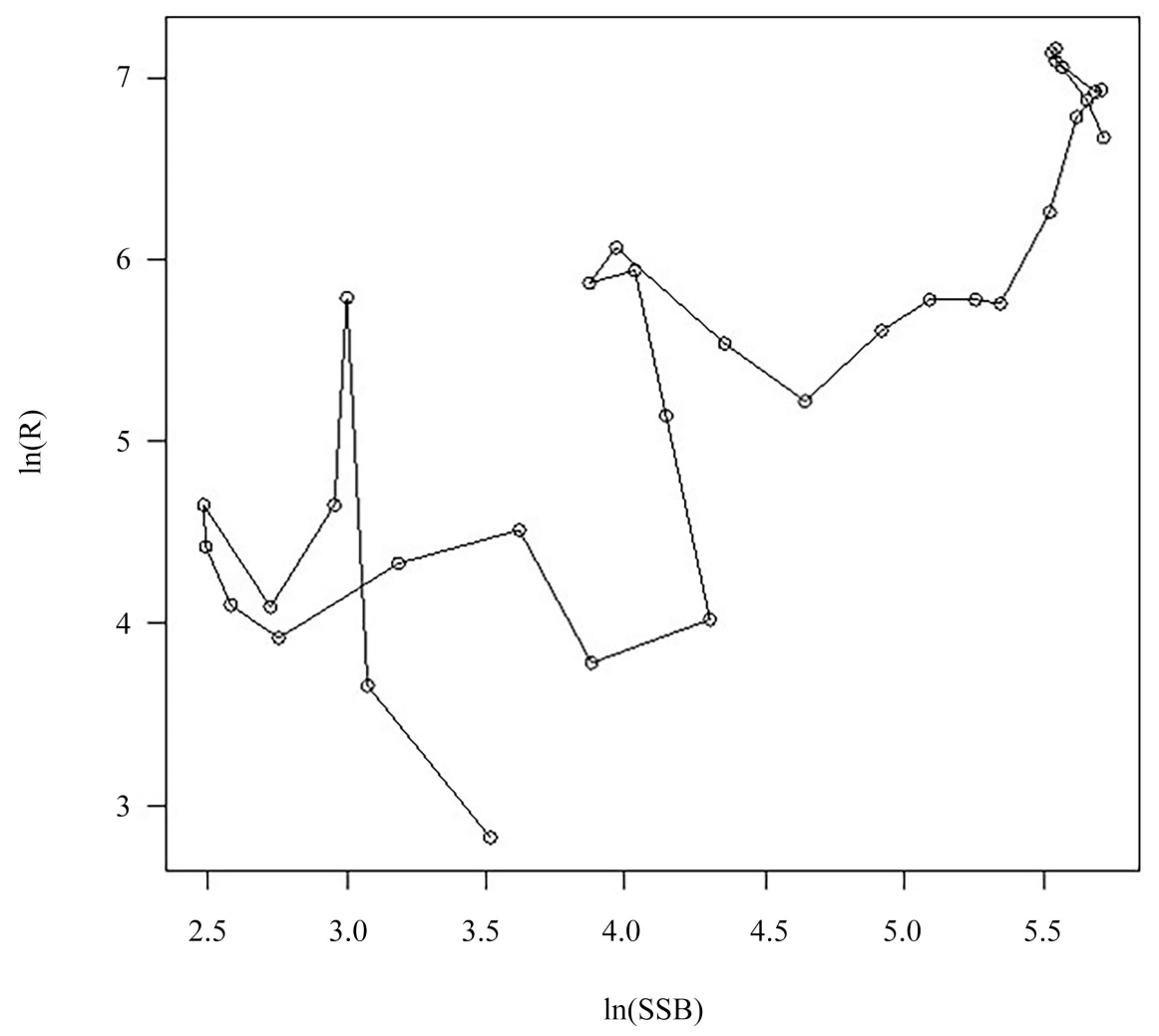

Figure A32. Silver hake-NAFO5Ze.

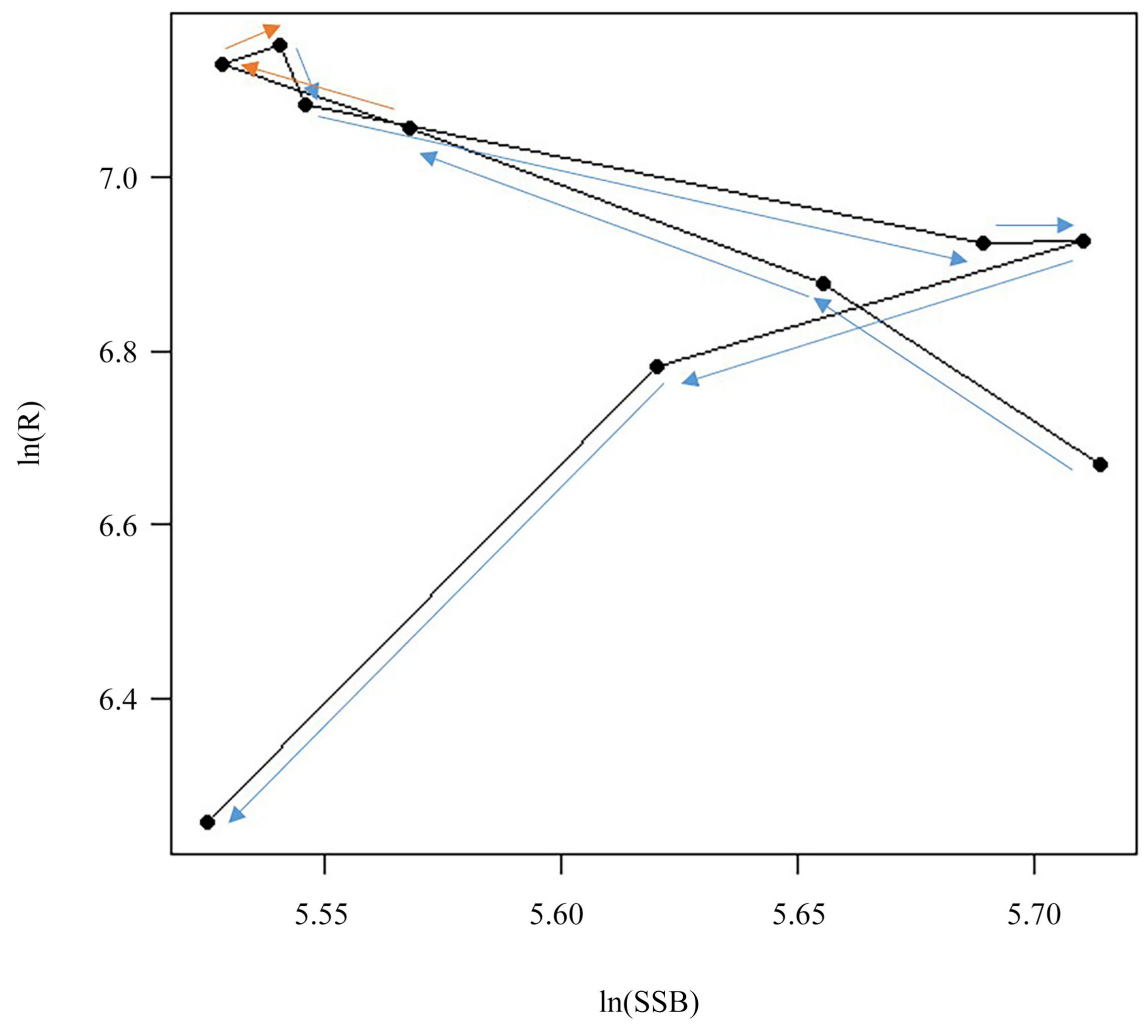

Figure A32(a). Silver hake-NAFO5Ze(Year 1954-1964). 




Figure A32(b). Silver hake-NAFO5Ze(Year 1964-1987).

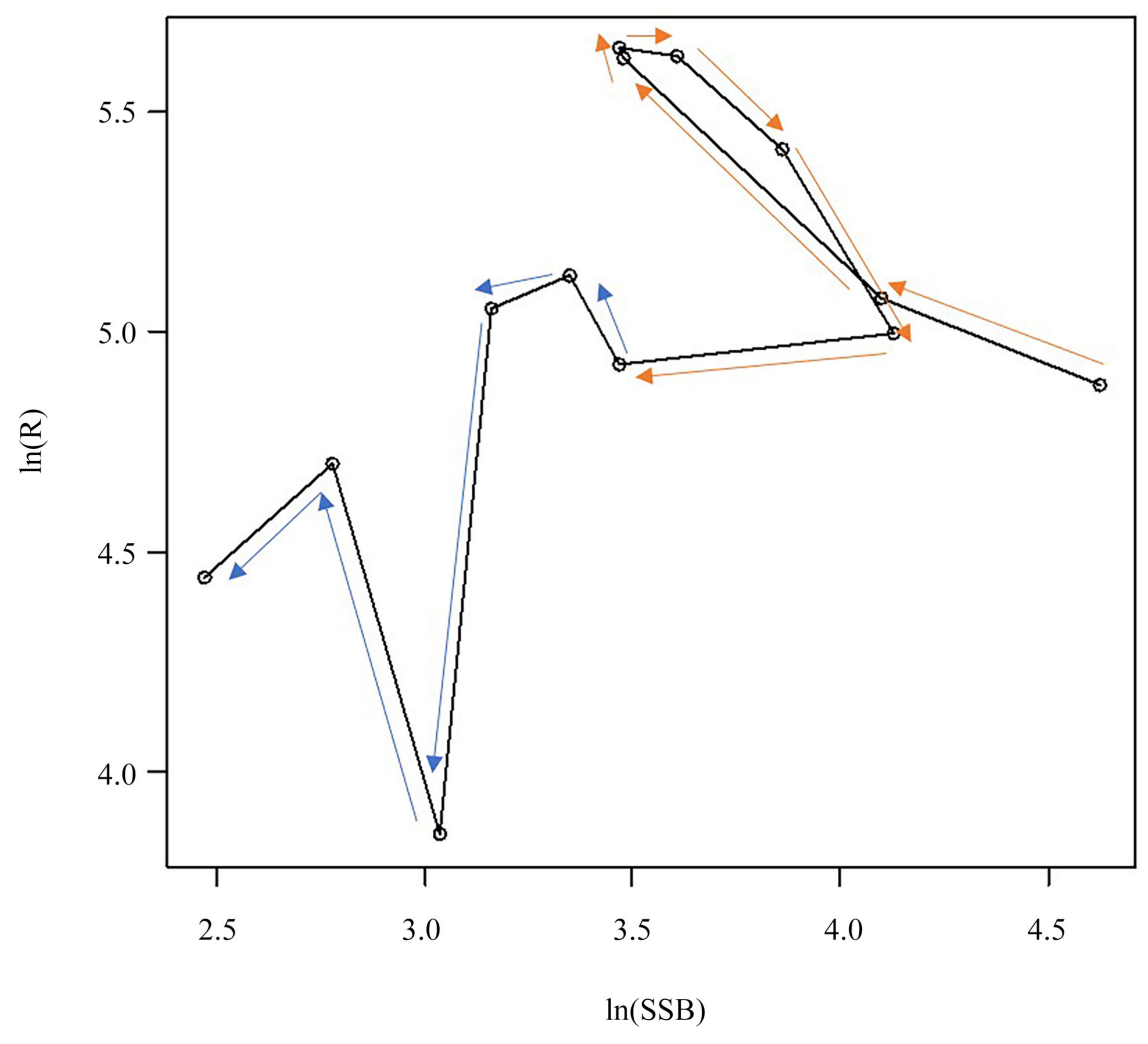

Figure A33. Red hake-NAFO GULF of Maine, N.Geroges Bank. 


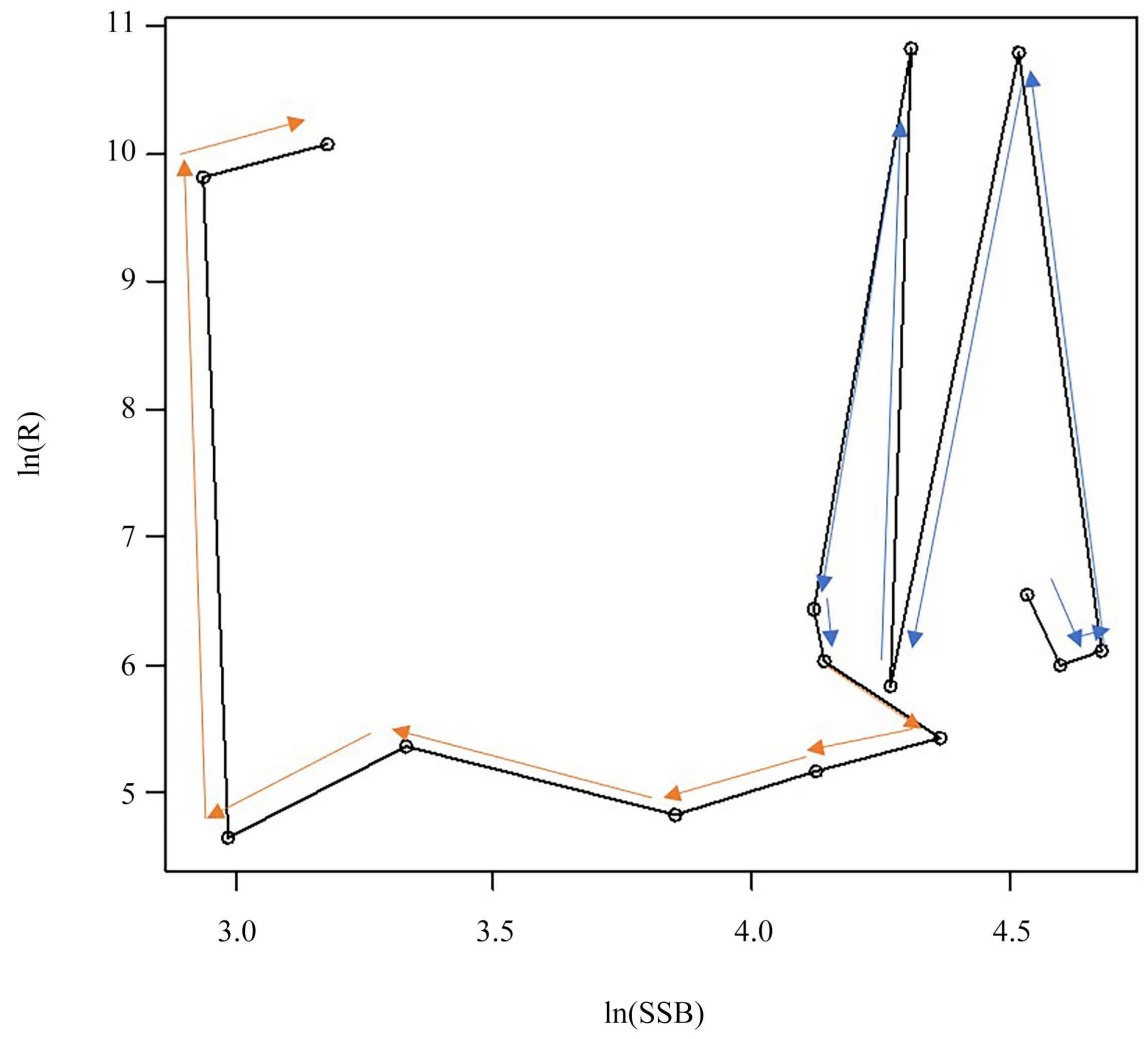

Figure A34. Red hake-NAFOS.New England.

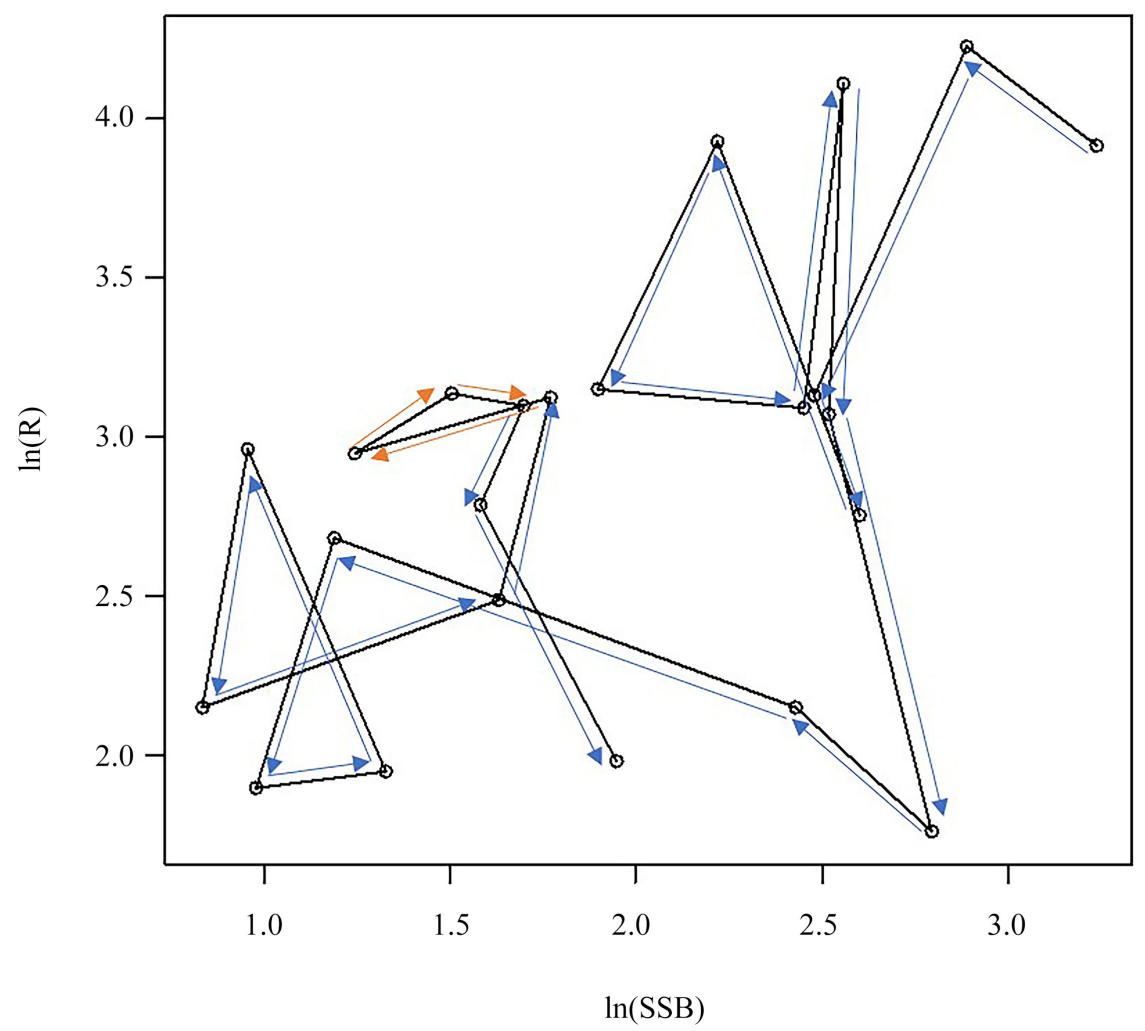

Figure A35. Yellow flounder-NAFO5Z. 


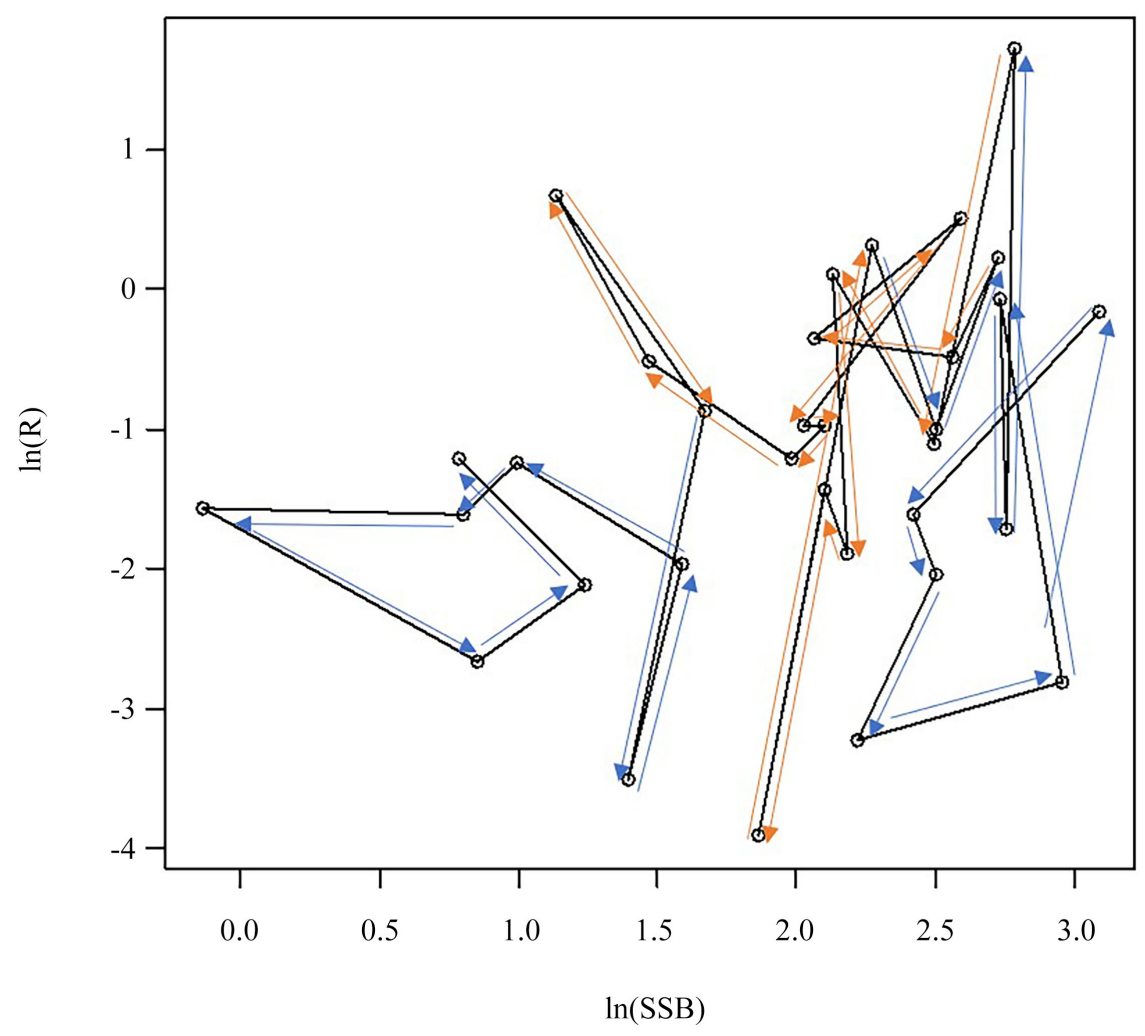

Figure A36. Cod-NAFO5Y.

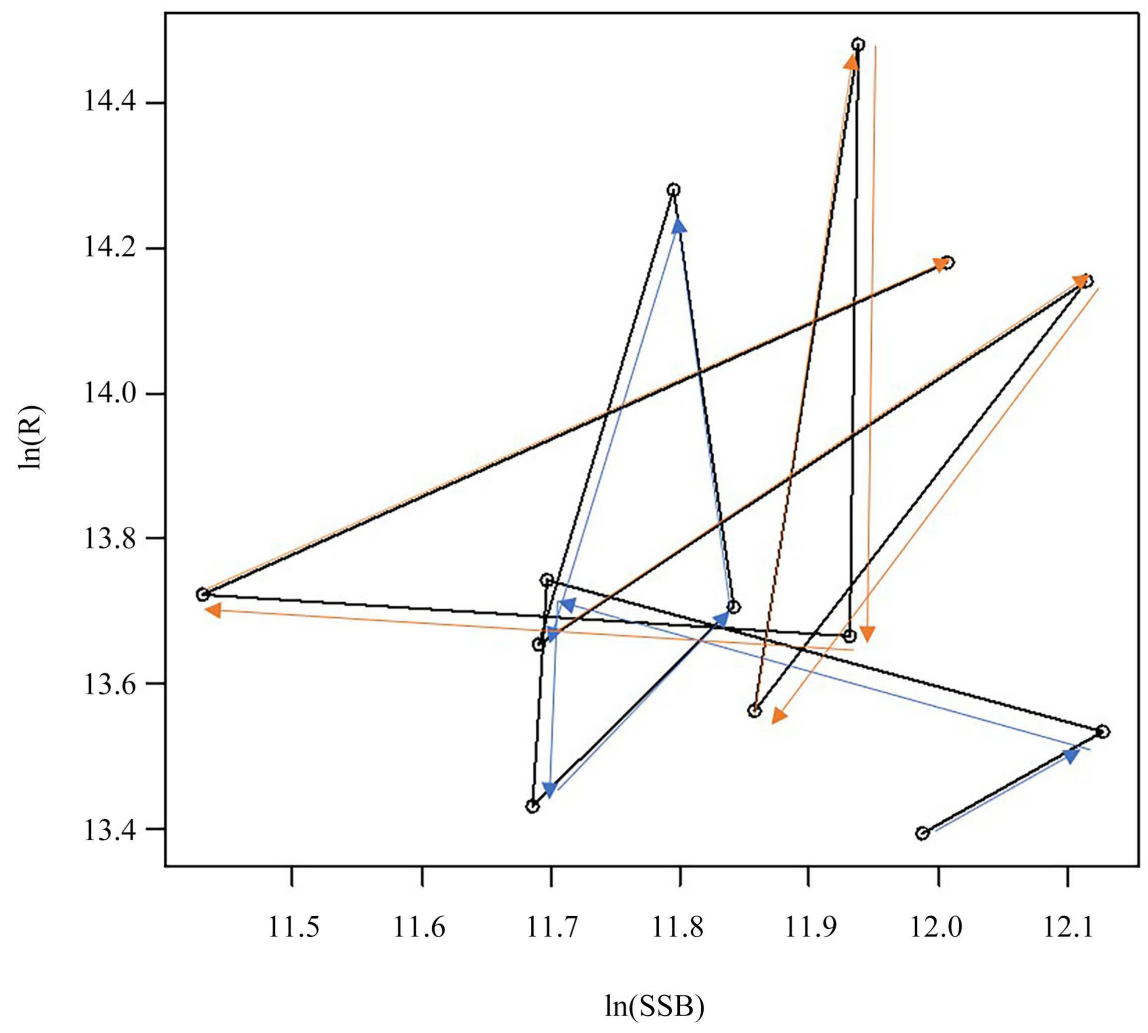

Figure A37. Silver hake-NAFO4VWX. 


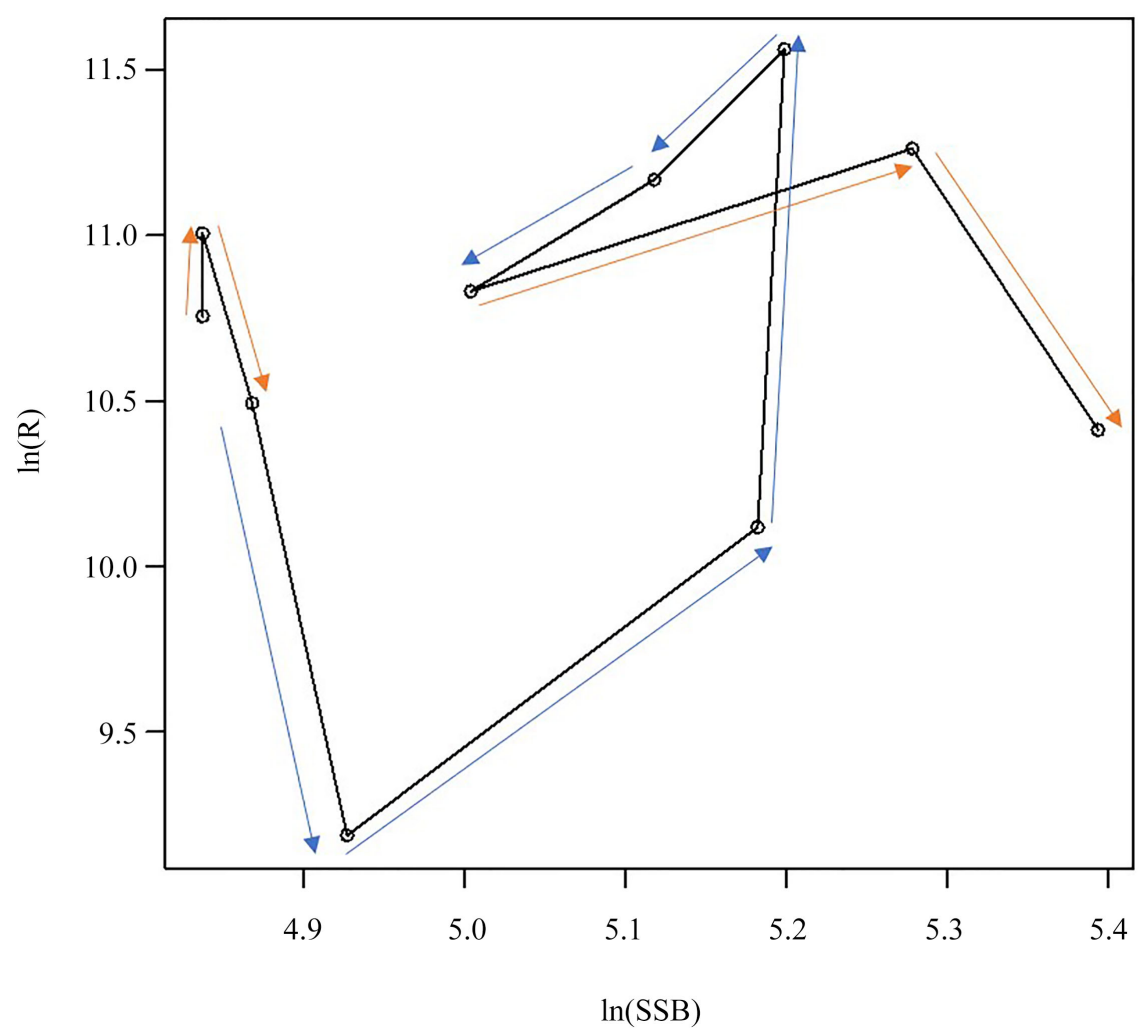

Figure A38. Pollok or Sithe-NANFO4VWX.

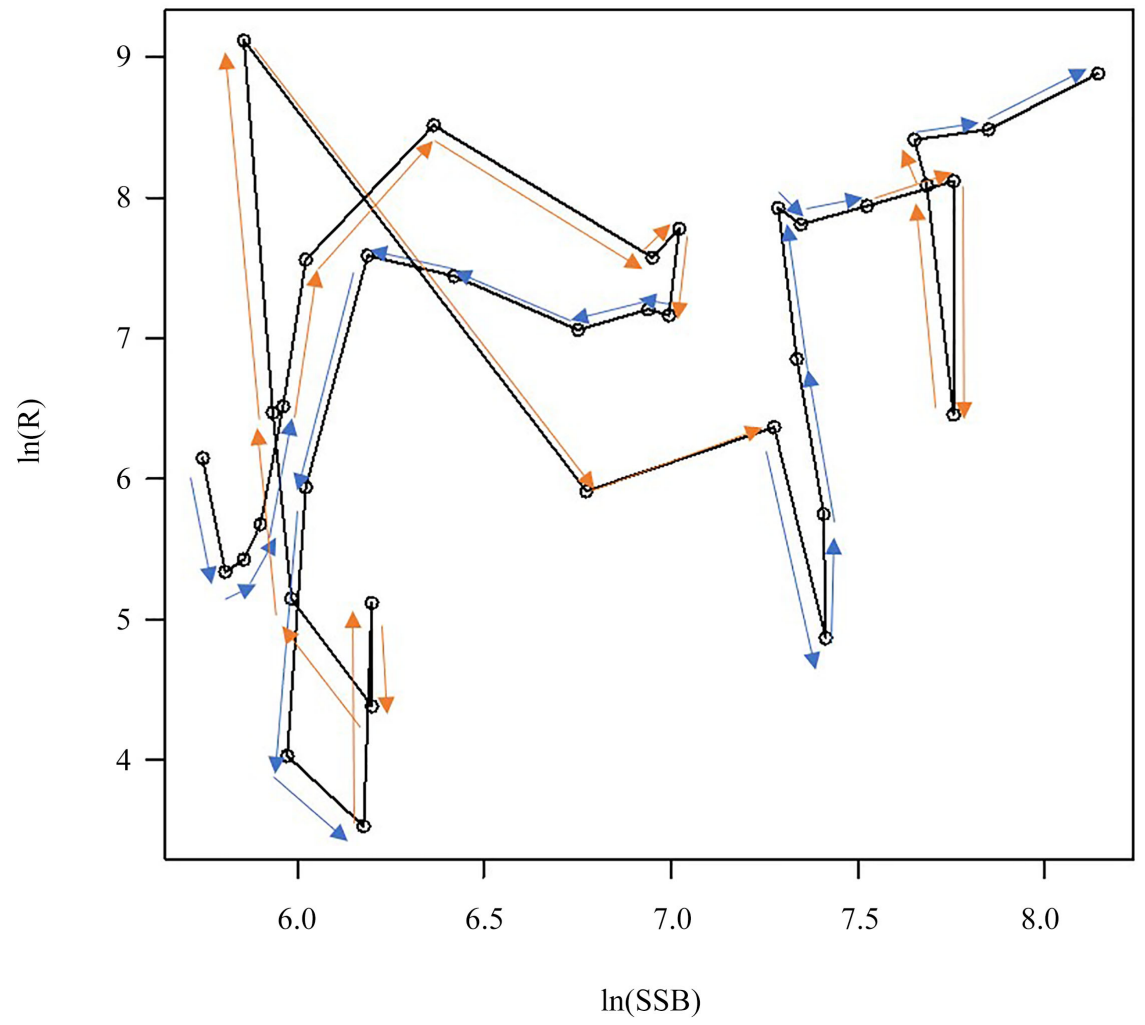

Figure A39. Mackerel-NAFO 2 to 6. 


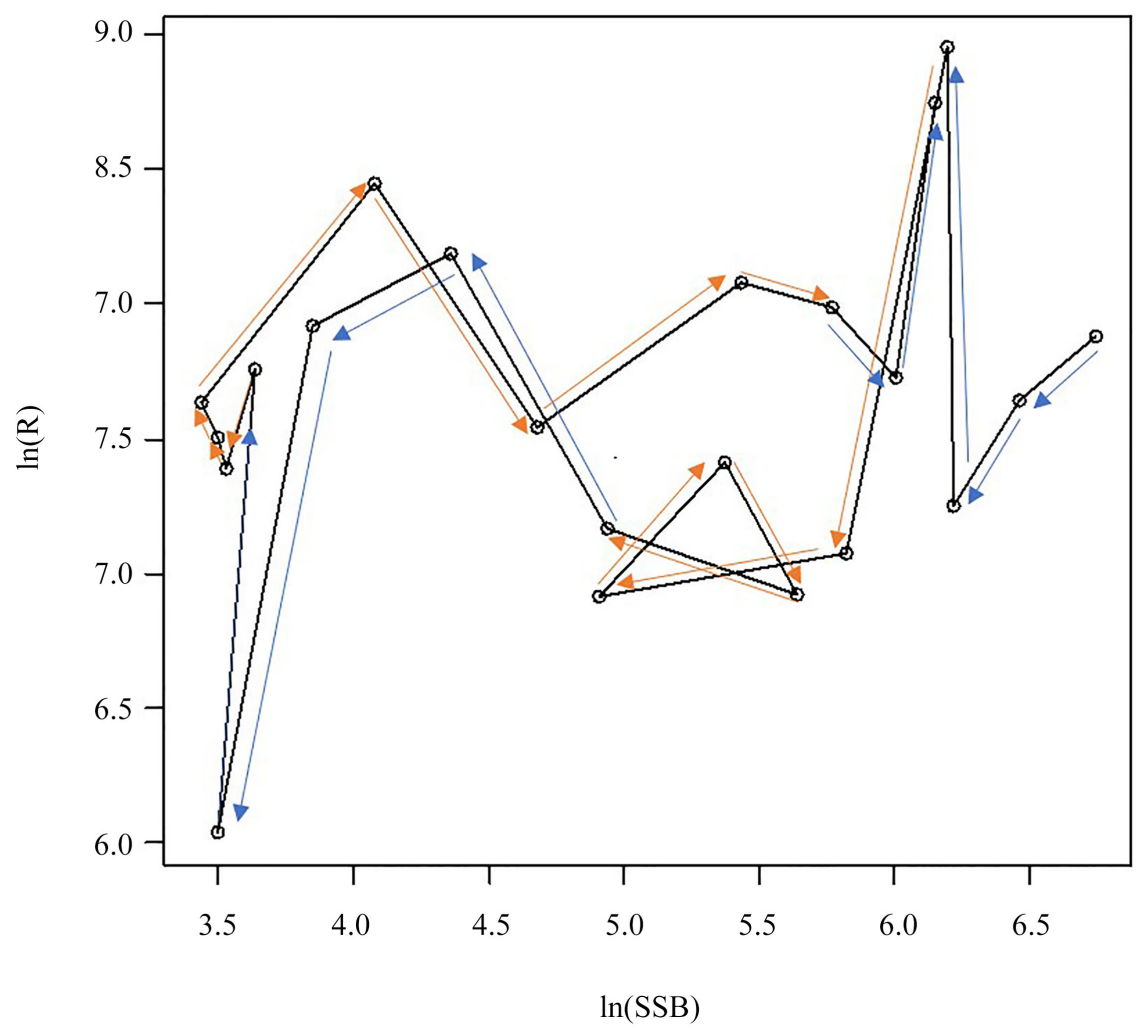

Figure A40. Herring-NAFO4-5.

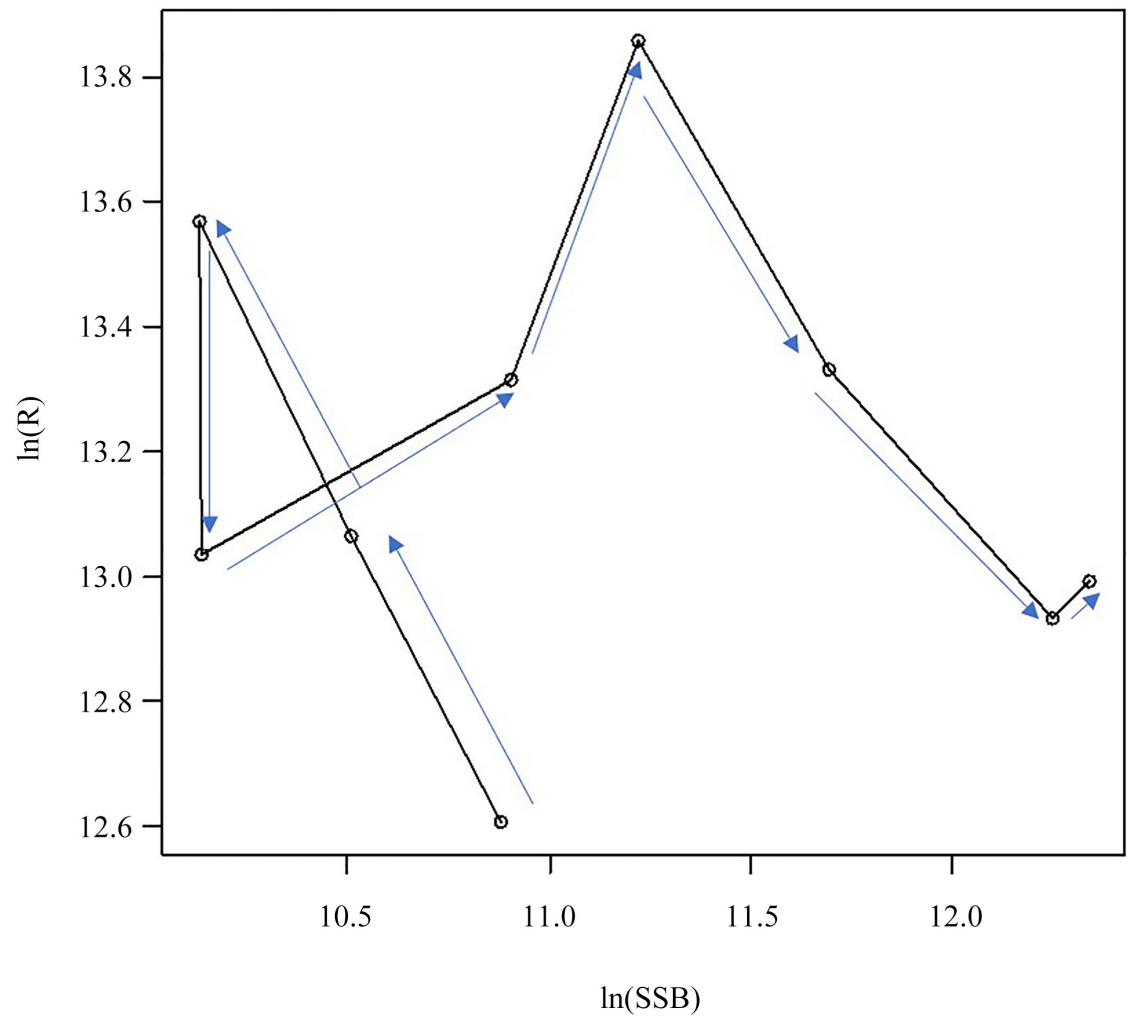

Figure A41. Herring-NAFO4T(Fall spawners). 


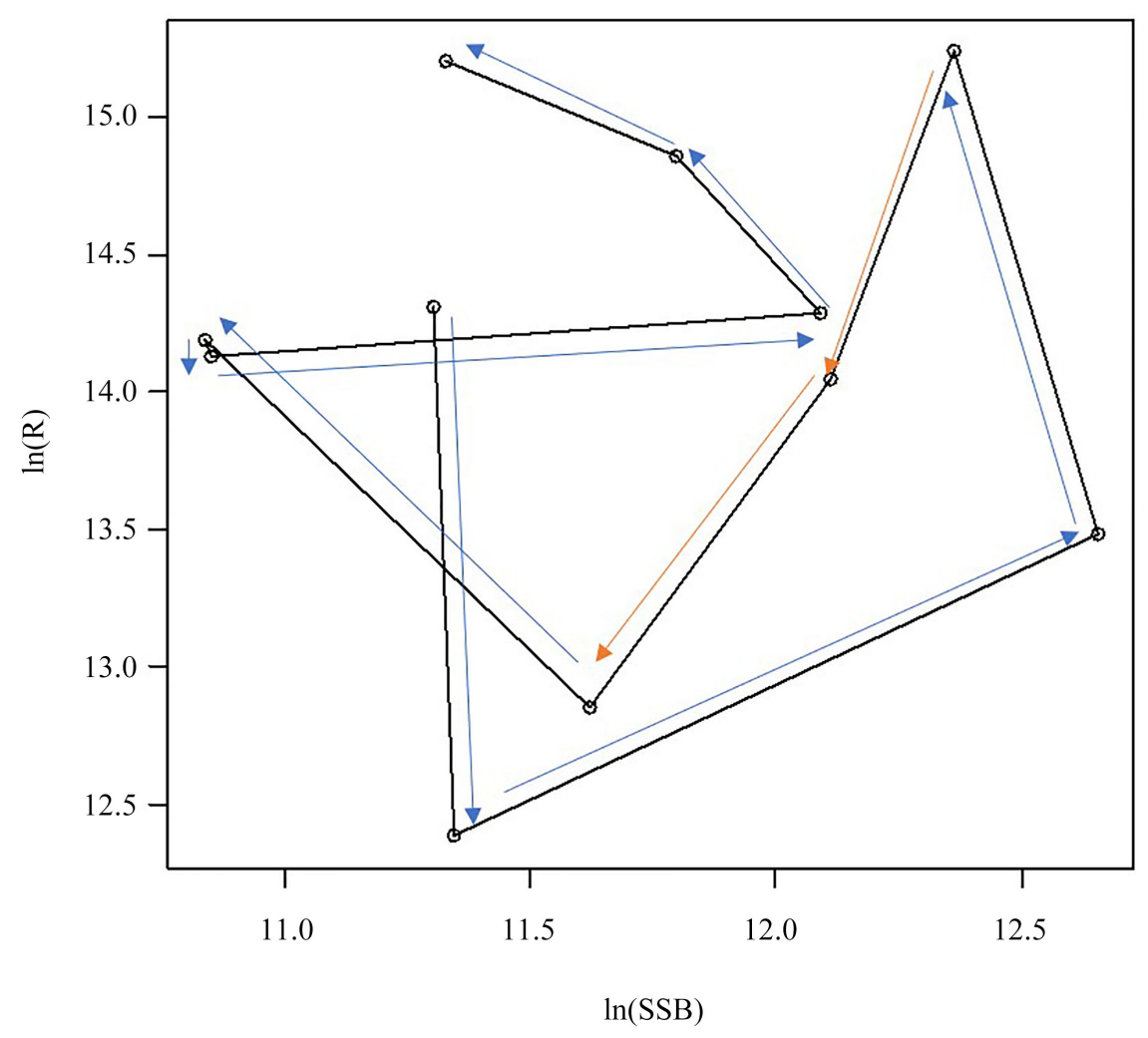

Figure A42. Herring-NAFO4WX.

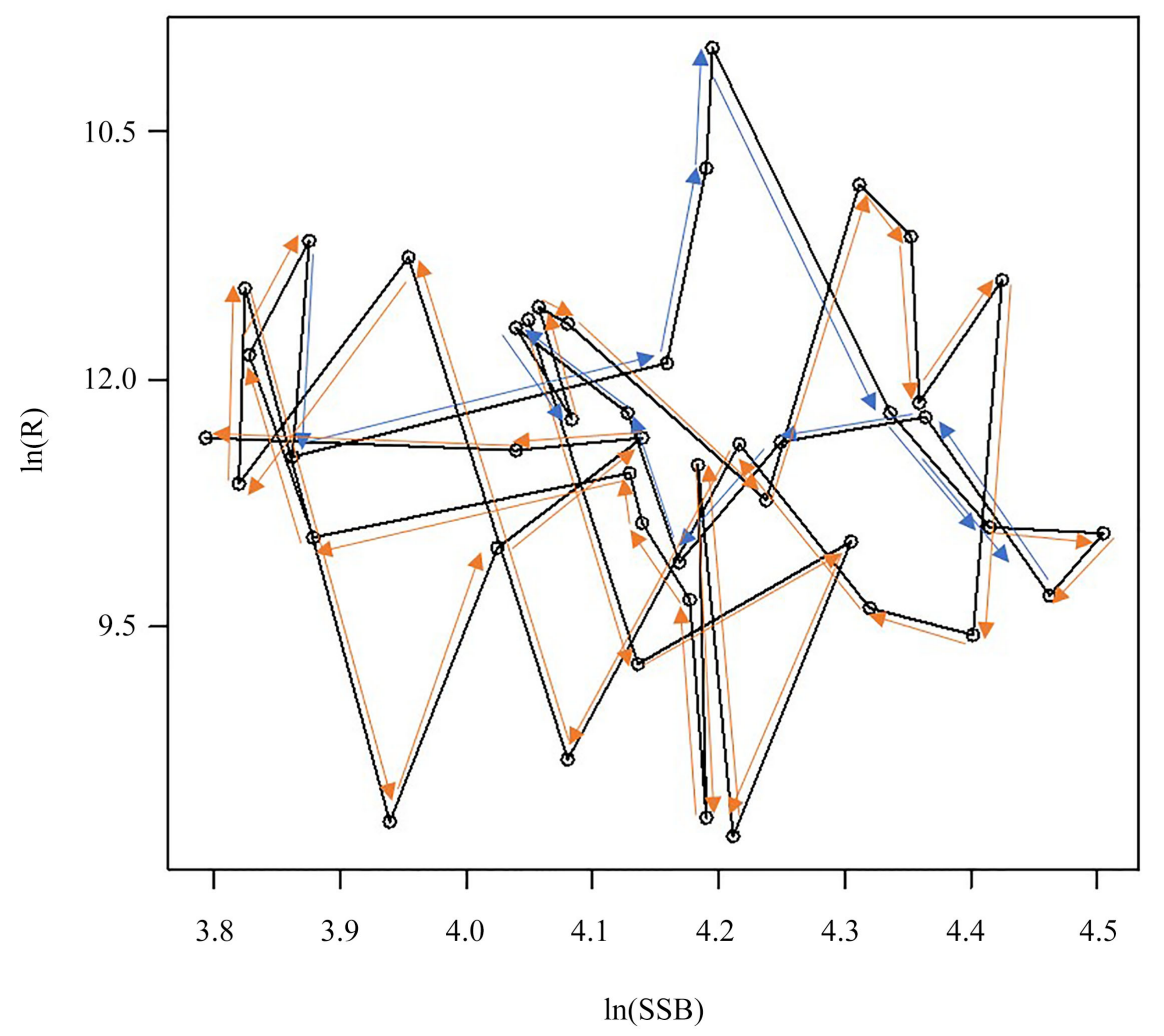

Figure A43. Cod-NAFO4X. 


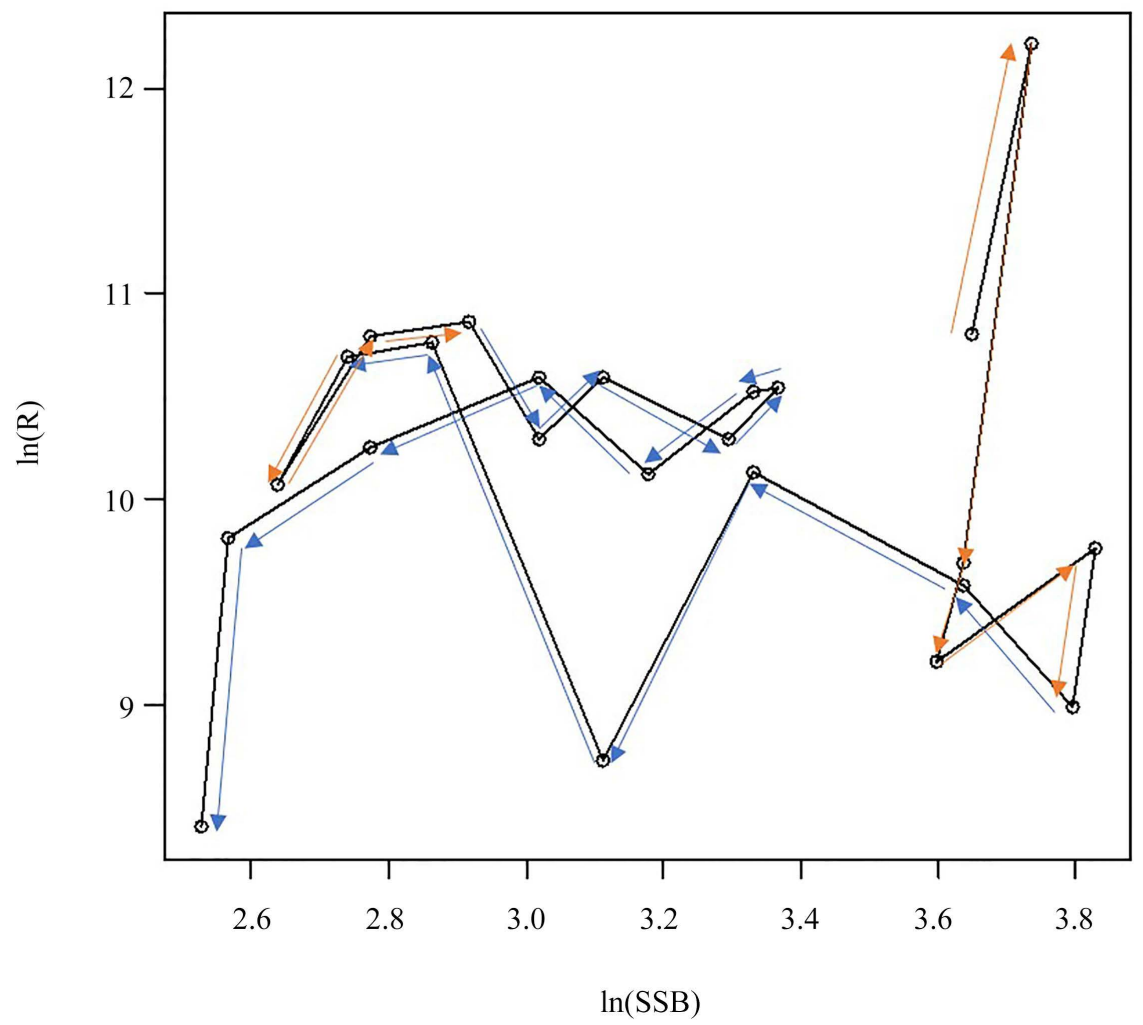

Figure A44. Haddock-NAFO4X.

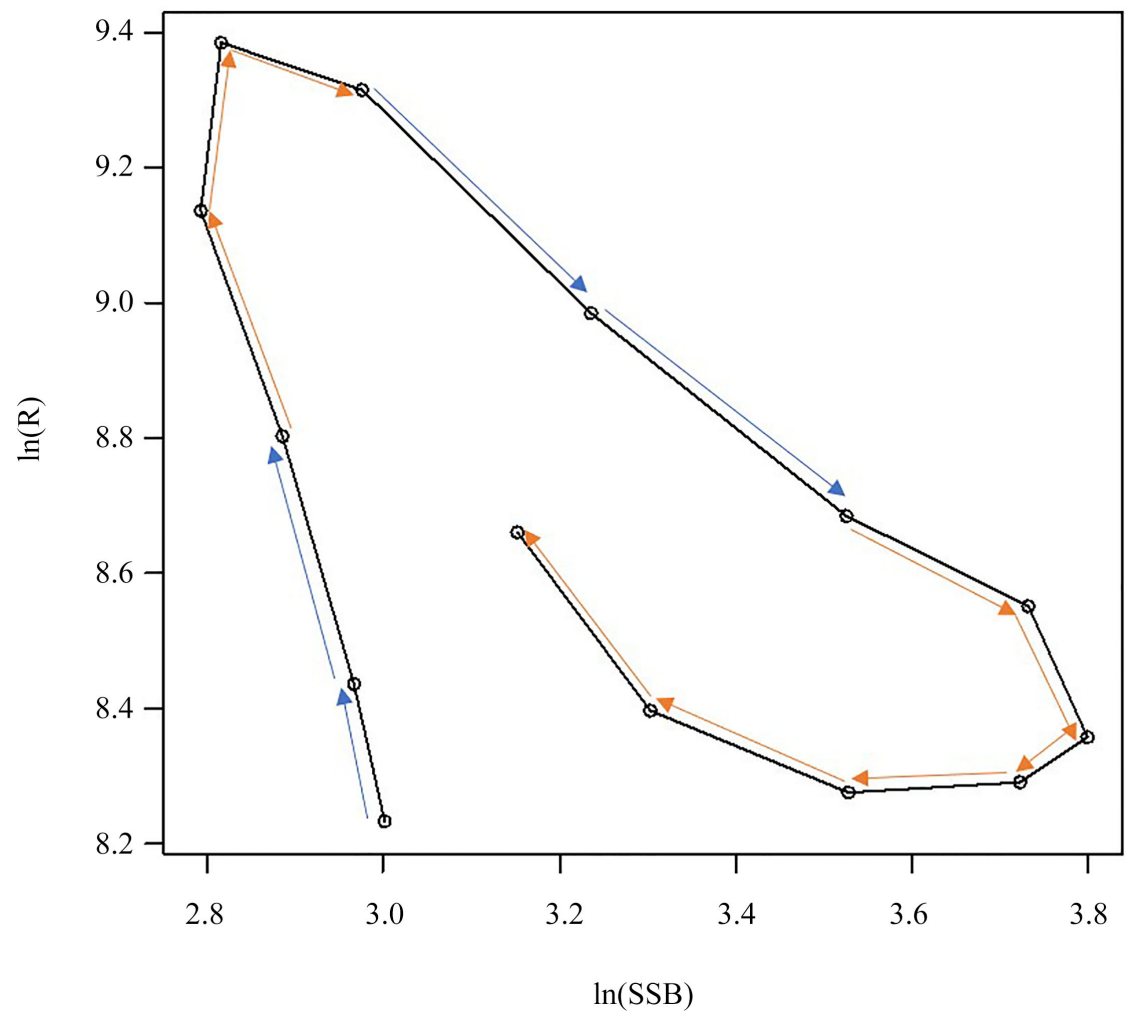

Figure A45. White hake-NAFO4T. 




Figure A46. American plaice-NAFO3LNO.

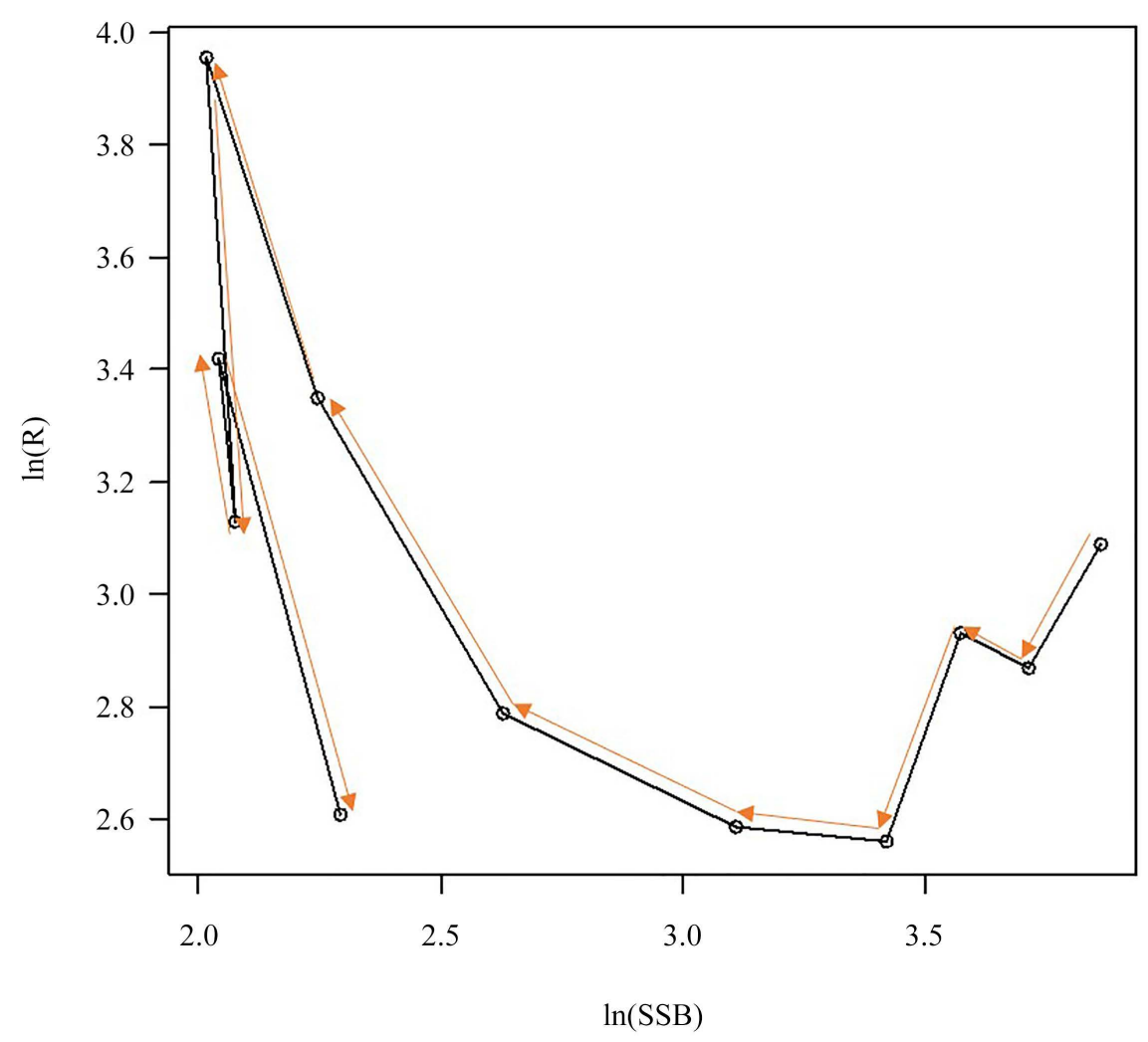

Figure A47. American plaice-NAFO5YZ. 


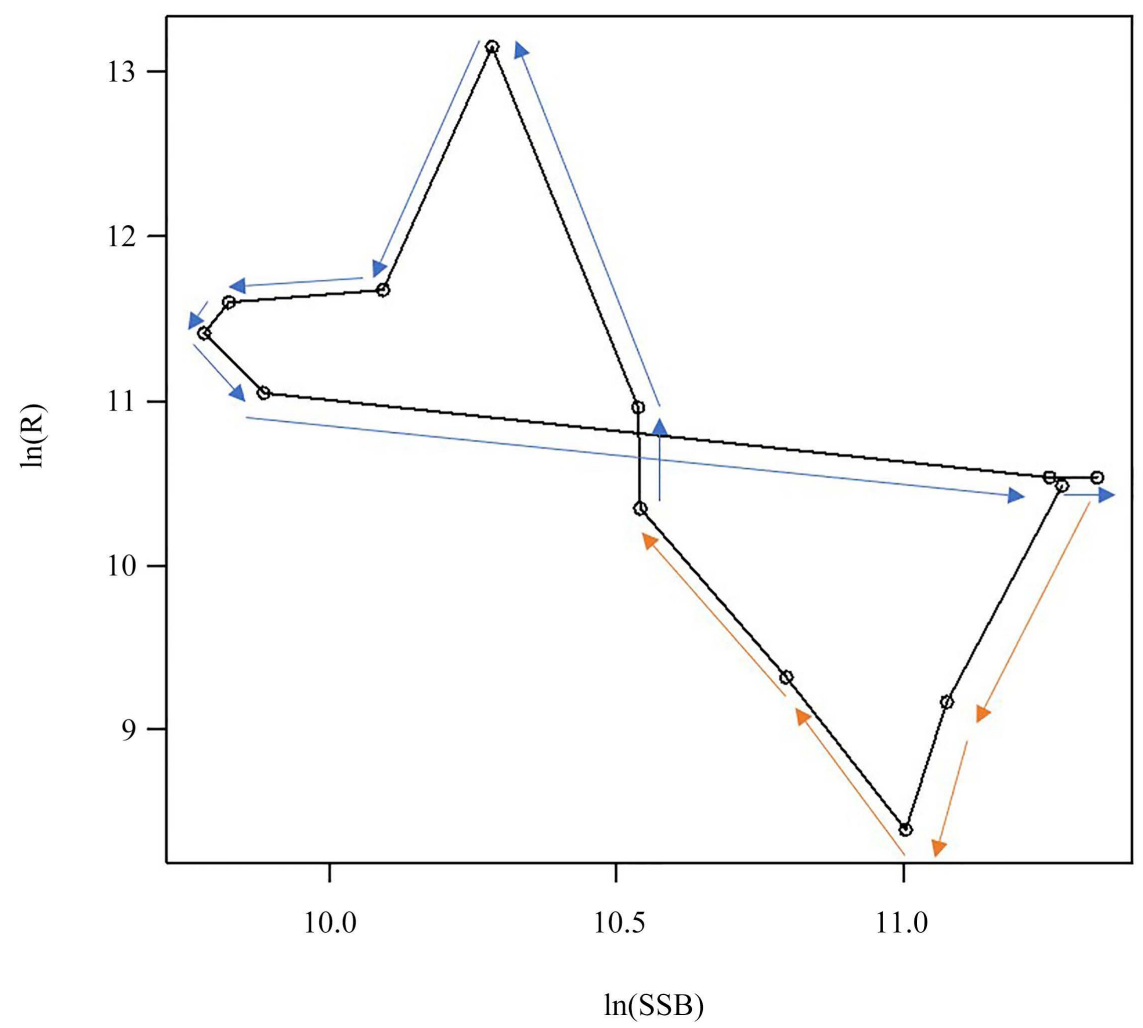

Figure A48. Herring-NAFO4R(Fall spawners).

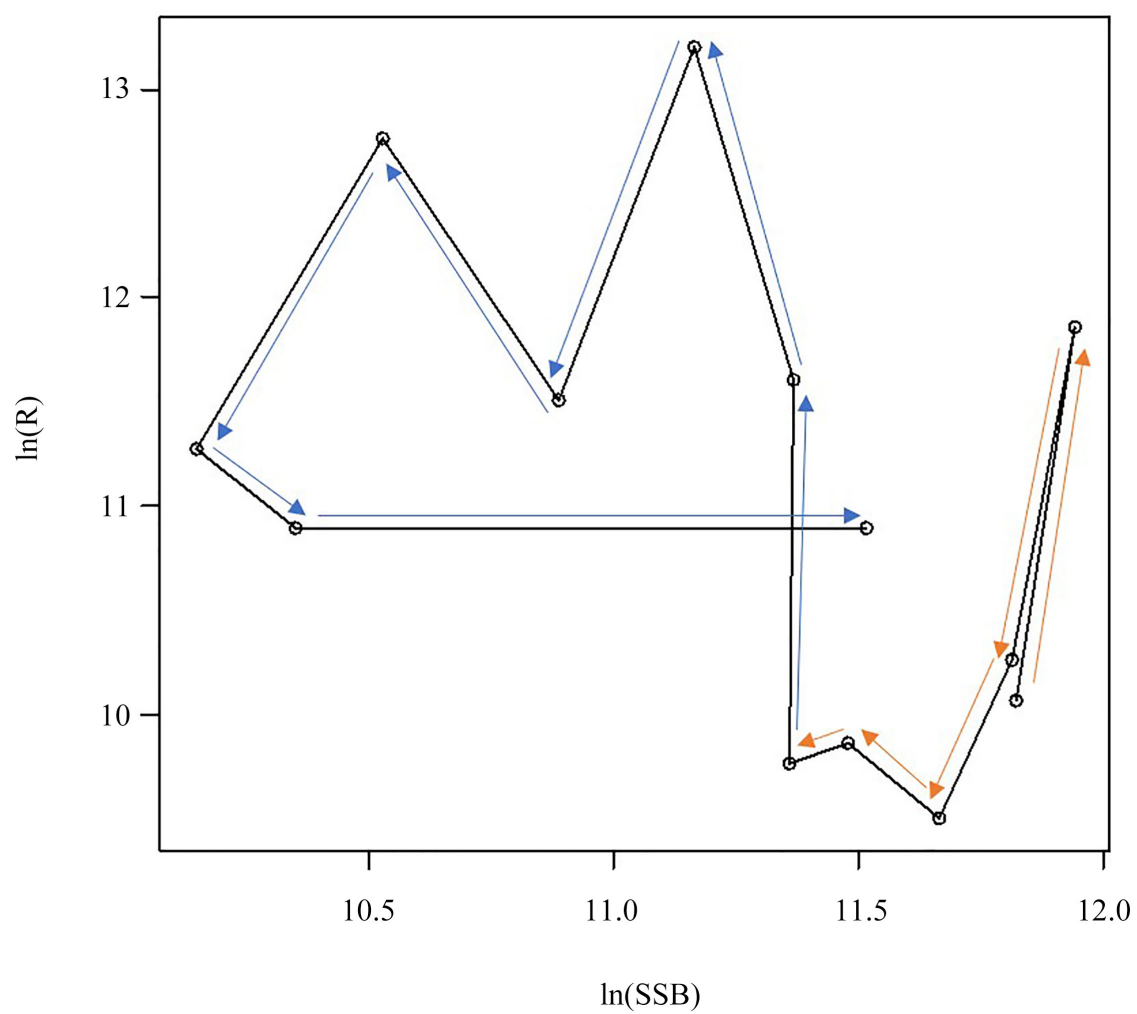

Figure A49. Herring-NAFO5R(Spring spawners). 


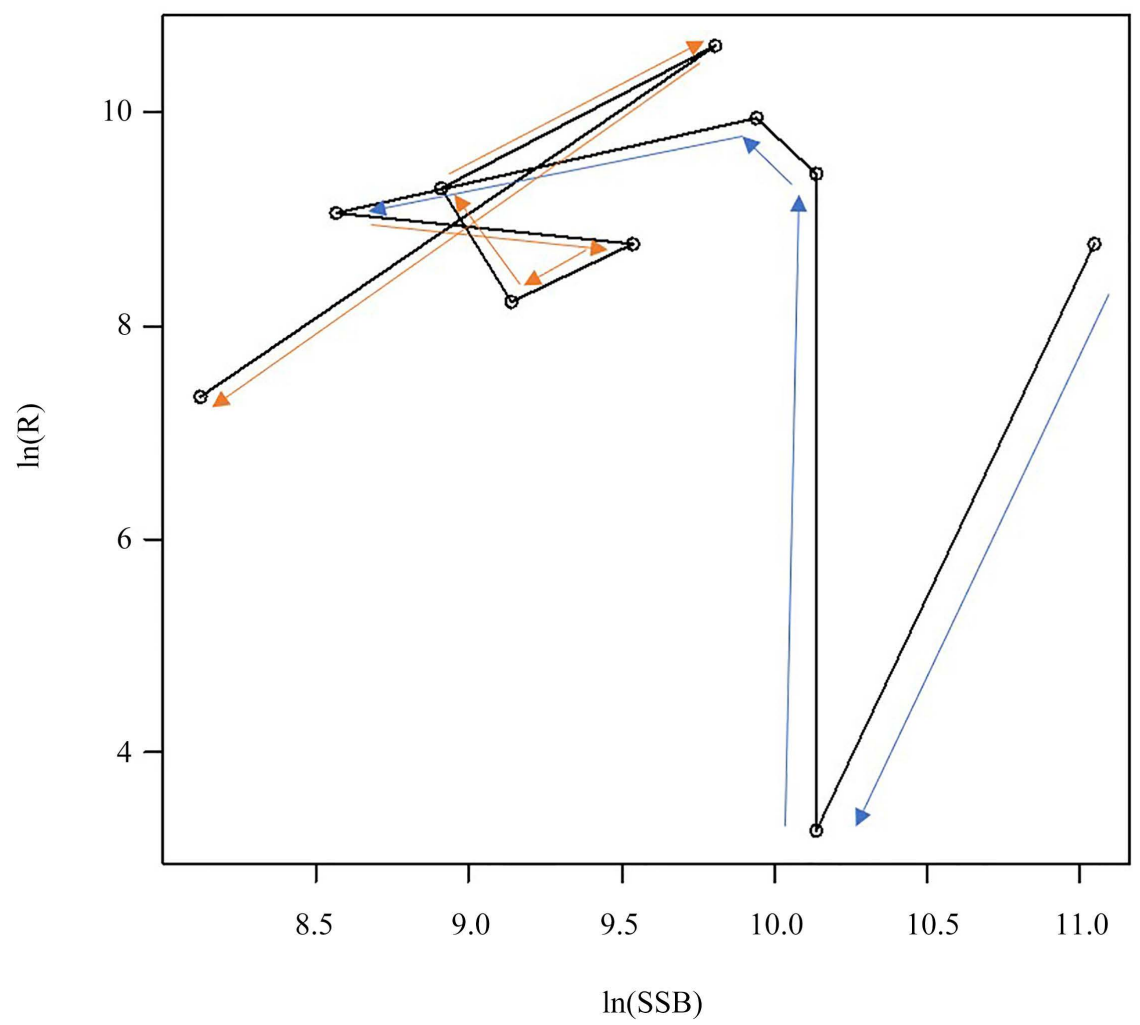

Figure A50. Cod-NAFO3M.

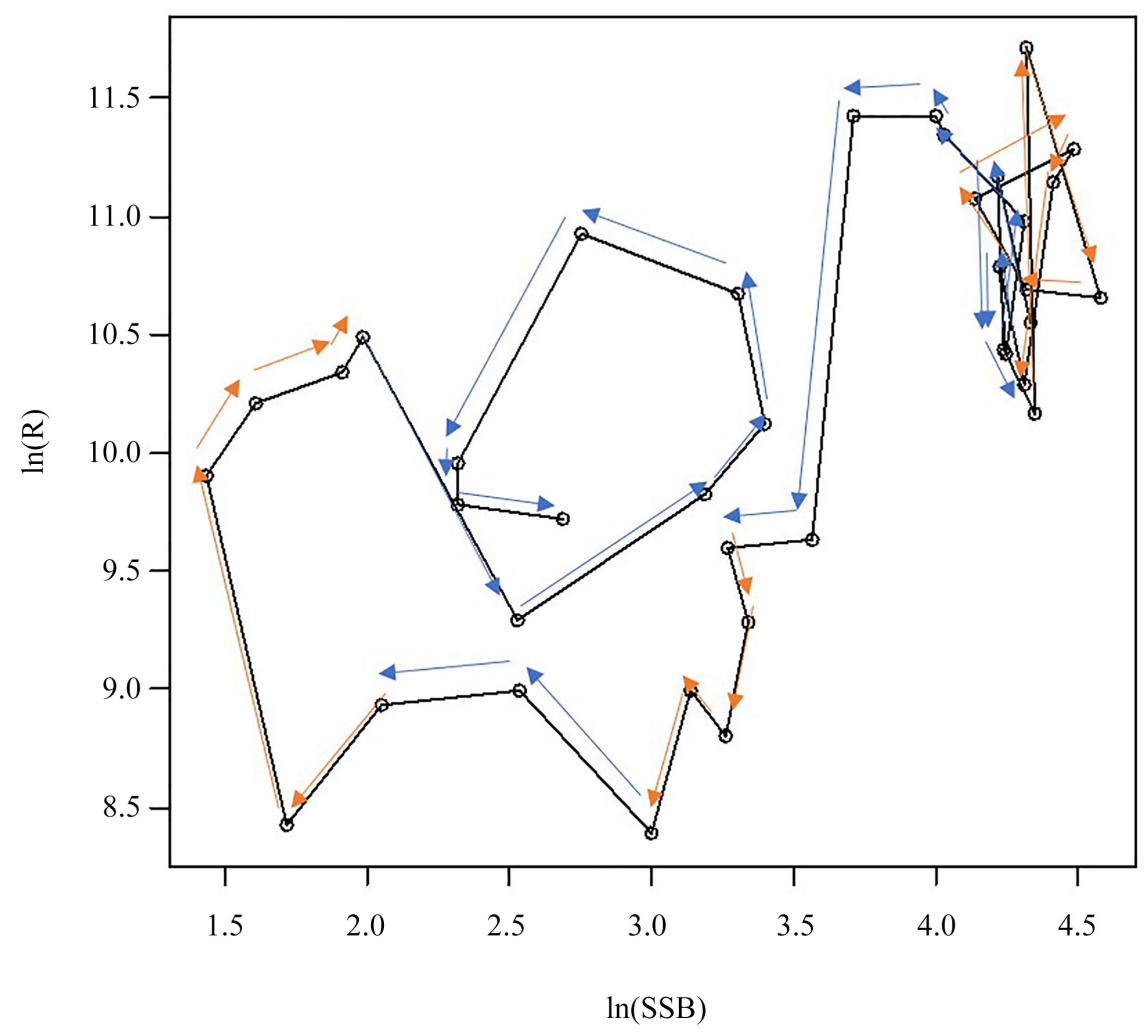

Figure A51. Haddock-NAFO4TVW. 


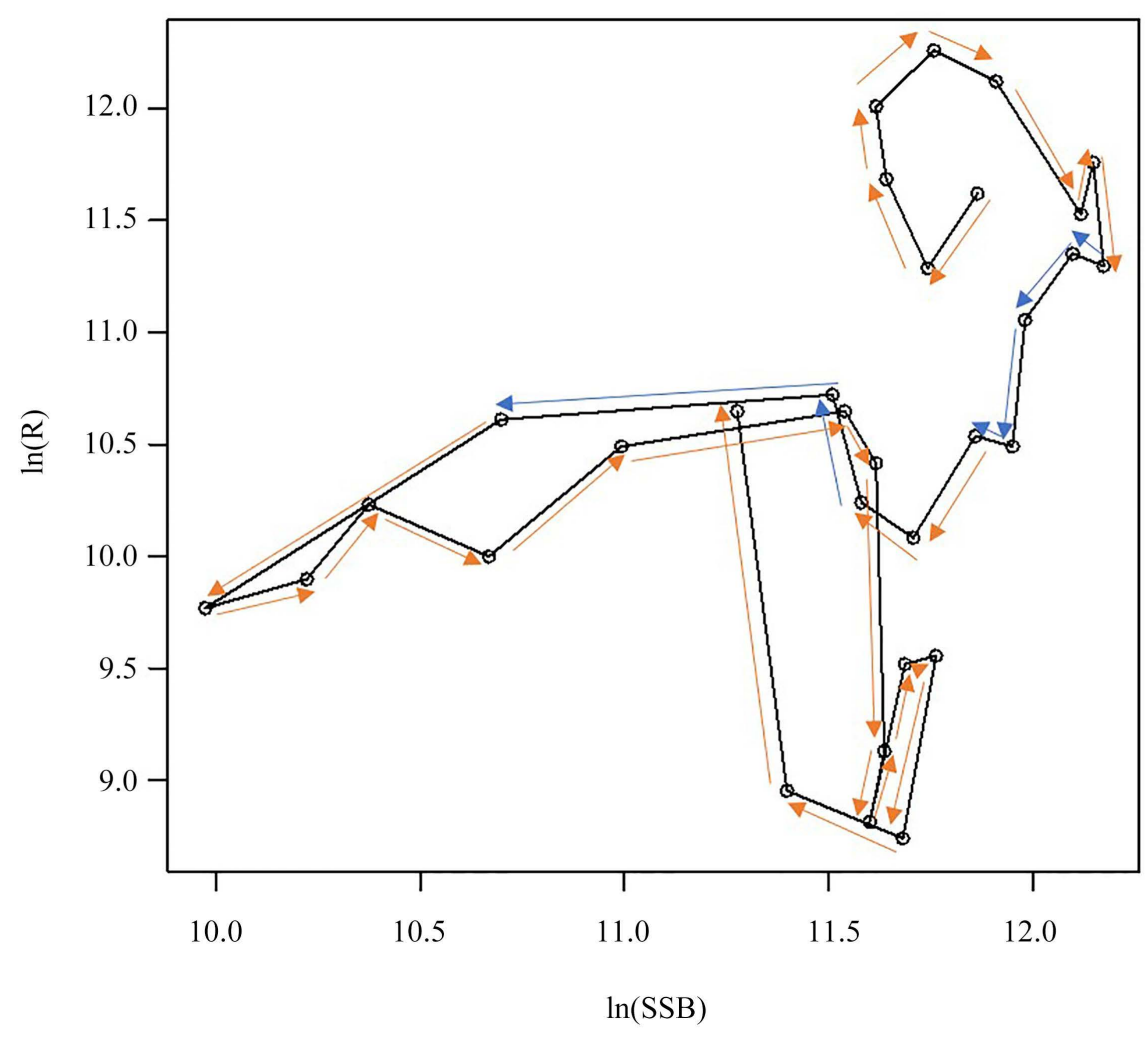

Figure A52. Cod-NAFO3NO.

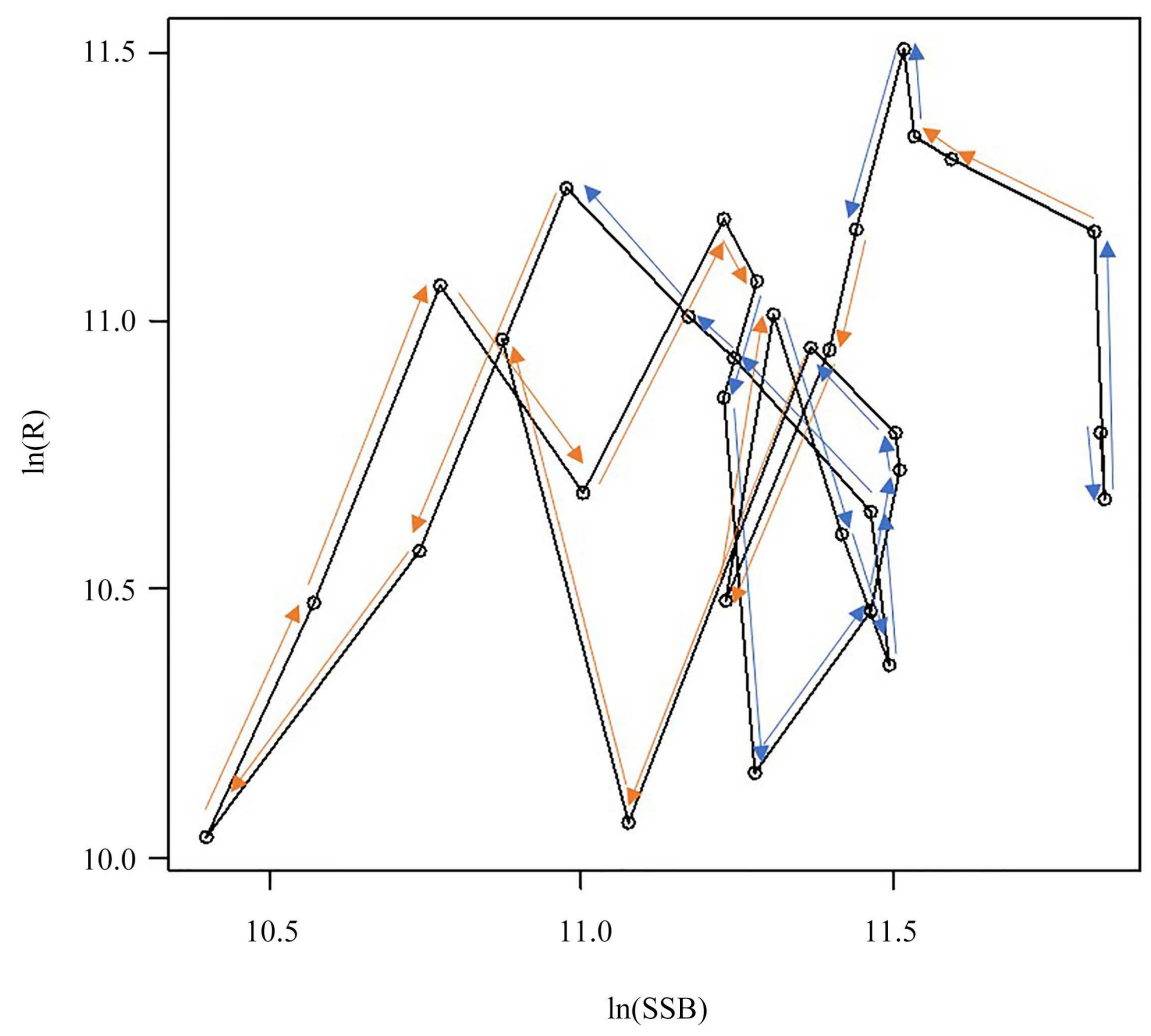

Figure A53. Cod-NAFO3Ps. 


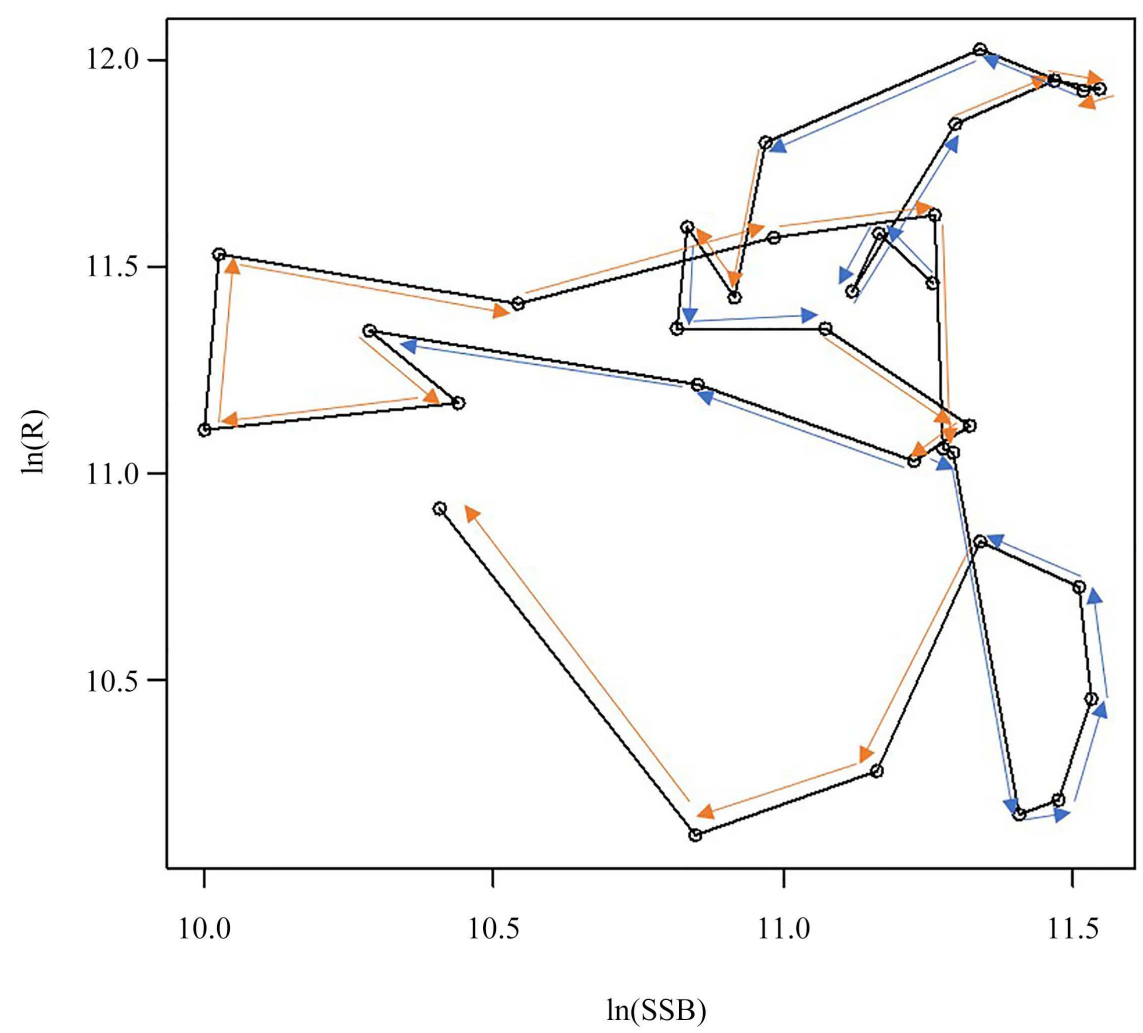

Figure A54. Cod-NAFO4VsW.

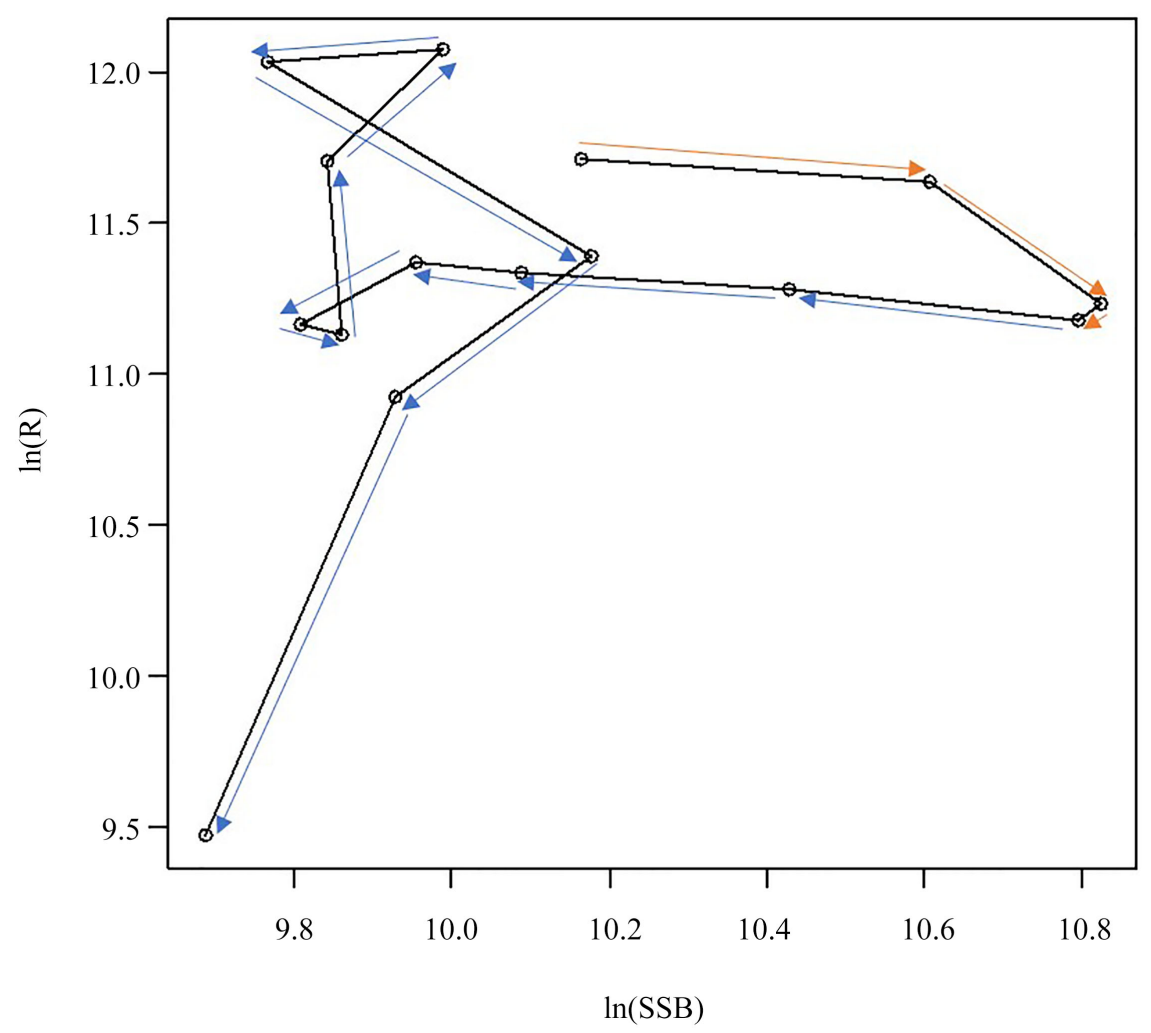

Figure A55. Yellow Flounder-NAFO3LNO. 


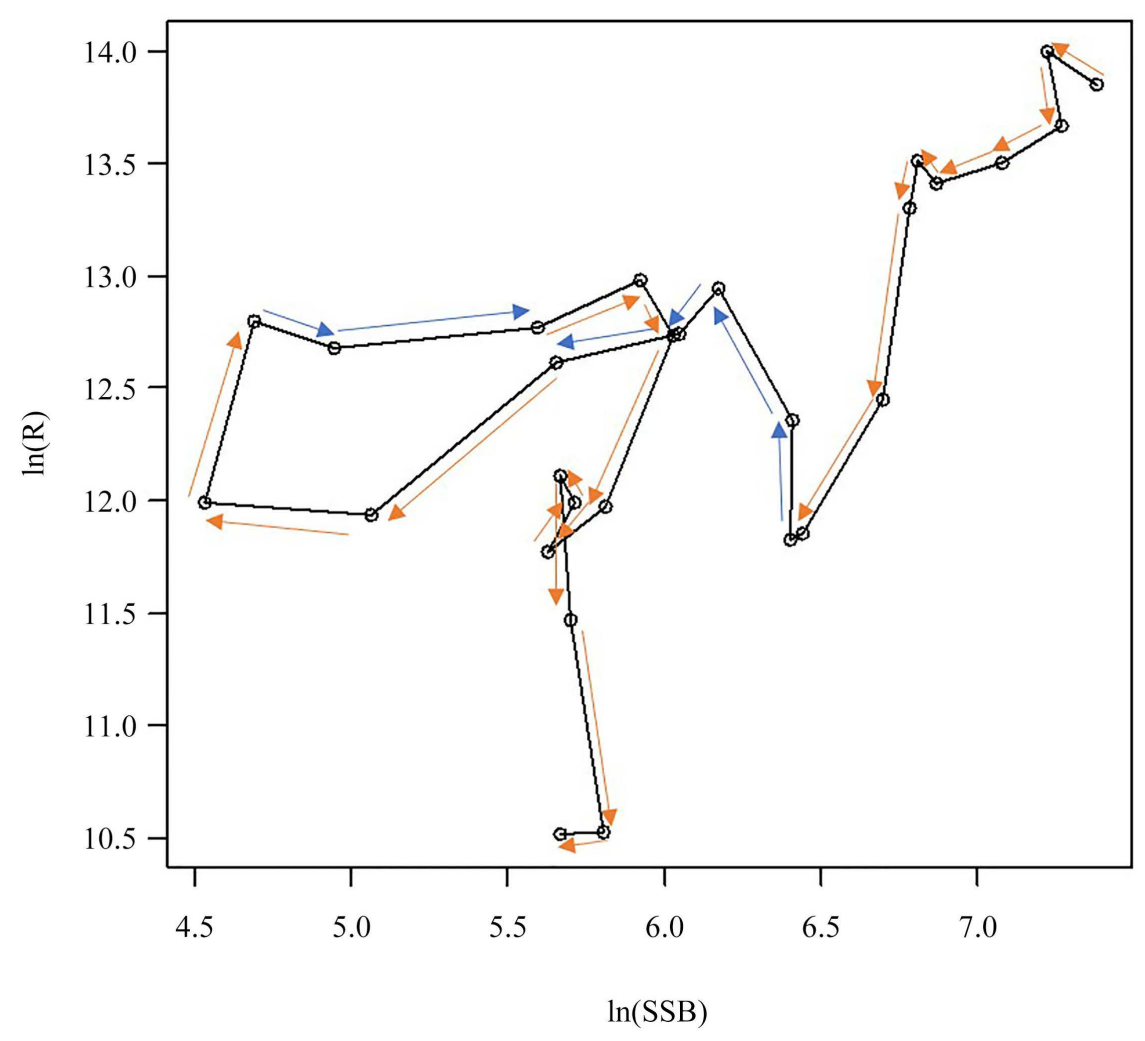

Figure A56. Cod-NAFO2J3KL.

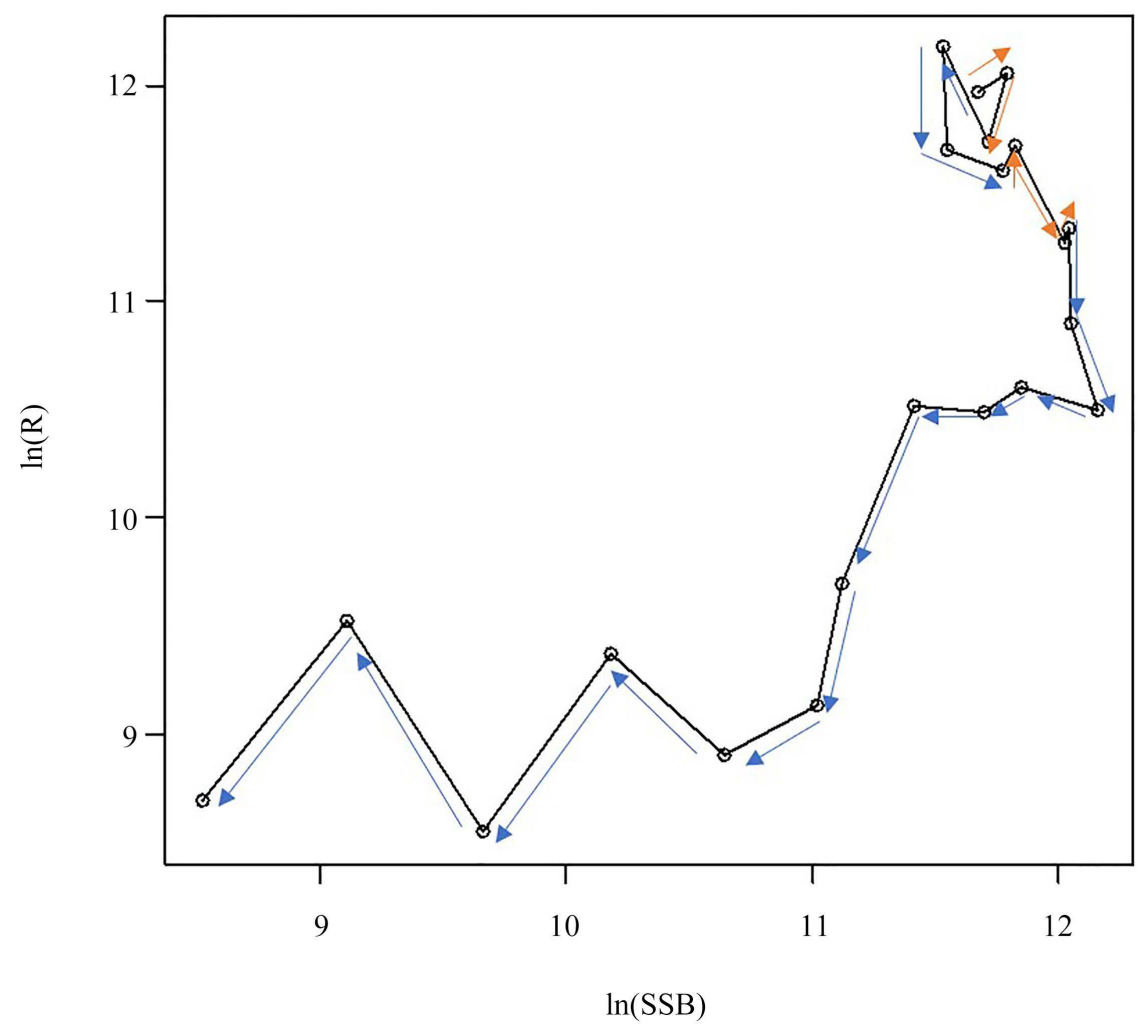

Figure A57. Cod-NAFO3Pn4Rs. 




Figure A58. Cod-NAFO4TVn.

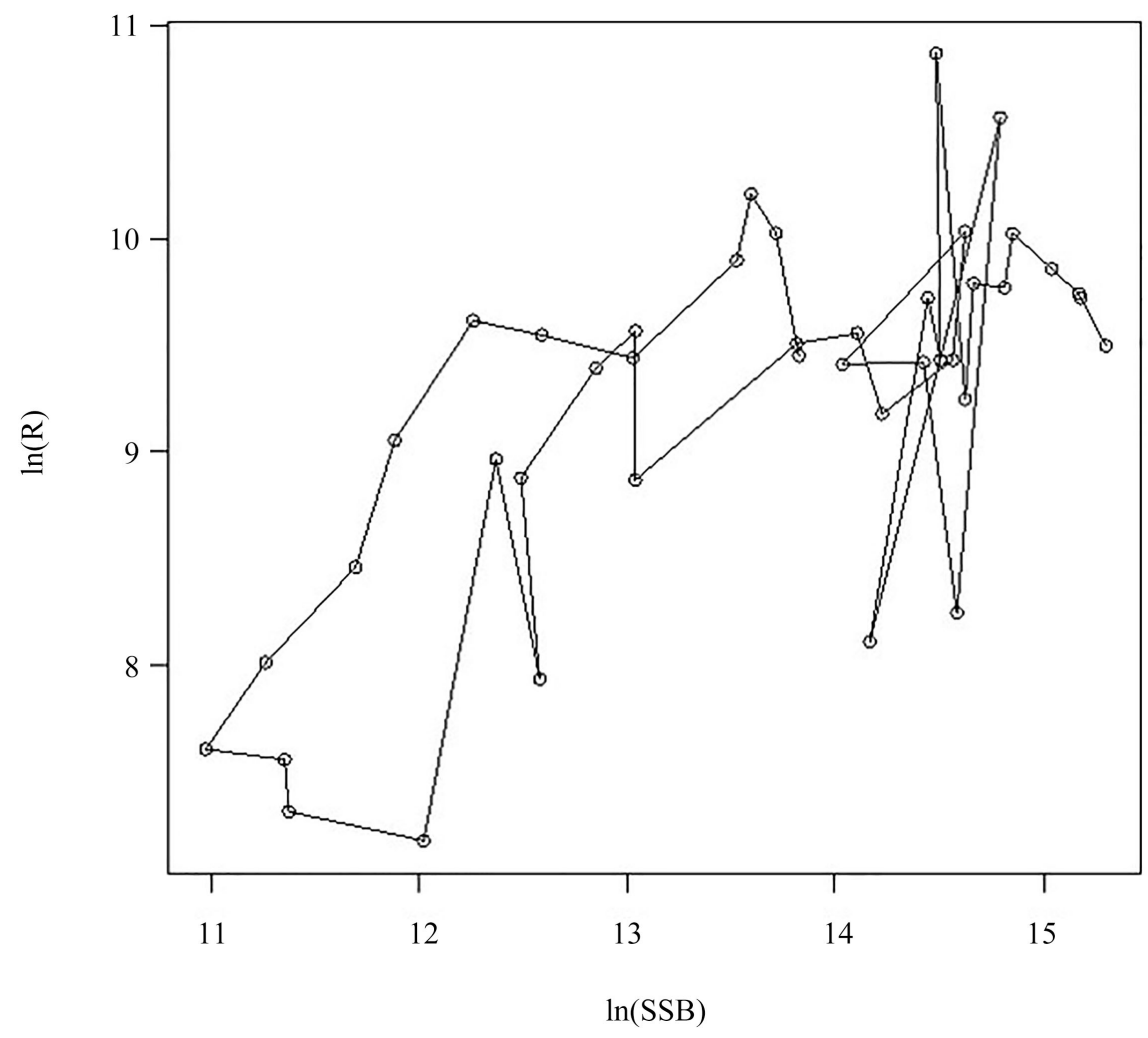

Figure A59. Herring-North Sea. 


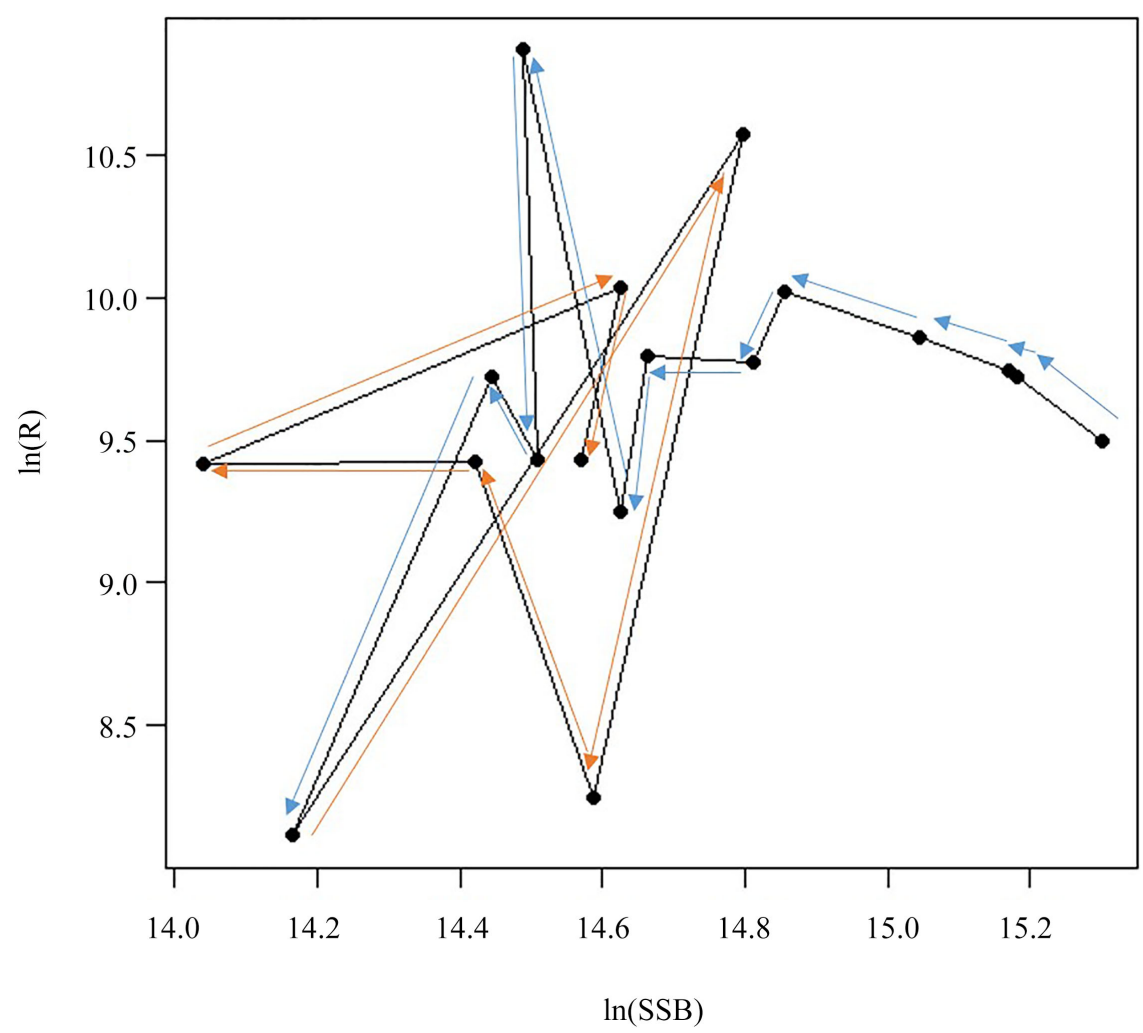

Figure A59(a). Herring-North Sea (Year 1947-1964).

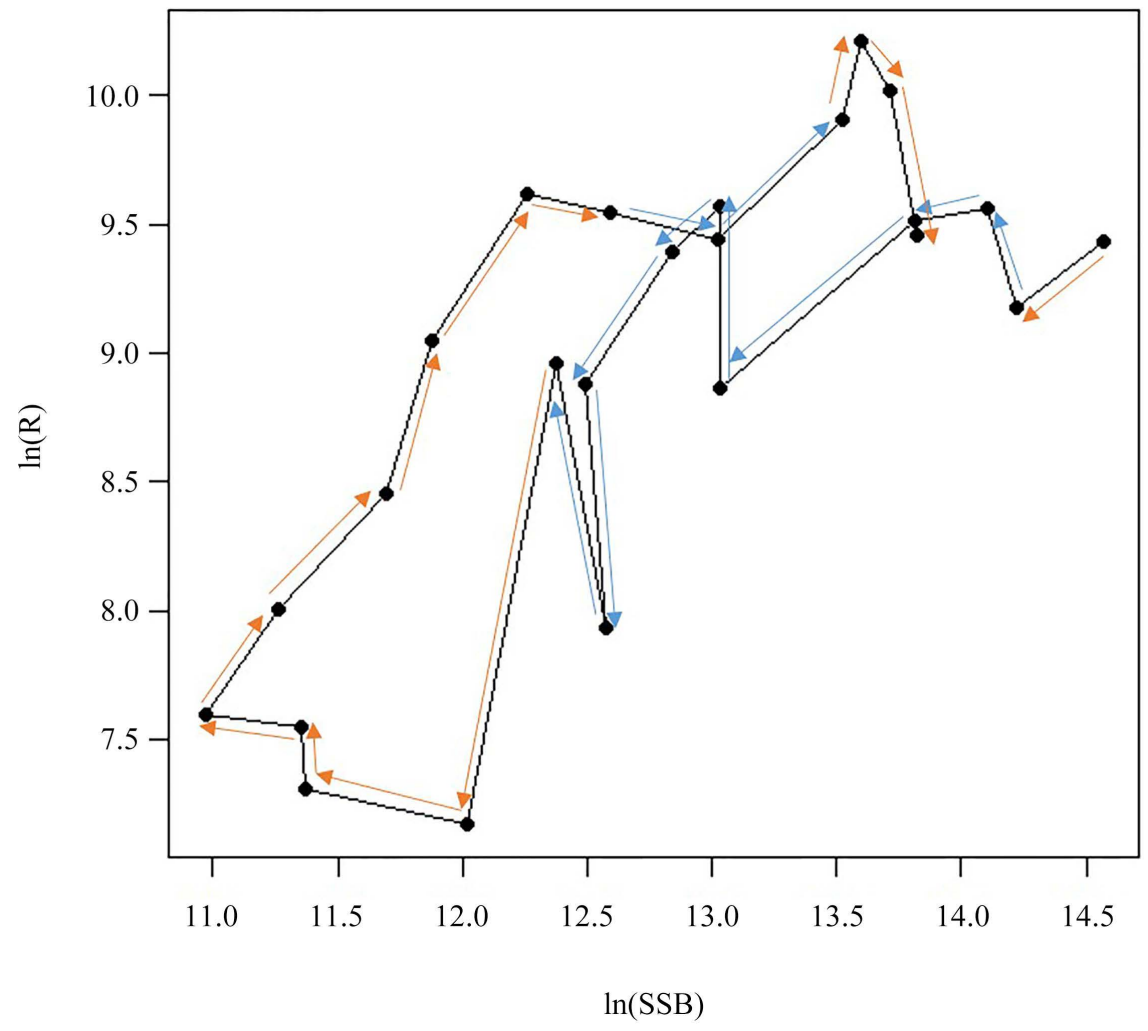

Figure A59(b). Herring-North Sea (Year 1964-1987). 


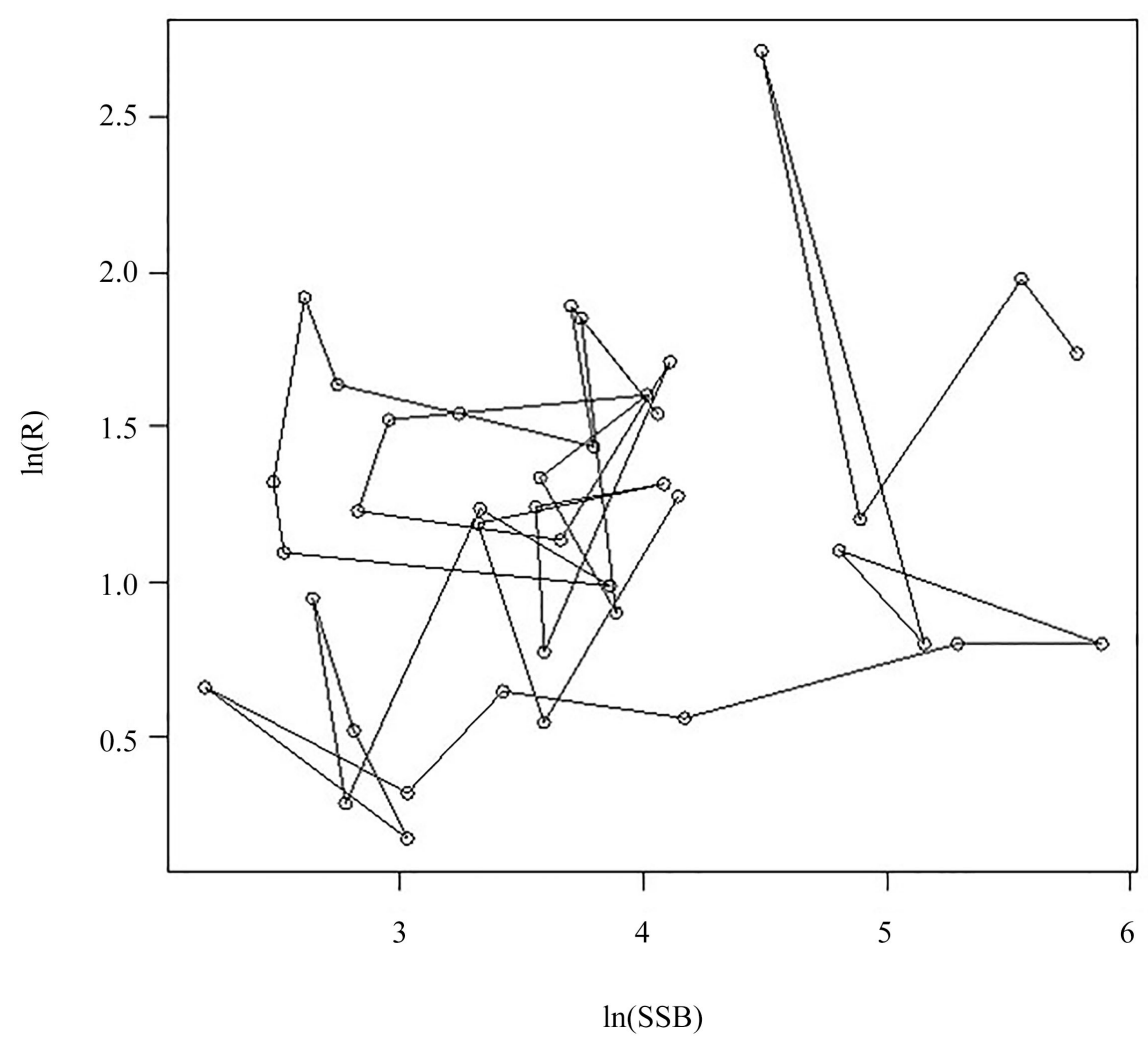

Figure A60. Atlantic Menhaden-U.S.Atlantic.

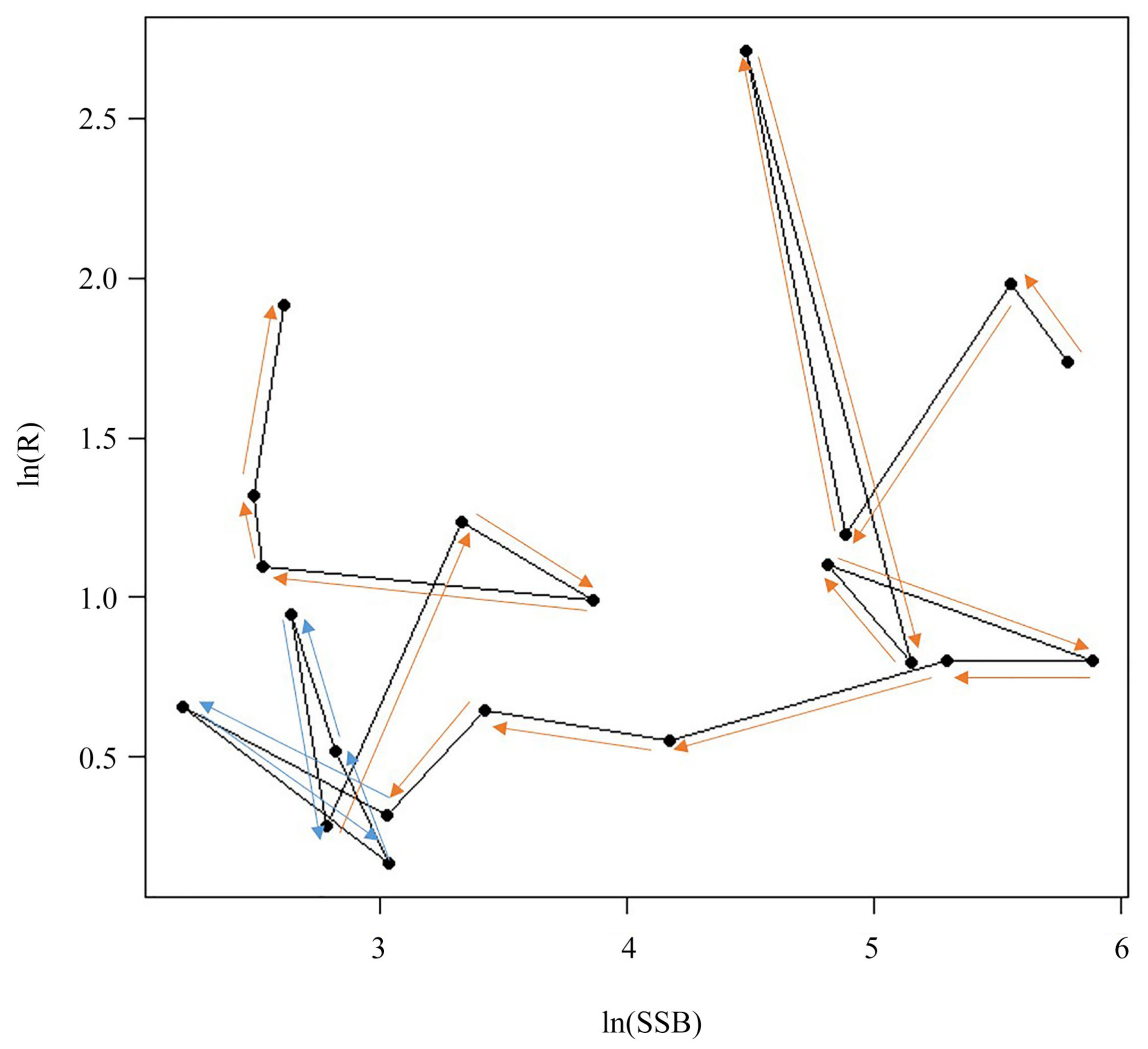

Figure A60(a). Atlantic Menhaden-U.S.Atlantic (Year: 1955-1975). 


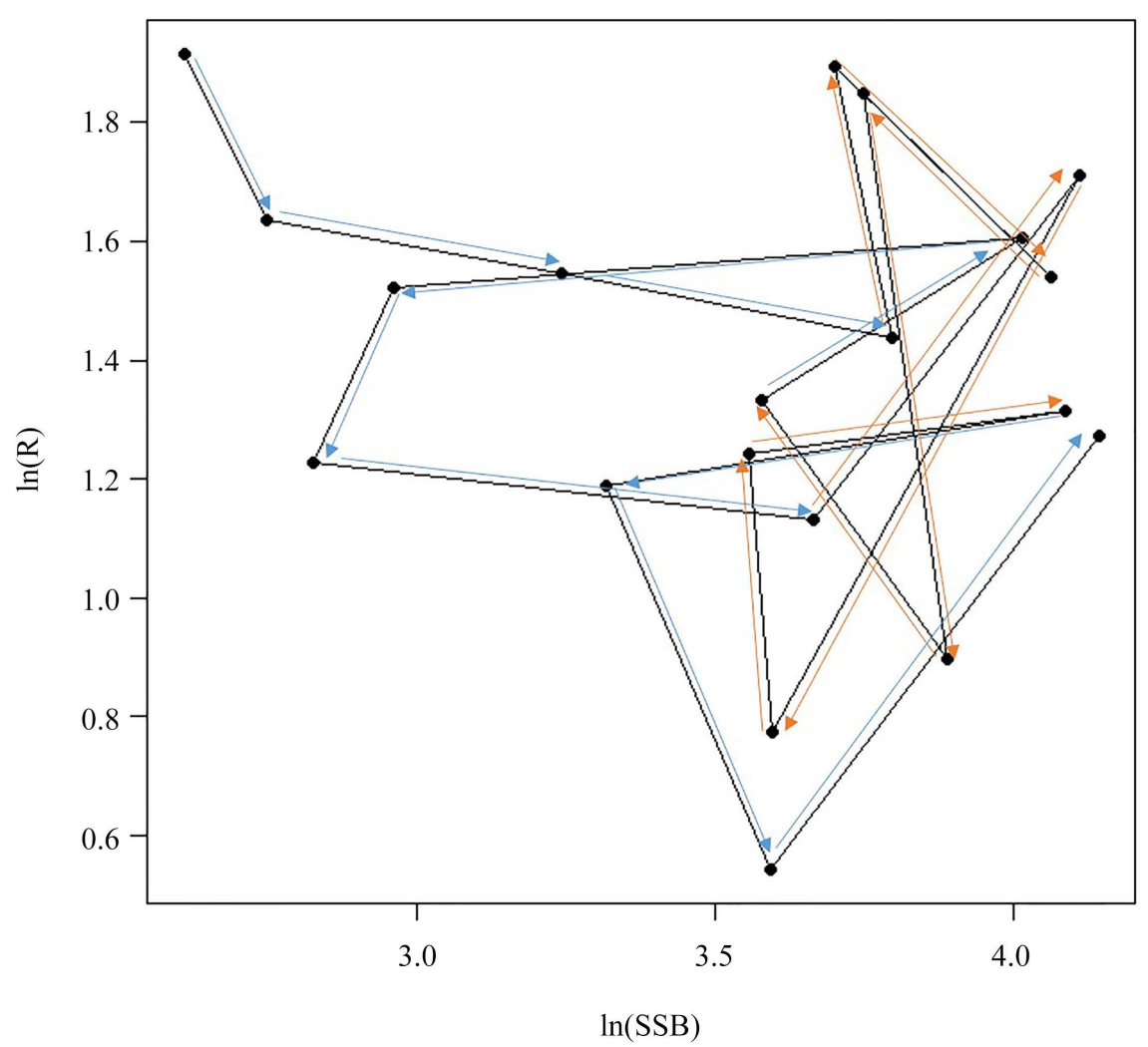

Figure A60(b). Atlantic Menhaden-U.S.Atlantic (Year: 1975-1994).

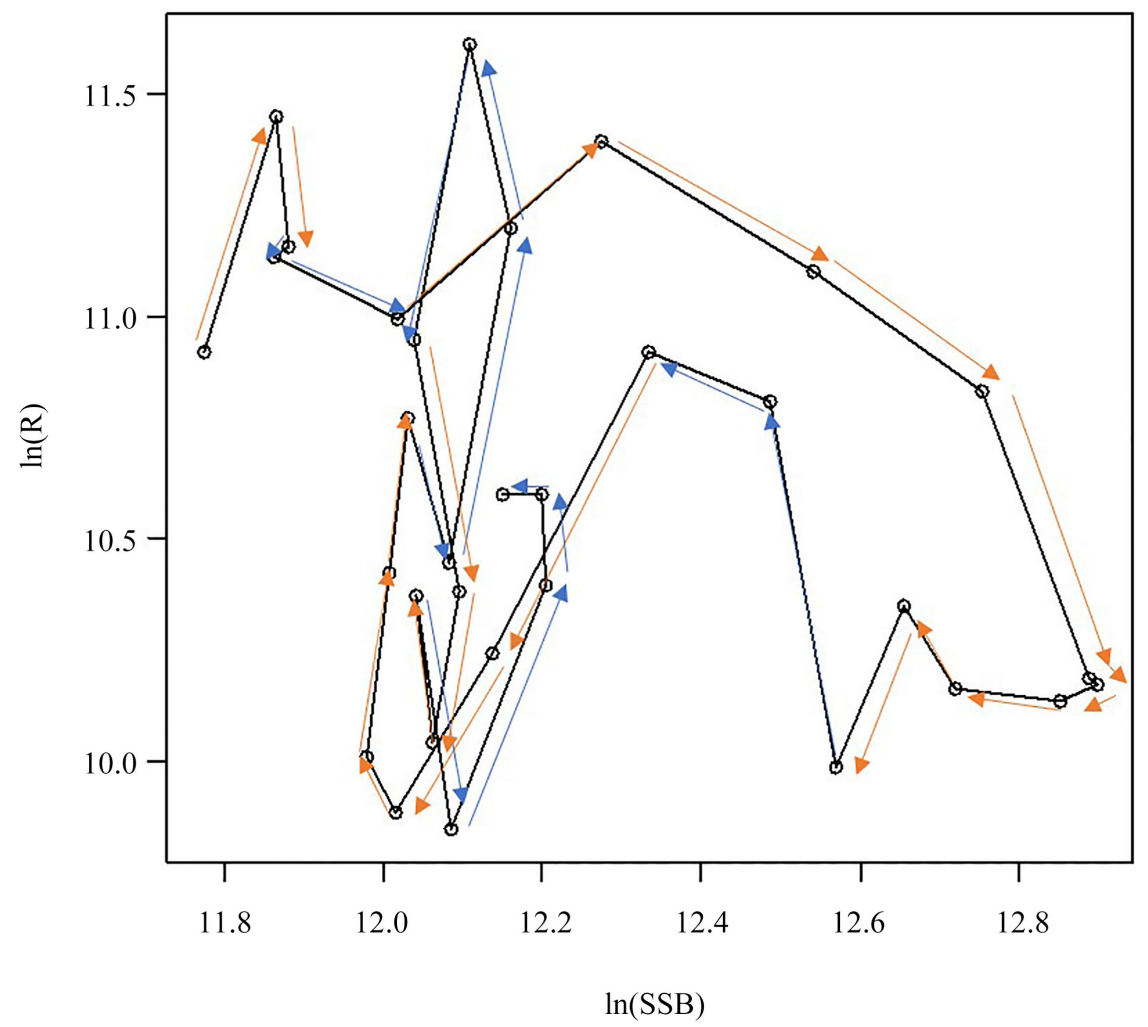

Figure A61. Pollock or Sithe-Iceland. 




Figure A62. Pollock or Sithe-Faroe. 